\title{
DOCENT ET DELECTANT
}

\section{ARCHITEKTUR UND RHETORIK AM BEISPIEL VON JOHANN BERNHARD FISCHER VON ERLACH}

\author{
VON FRIEDRICH POLLEROSS
}

\begin{abstract}
Während die Beziehung zwischen Rhetorik und bildender Kunst zu den wissenschaftlichen Leitthemen der letzten Jahre gehört ${ }^{1}$, wurde dem Zusammenhang zwischen barocker Redeund Baukunst bisher weniger Aufmerksamkeit geschenkt. Neben den expressis verbis diesem Thema gewidmeten Arbeiten von Bruno Contardi (1978) und Carsten-Peter Warncke $(1995)^{2}$ sind auch Aufsätze von Karl Möseneder (1982) und Karl Noehles (1990) zu nennen ${ }^{3}$.
\end{abstract}

Tatsächlich wurden schon in der Antike architektonische Begriffe von der Redekunst und die rhetorische Systematik von der Architekturtheorie übernommen. So hat etwa Cicero die Wahrheitsliebe als Basis (fundamentum) und die Rede als Gebäude (exaedificatio) bezeichnet (De oratore II, 63). In der vitruvianischen Architekturtheorie - mit der auch Fischer vertraut war - entsprechen folgerichtig die partes der Baukunst den officia oratoris und die Lehre vom architektonischen ornatus oder decorum den genera dicendi4.

In der frühen Neuzeit bildete die Rhetorik die allgemeinverbindliche Kommunikationstheorie und Form des Diskurses, wobei die antiken Rhetoriken des Aristoteles, Cicero und Quintilian sowie die Poetik des Horaz in unterschiedlicher Form bis zum Ende des 18. Jahrhunderts vorbildlich blieben5. Die Kunsttheorie hat dementsprechend nicht nur indirekt über Vitruv, sondern auch direkt auf die antiken Lehren der Redekunst zurückgegriffen, wobei vor allem Leon Battista Alberti (1435), Lodovico Dolce (1557), Gabriele

1) O. Bonfait ( $\left.\mathrm{Hg}_{\mathrm{g}}\right)$, Peinture et Rhétorique. Actes du Colloque de l'Académie de France à Rome $10-11$ juin 1993, Paris 1994. - M. Fumaroli, L'école du silence. Le sentiment des images au XVIe siécle, Paris 1994. J. Lichtenstein, The Eloquence of Colour. Rhetoric and Painting in the French Classical Age, Berkeley - Los Angeles - Oxford 1993. - R. W. LeE, Ut Pictura Poesis. Humanisme \& Théorie de la Peinture. XV́-XVIII siècles, Paris 1991 (zuerst engl. in: Art Bulletin, 22, 1940, S. 197-269). - H. Locher, „Barockkunst und Rhetorik“. Zur Tagung des Ulmer-Vereins in Bamberg, in: Kritische Berichte 15, 1987, S. 118-121.

2) B. CoNTARDI, La retorica e l'architettura barocca (Studi di storia dell'arte, 8), Rom 1978. - C.-P. WARNCKE, Rhetorik der Architektur in der frühen Neuzeit, in: Johann Conrad Schlaun 1695-1773. Architektur des Spätbarock in Europa, hg. von K. Bussmann, F. MATZner u. U. Schulze. Münster 1995, S. 612-621.

3) K. MOSEneder, "Aedificata Poesis“. Devisen in der französischen und österreichischen Barockarchitektur, in: Wiener Jb. f. Kunstgeschichte, 35, 1982, S. 139-175. - K. NOEHLES, Rhetorik, Architekturallegorie und Baukunst an der Wende vom Manierismus zum Barock in Rom, in: V. Kapp (Hg.), Die Sprache der Zeichen und Bilder. Rhetorik und nonverbale Kommunikation in der frühen Neuzeit (Ars Rhetorica, 1), Marburg 1990, S. $190-227$.

4) U. RAther, ${ }_{n}$ Architekrur", in: G. Ueding (Hg.), Historisches Wörterbuch der Rhetorik, 1, Tübingen 1992, Sp. 863.

5) J. KNAPE, „Barock“, in: Ueding, ebenda, Sp. 1285-1332. 
Paleotti (1582) und Giovanni Paolo Lomazzo (1584) zu nennen sind6. Die Beziehung zwischen Literatur und Architektur wurde in diesem Kontext vorwiegend für die Renaissan$\mathrm{ce}^{7}$ sowie unter dem Aspekt der Baukunst als "Nationalsprache ${ }^{48}$ behandelt. Im vorliegenden Beitrag soll nun der Zusammenhang zwischen barocker Rede- und Baukunst am Werk von Johann Bernhard Fischer von Erlach untersucht werden', wobei auf den Forschungen von Hans Sedlmayr, Franz Matsche und Karl Möseneder aufgebaut werden kann ${ }^{10}$.

\section{1. persuasio"}

Hauptaufgabe der Redekunst war die persuasio, die vorwiegend an die Affekte gerichtete Überzeugungsarbeit. Diese schon von Alberti auf die Bildkünste übertragene Aufgabe des docere, delectare und movere ${ }^{11}$ wurde auch im "Trattato della Pittura, e scultura, uso, et abuso loro, composto da un theologo e da un pirtore 1652 behandelt. Dessen Autoren, der Jesuit Gian Domenico Ottonelli und der Maler-Architekt Pietro da Cortona, waren überzeugt, daß ein Maler mit einem Bild ebenso wie ein eloquenter Redner mit Worten zur Tugend anspornen könne: La Pittura i Arte tanto giovevole, che, chi l'esercita virtuosamente pud far con l'immagine, cid che fa con le parole un eloquente Oratore nel muovere l'bumano affetto, z volont̀ all'impreso delle virtù 12. Gerade die römische Kunst des 17. Jahrhunderts wurde von diesen Prinzipien beherrscht. Die großteils von Jesuiten geprägte rhetorica divina galt ebenso für Gemälde ${ }^{13}$, welche Roger de Piles 1699 als Scìne, où chacque Figure joue son rôlle, bezeichnete ${ }^{14}$, wie für Skulpturen, insbesondere Reliefs und szenische Altarplastik ${ }^{15}$. Diesen theatralischen Illusionismus konnte Fischer vor allem bei den Altären und Festappa-

6) J. KNAPE, Rhetorizität und Semiotik. Kategorientransfer 2wischen Rhetorik und Kunstheorie in der Frühen Neuzeit, in: Intertextualität in der Frühen Neuzeit. Studien $2 u$ ihren theoretischen und praktischen Perspektiven (Frühneuzeit-Studien, 2), hg. von W. KonlmanN und W. Neuber, Franlfurt/Main etc. 1994, S. 485-532. N. Michels, Bewegung zwischen Echos und Pathos. Zur Wirkungsästhetik italienischer Kunstrheorie des 15. und 16. Jahrhunderts, Münster 1988.

7) H. H. AURenhammer, Multa aedium exempla variarum imaginum atque operum. Das Problem der imitatio in der italienischen Architektur des frühen 16. Jahrhunderts, in: KOHLMANN-NeUBER, Intertextualität (zit. Anm. 6), S. 533-587. - Сн. SмrTH, Architecture in the Culture of Early Humanism: Ethics, Aesthetics, and Eloquence: 1400-1470, New York u. 2. 1992, S. 133-197.

s) J.-M. Pérouse de Montclos, Larchitecture à la française. XVIe, XVII', XVIII sizecles, Paris 1982, S. 17 ff., S. $252 \mathrm{ff}$.

9) H. SEDLMAYR, Johann Bernhard Fischer von Erlach, Wien 1976. - H. LoRenz, Johann Bernhard Fischer von Erlach, Zürich - München - London 1992. - Zum aktuellen Forschungastand siehe: Fischer von Erlach und die Wiener Barocktradition, hg. von F. Polleross (Frühneuzeit-Studien, 4), Wien - Köln - Weimar 1995.

10) Erste Bemerkungen zu dieser Frage finden sich in: F. Pouleross, Kunstgeschichte oder Architekturgeschichte. Ergänzende Bernerkungen zur Forschungslage der Wiener Barockarchitektur, in: Ders., Fischer von Erlach (zit. Anm. 9), S. 59-128, hier S. 90-100.

11) K. Patz, Zum Begriff der "Historia“ in L. B. Albertis „de Pictura“, in: Zeitschrift für Kunstgeschichte, 49, 1986, S. 269-287. - LeE, Ut Pictura Poesis (zit. Anm. 1), S. 71-75.

12) Gian Domenico Otronelu - Pietro da Cortona, Trattato ..., Florenz 1652, S. 62 f.

13) M. Fumarol, Ut pictura rbetorica divina, in: Bonfait, Peinture et rhetorique (zit. Anm. 1), S. 77-103.

14) Roger de Piles, Abrégé de la vie des peintres ..., Paris 1699, S. 43, zitiert in: Ch. Braider, Picture and Modernity in Word and Image 1400-1700, Princeton 1993, S. 7.

15) Siehe z. B.: R. Premesberger, Eine Peripetie in Stein? Bemerkungen zu Alessandro Algardis Relief der Begegnung Leos des Großen mit Attila, in: Aachener Kunstblätter, 60, 1994, S. 397-416. 
raten für das Vierzigstundengebet der "Theaterarchitekten " Cortona und Bernini kennenlernen ${ }^{16}$. Schon 1633 hatte Pietro da Cortona die Kirche S. Lorenzo in Damaso durch ephemere Architekturen für die Quarantore in einen Oratoriensaal verwandelt und im folgenden Jahr beim Hochaltar von S. Giovanni dei Fiorentini den ersten Bühnenaltar Roms geschaffen ${ }^{17}$. Ähnliche Lösungen wurden von Bernini bei der Raimondi-Kapelle in S. Pietro in Montorio, bei der Cornaro-Kapelle, in der Alaleona-Kapelle in SS. Domenico e Sisto (Abb. 1) und bei der Kathedra Petri verwirklicht ${ }^{18}$.

Dank seiner Ausbildung und Tätigkeit als Bildhauer zwischen 1671 und 1686 in Rom und Neapel im Kreis um Bernini, den Dekorationskünstler Philipp Schor, den geistlichen Kunsttheoretiker Giovanni Pietro Bellori (1615-96) und den gelehrten Jesuiten Athanasius Kircher (1601-80) ${ }^{19}$ war der Grazer Bildhauersohn wohl von Beginn an mit der Anwendung der Rhetorik auf die bildenden Künste vertraut. Nach seiner Rückkehr in die Heimat war Fischer weiterhin als Bildhauer und Medailleur tätig. So entwarf er um 1688 die Reliefs der Dreifaltigkeitssäule in Wien (Abb. 8, 9), und bald konnte er die römischen Anregungen auch bei den eigenen Altarentwürfen umsetzen. Die Gestaltung des Altares als Schaubühne finden wir um 1690 beim Entwurf für den Hochaltar von Straßengel und 1692 beim ersten Projekt für den Hochaltar der Wallfahrtskirche Mariazell (Abb. 2) ${ }^{20}$. Bei der Kurfürstenkapelle in Breslau hat der Architekt nach 1715 diese Perspektivwirkung durch die sich verengenden Säulenstellungen der Chorapside auf die Raumarchitektur übertragen und durch den seitlichen Lichteinfall akzentuiert ${ }^{21}$. Die gleichen szenischen Effekte kennzeichnen die Altäre und Festapparate von Andrea Pozzo22, der parallel zu Fischer in Rom und 17031708 in Wien tätig war, und an dessen Werken la forza e l'energia dell'eloquenza expressis verbis gerühmt wurde. Pozzos Ausstattung der Wiener Jesuitenkirche verkörpert denn auch durch die Verbindung von Inschriften und ornamental-materiellem Prunk das docere und delectare in besonders eindringlicher Weise ${ }^{23}$.

Die von den Theoretikern geforderten verschiedenen Methoden der persuasio entsprechend der unterschiedlichen Bildung der Rezipienten ${ }^{24}$ waren im weltlichen und geistlichen Bereich die gleichen ${ }^{25}$. Besonders deutlich wird dies beim Widmungsblatt der "Perspettiva

16) H. TintEinot, Barocktheater und barocke Kunst, Berlin 1939, S. 134.

17) NoeHLes, Rhetorik (zit. Anm. 3) S. 213-220, Abb. $14 \mathrm{f}$.

18) G. CARER, Bernini. Flights of Love, the Art of Devotion, Chicago - London 1995. - M. S. WEIL, The Relationship of the Cornaro Chapel to Mystery Plays and Italian Court Theatre, in: ${ }_{n}$ All the world's stage ... . Art and Pageantry in the Renaissance and Baroque (Papers in Art History from The Pennsylvania State University, VI/2), Pennsylvania 1990, S. 458-486. - Contardo, La retorica (zit. Anm. 2), S. 85 ff.

19) E. SLadek, Der Italienaufenthalt Johann Bernhard Fischers zwischen 1670/71 und 1686. Ausbildung, Auftraggeber, erste Tätigkeit, in: PoLLeross, Fischer von Erlach (zit. Anm. 9), S. 147-176.

20) H. Aurenhammer, Kat. Johann Bernhard Fischer von Erlach, Wien - München 1956, S. 60-63, Nr. 12 f.

$\left.{ }^{21}\right)$ Gerade in diesem Zusammenhang wurde schon auf den Einfluß Cortonas verwiesen: ST. Mossakowsks, Die Kurfïrstenkapelle Fischers von Erlach im Breslauer Dom, in: Wiener Jb. f. Kunstgeschichte, XIX, 1962, S. 64-87, hier S. 80.

22) V. De Feo, Andrea Pozzo. Archittetura e illusione, Rom 1988.

23) U. KnalL-Brskovsky, Andrea Pozzos Ausstattung der Jesuitenkirche in Wien, in: Wiener Jb. f. Kunstgeschichte, XI, 1987, S. 159-173.

24) OTtonew - Corrona, Trattato (zit. Anm. 12), S. 60 f.

25) Zu den Analogien siche das Kapitel "SchloB- und Sakralarchitekrur“ in: H. CH. EHALT, Ausdrucksformen absolutistischer Herrschaft. Der Wiener Hof im 17. und 18. Jahrhundert (Sozial- und wirtschaftshistorische Studien, 14), Wien 1980, S. 101-103. 
de' pittori e architetti“ von Andrea Pozzo zu Ehren Leopolds I. von 1693: Die Reiterstatue des Kaisers ist nämlich von einer szenographischen Architektur umgeben, die einem Altarentwurf des Jesuiten genau entspricht ${ }^{26}$. Analog dazu wurde 1701 Pozzos Stich des „Teatro delle Nozze di Cana“ (also des ersten öffentlichen Auftrittes des Erlösers!) als Vorlage für eine Verherrlichung des jungen Erzherzogs und späteren Kaisers Karl VI. als aufgehende Sonne in einem Emblembuch des Jesuiten Jacob Boschius verwendet (Abb. 3, 4). Ebenso wie die Jesuiten hat auch Fischer bei seinen Triumphbögen und Trauergerüsten für die Habsburger die gleichen szenographisch-illusionistischen Mittel angewandt wie bei den Altären, etwa beim Triumphbogen über dem Reiterdenkmal Karls VI. vor dem Palais Schwarzenberg (1718) und beim Altar der Immaculata in Sallapulka (1720) ${ }^{27}$.

Die formalen Analogien zwischen Triumphbogen und Altar lassen sich ebenso aus der Verwendung der gleichen rhetorischen Mittel wie aus der bewußten inhaltlichen Verschränkung erklären. So übertrug etwa der Jesuit Jakob Lupperger in der Leichenpredigt auf Joseph I. die biblische Sonnensymbolik direkt auf den Kaiser:

Nicht ungereimt ist schon vorlängst das Weltgrosse Erz=Haus Osterreich dem großen Himmels=Gewölb verglichen worden; [...] in diesem österreichischen Himmel ist Josephus, als ein berrlichst=glänzende Sonn auffgangen und gebohren worden; [. . . dahero nicht unfüglich auf unsern Welt=gebohrnen Allergnädigsten Kayser Joseph haben können gedeutet werden jene Prophezeyungs= Worte, Orietur vobis Sol Justitiae\% es wird euch die Sonn der Gerechtigkeit auffgehen (Malach. 4.2), dann/ gleichwie die Sonn mit gegenartiger Würkungskraft das eysharte Wasser verschmölzet/ hingegen das weiche Erden=Kott erhartet/ [. . . , also [. . . hat sich Josephus eine Sonn der Gerechtigkeit/ und ein wohlgearteten Sohn des himmlischen Vaters gleich von seinem ersten Auffgang gezeigt; , qui Solem suum oriri facit super bonos of malos' (Matth. 5.45)! Gute und Böse bestralend zu Nutzen/ oder zu Schaden/nach eines jeglichen eigner Arts=Beschaffenheit ${ }^{28}$.

Ebenso wie sakrale Skulpturen und ephemere Architektur hatten die Bauwerke der Gegenreformation und des Absolutismus insgesamt eine persuasive Funktion ${ }^{29}$. Ein eindringliches Beispiel dafür liefert uns eine Zeichnung des schwedischen Architekten Nicodemus Tessin d. J., den Fischer vermutlich seit seiner römischen Zeit gekannt hat (Abb. 5). Die Graphik zeigt einen Thronsaal nach dem Entwurf von Abrahamo Paris, dessen Werk Fischer ebenfalls vertraut war ${ }^{30}$. Die Architektur hinter dem Thron wirkt wie eine Kirchenapsis $^{31}$ und erhält ihre besondere Würde durch die Superposition gekuppelter Säulen bzw. Pilaster. Dasselbe Motiv architektonischer Persuasio finden wir beim Entwurf des Karl

26) De Feo, Pozzo (zit. Anm. 22), Abb. 4.

27) H. LORENZ, Ủberlegungen zu einer unbekannten Festarchitektur Johann Bernhard Fischers von Erlach, in: Zeitschrift für Kunstgeschichte, 57, 1994, S. 430_439, hier Abb. 3. - SEdumayr, Fischer (zit. Anm. 9), Abb. 196.

28) P. Jakoв Lupperger S. J., Eclipsis solis svb ipsa meridie. Travergrosse Sonn=Verfinstervng (...), Wien 1705, fol. B2.

29) Siehe das Kapitel „La meccanica della persuasione“, in: CoNTARDI, La retorica (zit. Anm. 2), S. 9-40.

30) H. LoRenZ, Bernini e l'architettura barocca austriaca, in: Gian Lorenzo Bernini architetto e l'architettura europea del Sei-Settecento, hg. von G. Spagnesi und M. Fagiolo, Rom 1984, 2. Bd., S. 641-660, hier S. 650, Abb. $8 \mathrm{f}$.

31) Tatsächlich hat Tessin bei seinem Entwurf für das Schloß in Stockholm den Hochaltar der Schloßkapelle und den Thron des Reichssaales als direkte Pendants aufeinander bezogen: Kat. Le Soleil et l'Etoile du nord. La France et la Suède au XVII'e siècle, Paris 1994, S. 47, Nr. 13. 
Eusebius von Liechtenstein für Schloß Plumenau in Mähren, das um 1680 errichtet wurde (Abb. 7). Tatsächlich war der österreichische Fürst überzeugt, daß nur die Säulenordnungen, die man auch an den miracula mundi und am Petersdom finde, Magnifizenz und Pracht hervorbringen und $\mathrm{da} B$ ohne diese nichts kann gezieret werden, kein Altar, keine Kirche, keine Catedra, Triumph-oder andere Pforte, kein Haus. Karl Eusebius formulierte diese selbstverständliche Gleichsetzung von Altar und Triumphbogen im „Architekturtraktat “ zur Erziehung seines Sohnes Johann Adam Andreas, für den Fischer um 1690 tätig war. Die persuasive Funktion der Baukunst begründet Liechtenstein damit, daß eine schöne und prächtige Architektur gleichsam automatisch alle Augen auf sich zieht und sowohl beim gebildeten als auch beim ungebildeten Betrachter durch ihre stumme Rhetorik Verwunderung hervorruft:

Dan die Zierdt der Architectur gibet dises und ziecht und wendet aller Anschauen an sich, ob seiner Brachtigkeit und habenden Annehmblichkeit in sich; unaussprechlig ist dessen Gewalt aussprechen, alle Augen also an sich zu ziechen. Dan unangeschauter wiert wohl und kan keiner voribergehen, seie [er] vornehmen oder schlechten Standts, hochen oder schlechten Verstandt, Man oder Weib Standt, erwachsen und matur oder noch unerwachsen; alle werden sistieren miessen, nolentes volentes, und dises Wunderwerk anschauen; der Vornehme und Witzige zu noch mehrerer Verwunderung die Kunst erkennent und ermessent, der Ungelehrte aber, wessen Stand er wehre, ob vorstehenden Bracht und Majestet mit Verwunderung gestellet und aufgehalten wiert, so die Architectur durch ihr eigenthumbliche Zierde verursachet [.. . $]^{32}$.

Analog zur Differenzierung der religiösen Betrachter durch Ottonelli und Cortona in idioti, letterati und spirituali unterschied also Liechtenstein zwischen gebildeten und ungebildeten Rezipienten. Dieser Zweiteilung folgte auch Johann Christian Lünig. In seinem „Theatrum Ceremoniale Historico-Politicum “ propagierte er 1719 nämlich sinnliche Empfindung und Einbildung, das heißt solche Dinge, welche die Sinne kitzeln und in die Augen fallen, zur Überzeugung des Pöbels, während bei den Gebildeten Witz und Verstand, also die bündigsten und deutlichsten Motive, ihr Ziel erreichen würden ${ }^{33}$. Geistliche und politische Bauwerke sollten also einerseits durch die Quantität der materiellen Pracht die Sinne der Masse überwältigen, andererseits durch die Qualität an "Schönheit" und "Kunst" die Kenner überzeugen.

Gerade eine der ersten architektonischen Manifestationen Fischers, die utopische Vorstellung einer kaiserlichen Residenz in Schönbrunn von 1688/89, effültte diese persuasiven Voraussetzungen durch die auf optische Täuschungen ausgerichteten perspektivischen Manipulationen ${ }^{34}$, während ihr jede realisierbare Funktionalität fehlte (Abb. 17) ${ }^{35}$. Egal, ob der Entwurf als Präsentationsstück des jungen Künstlers zur Erlangung einer Hofstelle oder - wie zuletzt Schmitt vermutete - als Lehrbehelf für den Architekturunterricht des Thron-

32) Zitiert nach: V. Fleischer, Fürst Karl Eusebius von Liechtenstein als Bauherr und Kunstsammler (16111648), Wien - Leipzig 1910, S. 91-92.

33) Johann Christian LONiG, Theatrum Ceremoniale Historico-Politicum, oder Historisch- und Politischer Schauplazz Aller Ceremonien (. . .), Leizig 1719, 1. Dept., Capur I.

$\left.{ }^{34}\right)$ S. ScHmITT, Johann Bernhard Fischers von Erlach Schloß Schönbrunn in Wien. Studien über Schönbrunn I und das Schönbrunn-II-Ausführungsprojekt von 1696, Phil. Diss., München 1990, S. 11-17.

35) H. LOREnZ, Der habsburgische "Reichsstil" - Mythos und Realität, in: Künstlerischer Austausch/Artistic Exchange. Akten des XXVIII. Internationalen Kongresses für Kunstgeschichte Berlin, 15.-20. Juli 1992, hg. von Th. W. GaethGens, Berlin 1994, S. 163-176, hier S. 163 f. 
folgers diente, er verfehlte seine Wirkung nicht: 1689 wurde Fischer als Architekturlehrer des Thronfolgers angestellt, und sieben Jahre später wurde mit dem Bau eines Schlosses in Schönbrunn für den Römischen König nach Fischers Plänen begonnen.

\section{2. , architectura loquens"}

Eine konkretere Definition der persuasiv-rhetorischen Mittel als die Texte von Liechtenstein und Lünig liefert die Beschreibung des Trauergerüstes zu Ehren Philipps II. 1598 in Florenz. Vincentio Pitti lobt darin nämlich die altezea dell'Invenzione, die bellezza della dispositione, die maestria und die maestà des Katafalkes sowie die diligenza des Verantwortlichen, vor allem aber die Magnificenza des Großherzogs ${ }^{36}$. Es ist wohl kein Zufall, daß wir die direkte Anwendung der rhetorischen Termini bei der literarischen Wiedergabe eines Trauergerüstes finden, wird doch die ephemere Repräsentationskunst in besonderer Weise durch ihre funktionale und formale Verbindung von Bild und Text, Architektur und Rhetorik charakterisiert. Der Jesuit Claude-François Menestrier verwendete 1683 den Begriff dessein für den geistigen Entwurf beziehungsweise den Concetto eines Trauergerüstes ${ }^{37}$, und ein Lehrbuch der Rhetorik von 1718 bezeichnete ein Castrum Doloris als Trauer=Burg, Trauer $=S c h l o \beta$, da über das Geriuste [...] allerhand ,Inscriptiones" und Gemählde affigiret werden $^{38}$. Ein 1701 in Wien zu Ehren Karls II. von Spanien aufgerichtetes Trauergerüst wandte sich daher expressis verbis an den lesenden Betrachter und betrachtenden Leser: Lector spectas o legis spectator ${ }^{39}$.

Fischer war mit ephemerer Architektur schon von seiner Tätigkeit in Italien her vertraut, und es war wohl gerade die dabei erworbene rhetorische und historische Kompetenz, die die rasche Integration des jungen Architekten in den Kreis der Hofgelehrten ermöglichte. Denn das vom späteren Wiener Fürstbischof Franz Ferdinand von Rummel 1686 für Joseph I. konzipierte Erziehungsprogramm forderte die Vermittlung der wesentlichsten Kenntnisse in Poetik, Rhetorik, Philosophie und vor allem Geschichte ${ }^{40}$. Aufgrund seiner Erfahrungen im Umkreis von Bernini und der römischen und neapolitanischen Antiquare ${ }^{41}$ verstand sich Fischer offensichtlich von Beginn an mehr als "Kenner der schönen Künste und Wissenschaften" denn als Praktiker der Architektur. Dafür sprechen nicht nur der Mißerfolg gegenüber seinem ebenfalls aus Rom nach Wien gekommenen Kollegen Dome-

36) Vincentio PrtTl, Essequie della Sacra Cattolica Real Maesta (. . .), Firenze 1598, S. 74 f. zitiert in: T. FranGENBERG, Der Betrachter. Studien zur florentinischen Kunstliteratur des 16. Jahrhunderts (Frankfurter Forschungen zur Kunst, 16), Berlin 1990, S. 180.

37) L. Popelka, Castrum doloris oder ${ }_{n}$ Trauriger Schauplata ${ }^{\star}$. Untersuchungen zu Entstehung und Wesen ephemerer Architektur (Osterr. Akademie d. Wissenschaften, Veröffentlichungen d. Kommission f. Kunstgeschichte, 2), Wien 1994, S. 92-99, hier S. 93.

38) Johann Christoph Mxnnung, Expediter Redner oder Deutliche Anweisung zur galanten Deutschen Wohlredenheit, 1718 (Reprint Kronberg/Ts. 1974), S. 49.

39) Gottueb Eucharuus RunCK, Leopolds des Grossen Röm. Käysers wunderwürdiges Leben und Thaten Aus geheimen Nachrichten eröffnet, Leipzig 1708, S. 862.

40) Schмiтt, Schönbrunn (zit. Anm. 34), S. 67 ff.

1) SLADEK, Fischer (zit. Anm. 19), passim. 
nico Martinelli42, sondern auch die Quellen. In einem Brief an den Fürsten Liechtenstein über seine Berufung in den Hofstaat Josephs I. beschreibt Fischer 1689 nämlich seine Tätigkeit als Unterricht in seiner Profession in Architectur perspectiv und dergleichen Wissenschaften ${ }^{43}$.

Tatsächlich ist es charakteristisch, daß die im folgenden zu behandelnden Werke durchwegs der architectura publica angehörten und in Zusammenarbeit mit antiquarisch-numismatisch oder theologisch gebildeten Beratern entstanden sind. Deren Einfluß auf den rhetorischen Charakter der Architektur Fischers wurde bisher vor allem im Zusammenhang mit den Bauten für Karl VI. behandelt. Zu wenig Beachtung fand hingegen der Umstand, daß der Bildhauer-Architekt sowohl bei sakralen als auch bei profanen Werken mit denselben Programmberatern kooperierte, wodurch sich auch ein methodischer Zusammenhang zwischen den beiden Werkgruppen ergibt. Wurde etwa das religionspolitische Programm der Karlskirche vom weltlichen Antiquarius Heraeus ersonnen, so standen Fischer um 1690 für höfische Aufgaben vorwiegend geistliche Concettisten zur Seite. Das Programm des Grazer Mausoleums sollte dem Bericht der Hofkammer von 1687 zufolge die Taten Leopolds I. mit guten Concepten und schönen Inventionibus zeigen, damit alles gleich zusammen correspondiere. Da die Darstellungen nicht nur auf einer Schrift des in Graz ausgebildeten Jesuiten Martin Stredonius basieren, sondern auch Embleme jesuitischer Publikationen kopieren beziehungsweise vorwegnehmen und das Wappen der Gesellschaft Jesu einbeziehen, kommt als Verfasser dieses gelehrten Programms nur ein Mitglied der Societas Jesu in Frage ${ }^{44}$. Der Autor des emblematisch-typologischen Programms der ebenfalls von Leopold I. in Auftrag gegebenen Wiener Pestsäule ist hingegen bekannt. Es ist der spätere Beichtvater des Kaisers, Dr. Franz Menegatti, den Leibniz als den gelehrtesten Jesuiten Deutschlands bezeichnete 45 . Ebenfalls dem Jesuitenorden gehörte Franz Keller an, dessen Publikation „Augustae Carolinae virtutis monumenta ..." von 1733 „eine offiziöse Deutung des gesamtprogrammatischen Charakters" der Bautätigkeit Karls VI. enthältt6. Die Gedanken für Fischers mit sinnreichen Statuen und denkwürdigen Emblematen gezierten Ehrenpforten zum Einzug des Kaisers und seines in Augsburg zum Römischen König gekrönten Sohnes im Jahre 1690 lieferte Dr. Karl Josef de la Bresche, ein Kanonikus des Wiener Domkapitels (Abb. 18) ${ }^{47}$. Der St. Lambrechter Benediktiner Petrus Gürnigg, der die Verrechnung des Mariazeller Altares mit dem Architekten besorgte ${ }^{48}$, hat wohl während seiner Tätigkeit als Professor für Philosophie und Theologie 1690-1705 am Wiener Schottenstift

42) H. LoRenz, Domenico Martinelli und die österreichische Barockarchitektur, Wien 1991, S. 40-43. Ders., Fischer (zit. Anm. 9), S. 15-18.

43) Zitiert nach: SedumaYr, Fischer (zic. Anm. 9), S. 335, Nr. 16.

4) G. Kodoltrsch, Drei steirische Mausoleen - Seckau, Graz und Ehrenhausen, in: Innerösterreich 1564 1619 (Joannea, III), Graz 1968, S. 325-370, hier S. $348 \mathrm{ff}$.

45) Zur Pestsäule siehe zuletzt: M. Kousr, Die Brüder Strudel. Hofkünstler und Gründer der Wiener Akademie, Innsbruck 1993, S. 72-74 u. 182-186.

46) F. Matsche, Die Kunst im Dienst der Stantsidee Kaiser Karis VI. Ikonographie, Ikonologie und Programmatik des "Kaiserstils" (Beiträge zur Kunstgeschichte, 16), Berlin - New York 1981, 1, S. 386 f. - Der von Matsche als Autor genannte Anton Höller dürfte nur der Promotor sein: E. KLeCker - B. Mersich, „Nobiliora habitant nunc atria Musae“. Der Prunksaal der Osterreichischen Nationalbibliothek in einem lateinischen Hochzeirsgedicht, in: Biblos, 43, 1994, Heft 1-2, S. 41-57, hier S. 47 f.

47) Aurenhammer, Fischer 1956 (zit. Anm. 20), S. 52 f.

4) A. SAMmer, Mariazeller Hochaltar Joh. Bernh. Fischer v. Erlach, Mariazell 1979, S. 29. 
auch inhaltlich auf die Konzeption Einfluß genommen. Analog dazu scheint es naheliegend, daß Fischer in Salzburg mit seinem Vertragspartner, Raimund Anton von Rehlingen, die theologisch-künstlerische Form des Hochaltares der Kollegienkirche diskutierte. Denn der 1701 wegen seiner ziemlichen Wissenschaft im Bauwesen zum Baudirektor des Salzburger Erzbischofs berufene Reichsgraf trat 1711 in Rom als Fr. Raimondo della Madre di Dio in das Kloster der unbeschuhten Karmeliter zu S. Maria della Scala ein ${ }^{49}$.

Bei den Ehrenpforten, die 1699 in Wien zu Ehren des Römischen Königs und seiner Gattin errichtet wurden, arbeitete Fischer erstmals nachweislich mit einem weltlichen Gelehrten zusammen. Das Programm der Dekorationen wurde nämlich ebenso wie jenes der damals den Herrschern überreichren Medaillen von Johann Jacob Haakius, einem Bewerber um die Stelle des Hofbibliothekars, poetico emblematico heraldico veterisque rei numismaticae studio, verfaßt ${ }^{50}$. Der 1710 von Joseph I. zum Direktor der kaiserlichen Münz- und Antiquirärensammlung ernannte Carl Gustav Heraeus (1671-1725) verfaßte 1711 die Auffschriften und Sinnbildungen sowie die gedruckte Beschreibung des von Fischer für den verstorbenen Kaiser in der Augustinerkirche inventierten Trauergerüstes (Abb. 28). Ein Jahr später schrieb er die Widmung für Fischers erste und dem neuen Kaiser präsentierte handschriftliche Fassung der "Historischen Archirektur" (Abb. 40). Die Voraussetzungen für die Entstehung solcher "Wort-Bild-Synthesen " des "Kaiserstils" waren also bereits vor dem Amtsantritt Karls VI. gegeben, wenngleich diese Bestrebungen ab 1716 mit der Ernennung eines kaiserlichen Generalbaudirektors in der Person des Grafen Gundacker von Althan eine neue Dimension erreichten. Die komplizierte Entstehungsgeschichte des von Rinck als Meisterstïck der sinnreichen Erfindung des Herrn von Fischer bezeichneten Wiener Vermählungsbrunnens ist wohl ein Beispiel dafür, wie intensiv inhaltliche und formale Faktoren einander bedingen konnten ${ }^{51}$. Nach dem Ausscheiden von Heraeus aus dem Hofdienst arbeitete der ebenfalls in der Geschichts- und Münzwissenschaft bewanderte Conrad Adolph von Albrecht in dieser Funktion vor allem mit dem jüngeren Fischer zusammen. Die entsprechende Kooperation zwischen Künstler und "Libretrist" belegt etwa Albrechts Beschreibung: Des von mir angegebenen durch Herrn v. Fischer in Wienn gezeichneten, nachmals bey meiner Abreyße von Prag zu vollkommener Außfübrung gebesserten und mit gehöriger Grabschrifft versehenen Epitaphy Seiner Excellenz Herrn Grafen von Schlick52. Ebenso wie Heraeus verfaßte Albrecht eine illustrierte Zusammenstellung seiner Programme, deren Drucklegung jedoch nicht zustande kam:

Verschiedene Erfindungen Hieroglyphisch-Historisch-und Poetischer Gedancken, mit vielerley darzu erforderlichen Lapidarischen Inschriften, welche alle zu denen unter Caroli VI. [...] vorgenohmenen Hof-Gebäuden der Kayl: Burgg, Bibliothec, St. Caroli Kirchen und Josephi Säulen Ingleichen Anderwärtigen auf Kayl: Befehl erbebten, oder zu Ehre, und Nachrubm

49) F. WAGNER, Immaculata und Transfiguration - Bemerkungen zum Hochaltar der Salzburger Kollegienkirche, in: Alte und moderne Kunst, 24, 1979, Nr. 164, S. 14-17.

so) H. Haselberger-Blaha, Die Triumphtore Fischers von Erlach, in: Wiener Jb. f. Kunstgeschichte, XVII, 1956, S. 63-85, hier S. 81 f.

51) RinCK, Leopold I. (zit. Anm. 39), S. 954 f. - B. Mikuda-Hottel, Der ,Colossus' der Fischer von Erlach auf dem Hohen Markt zu Wien. Ein Beitrag zur Entwurfs- und Planungsgeschichte, in: Polueross, Fischer (zit. Anm. 9), S. 229-248.

52) Albrecht-Codex, fol. 149, zitiert in: E. P. Garretson, Conrad Adolph von Albrecht. Programmer at the Court of Charles VI, in: Mitteilungen der Osterreichischen Galerie, 24/25, 1980/81, S. 19-92, hier S. 74. 
Deroselben Allerdurchleuchtigsten Namen hin und wider aufgesetzten ansehentlich-Offentlichen Denckmablen, [. . .] in Bau, Mablerey u. Bildhauer Kunst-Wercken [. . .] ersonnen worden, in Teutscher Mutter Sprachen darumen verfasset, damit die mehren Theils auch Teutsche Arbeits Vollführer den bequemlichen Verstand ibrer zu Ende zu bringen habenden Stücken mitgeniessen können.

Der mit zahlreichen Illustrationen versehene "Codex Albrecht" der Österreichischen Nationalbibliothek enthält für unseren Zusammenhang schon in seinem Titel wichtige Informationen (Abb. 26, 39). Beachtung verdient zunächst die Tatsache, daß Albrecht die kaiserlichen Bauten ausdrücklich als öffentliche Denkmale bezeichnet und damit in den Bereich der "Denkmalsrhetorik“ 53 einbezieht. Ein gutes Beispiel für diese Bauaufgaben bildete schon das 1712 unter der Beratung des Heraeus von Fischers Rivalen als Hofarchitekt zum Einzug des von seiner Krönung in Frankfurt zurückkehrenden Kaisers errichtete neue Burgtor, dessen Programm, das heißt die Erklärung deren Ornamenten an solchem Thore zu jedermanns deutlichen Verstandnuß in Druck befordert worden war. Aus dieser Beschreibung geht die Verbindung von Rede- und Baukunst deutlich hervor:

Die Zieraten dieses Thors (an welchem die Ordnung der, Architectur" dem Herm Johann Lucas Hildebrand, Kayserlichen Hof =,Ingenieur; allein obgelegen) hat man nach dem Exempel anderer Pforten nicht wollen obne Bedeutung seyn lassen, um die Steine, wie bey der alten Römer Zeit, sowohl durch Figuren, als durch Schriffien redend zu machen ${ }^{54}$.

Die Absicht, die Architektur durch Figuren und Schriften zum Sprechen zu bringen, verrät auch Heraeus' Hinweis auf die bei Fischers Festdekoration vor dem Palais Schwarzenberg 1718 den Bau redend machenden Zierathen und Bedeutungen55. Die Formulierungen verweisen auf die vor allem von Emanuele Tesauro (1592-1673) theoretisch fundierte rhetorische Struktur der barocken Bildlichkeit ${ }^{56}$. Der piemontesische Rhetorikprofessor unterschied in seinem ab 1654 in mehreren Auflagen erschienenen "Cannochiale Aristotelico“ nämlich zwischen sprechenden und stummen Zeichen sowie solchen von einer stummen Beredtheit oder auch von einem beredtem Schweigen 57 . Sowohl in Festdekorationen und Trauergerüsten, als auch in der Ausstattung der Residenzen der Herzöge von Savoyen setzte der Exjesuit seine Theorien in die Praxis um. Tesauros Programme wurden 1688 auch in Frankfurt und Leipzig publiziert, darunter jene für den Palazzo Reale in Turin:

Nibil his in Aedibus est, quod non rapiat oculos; Regiamque Caroli Emmanuelis, eo Nomine Secundi, Magnificentiam, vel tacendo, non eloquatur. Plurimus bic Auri nitor, pretiosa suppellex, admirabiles Sculturae, nobilis Pictura, nobiliores Historiae, immemorabilis aevi memoriam revocantes. Atqui, cùm singulae Picturae suis inscriptionibus animentur, omnium tamen argumenta, unius Emmanuelis Thesauri ab ingenio atque calamo, manere voluit optimus Princeps 58 .

53) P. SPRINGER, Denkmalsrhetorik, in: Ueding, Historisches Wörterbuch (zit. Anm. 4), 2, Tübingen 1994, Sp. 527-536.

54) CarL. Gustav Heraeus, Inscriptiones et Symbola varii argvmenti, Nürnberg 1721, S. 175 f.

55) Zitiert in: LoRenz, Festarchitektur (zit. Anm. 27), S. 435.

56) Heraeus bezog sich an einer Stelle seines Werkes ausdrücklich auf Tesauro: Gedichte und Lateinische Inschriften des Kaiserl. Raths, auch Medaillen= und Antiquitäten=Inspectors Herrn Carl Gustav Heraeus. Nach des Herrn Verfassers Ubersehung, Und Hinzufügung der in dem ersten Exemplar abgängigen Stücke, Nürnberg 1721 , S. $96 \mathrm{f}$.

57) Zitiert in: H. BAUER, Barock. Kunst einer Epoche, Berlin 1992, S. 189.

58) Emmanuel Thesaurus, Inscriptiones, Frankfurt - Leipzig 1688, S. 111. 
Tesauro vertrat ebenso wie Menestrier die Auffassung, Rhetorik sei die Kunst, mit Bildern zu überzeugen. Beide widmeten sich daher mit besonderer Aufmerksamkeit den Devisen und Emblemen, also der direkten Verbindung von Wort und Bild59. Analog dazu versteht auch Albrecht unter den für die Fischerschen Bauten ersonnenen "Gedanken" nicht allein Texte in Form von Bauinschriften, sondern deren Verbindung mit Bildern in Form von Skulptur oder Malerei. Inhaltlich unterscheidet er bei diesen Wort-Bild-Synthesen historische, das heißt aus der Geschichte entnommene Themen, poetische, also von den Mythen sowie der Literatur inspirierte Gedanken-Erfindungen, und schließlich die „Hieroglyphen", Sinnbilder. Der Hofconcertist bezog sich hier auf die etwa vom Maler und Kunstrtheoretiker Gerard de Lairesse 1707 vorgestellten vier Bildgattungen ${ }^{60}$. Als Anregung für Gedanken-Erfindungen standen den Künstlern und Konzeptverfassern eigene Handbücher, die sogenannten Collectaneis, zur Verfügung ${ }^{6}$. Eines dieser Werke, die "Iconologie ou la science des emblèmes, devises etc., qui apprend à les expliquer, dessiner et inventer" des Jean Baudoin (Amsterdam 1698), präsentiert sich daher schon im Titel als très utile aux orateurs [. . .] et géneralement d toutes sortes de curieux des beaux-arts et des sciences. Die von Heraeus für die "redenden Steine" des Burgtores verwendete Bezeichnung Zierat entspricht jedenfalls genau der Definition der Wort-Bild-Synthesen in der deutschen Emblemtheorie. Schon Johann Fischart harte 1581 den Ursprung und Gebrauch der Emblematen oder Eingeblömeten Zierwercken ausdrücklich auf die antike und zeitgenössische Architektur und deren behauene, versetzte und gewölbte Vorbauten, Erker, Bildwerke und Gemälde bezogen62.

Die Emblemtheoretiker der zweiten Hälfte des 17. Jahrhunderts, zum Beispiel Pierre Le Moyne, verwiesen ebenfalls auf die Funkrion der Emblematik zur Zierde fürstlicher Architektur: La Devise estant une Philosophie courte of figure [. . .] inventé pour instruiere of pour honorer les Grands, pour embellir o pour parer les Maisons des Grands. Zur Gattung der expression metaphorique composte de figures of de paroles seien nach Meinung des französischen Jesuiten auch Gemälde sowie monumentale Skulpturen zu zählen:

les Tableaux, les Bas-reliefs, les Statues sont des metaphores. Le Jupiter de Phidias, Le Colosse de Rhodes, que l'Antiquite a regardez comme deux miracles, n'estoient que deux metaphores. Et si le Sculpteur Stecicrate eust executé le projet enorme quil fit d'une Statue, qui devoit porter une Ville d'une main, of verser de l'autre une Riviere il n'eust fait aprez tout qu'une metaphore ${ }^{63}$.

Genau aus diesem Verständnis heraus errichteten 1705 die Jesuiten in Olmütz anläßlich der Trauerfeierlichkeiten für den verstorbenen Kaiser einen Colossus Olim Soli Orienti a Rhodijs nunc Soli Occidenti sive Augustissimo of Invictissimo Imperatori Leopoldo Primo (Abb. 11)64. Von einem Wiener Jesuiten wurde dieser Gedanke 1717 aufgegriffen, um

59) Claude-François Menestrier, L'Art des Emblèmes ou s'enseigna la Morale par les Figures de la Fable, de l'Histoire \& de la Nature, Paris 1684. Mit einem Beitrag „Barocke Bildphilosophie und Emblem. Menestriers L'Art des Emblemes ${ }^{\alpha}$, hg. von K. MOSENEDER, Mittenwald 1981.

60) Des Herrn Gerhard de Lairesse Grosses Mahler=Buch (. . .) Nürnberg 1728, I, S. 169 ff.

6i) KNAPE, Barock (zit. Anm. 5), Sp. 1300 ff.

62) W. Neuber, Locus, Lemma, Motto. Entwurf zu einer mnemonischen Emblematiktheoric, in: J. J. BERNS W. Neuber (Hg.), Ars memorativa. Zur kulturgeschichtlichen Bedeutung der Gedächtniskunst 1400 -1750 (Frühe Neuzeit, 15), Tübingen 1993, S. 351-372, hier S. 359.

${ }^{63}$ ) P. Le Morne S. J., De l'art des devises, Paris $1668^{2}$, S. 85 f.

64) P. Juluus Zwicker S. J., Colossus . ., Olmürz 1705. 
Karl VI. ein rhetorisch-bildliches Denkmal zu errichten (Abb. 12)65. Fischer hat die beiden von Le Moyne angeführten "Weltwunder" ebenso in seine Architekturgeschichte integriert wie die Umwandlung des Berges Athos in einen Colossus (Abb. 13). Da sich der Hofarchitekt des Kaisers offensichtlich als neuer Dinokrates verstand ${ }^{66}$, ist die Beschreibung dieser Invention von besonderem Interesse für uns. Johann Bernhard lobt des Großen Alexanders Architech, der den Bau angegeben, nämlich wegen des ungemeinen Vorschlages, und berichtet auch, daß Alexander diesen Gedanken für seiner Hoheit und Größe würdig hielt 67.

Diese direkte Analogie zwischen einer künstlerischen Invention und ihrem fürstlichen Adressaten ist ein Grundprinzip der barocken Emblematik, und Le Moyne nennt als ebenso altehrwürdiges wie gelungenes Beipiel dafür die Devise Karls V.:

Les premieres of les plus anciennes, qui doivent servir de regles of de modeles à toutes les autres, [. . .] ne presentoient aux yeux, que des symboles de valeur o de courage: [. . . Ce sont ceux des Colomnes de Charles-quint, qui disoient quil ne sarrestoit pas à elles: of que ses victoires iroient, bien loin au delà de celles d'Hercule 68 .

Ein 1701 erschienenes Emblembuch des Jesuiten Jakob Boschius verweist sowohl auf die Säulen als Sinnbild der Constantia und der Devise Plus ultra, bringt aber auch ein Imago von St. Peter in Rom. Dieses Emblem bezieht sich ebenfalls nicht auf das gesamte Bauwerk, sondern, wie die Bezeichnung Amphitheatrum lehrt, lediglich auf die als ikonographisches Motiv isolierten Kolonnaden (Abb. 14). Die benachbarte pictura präsentiert die gleichfalls von Bernini geschaffenen Statuen der Engelsbrücke unter dem Motto DUCIT ET DOCET und verweist damit auf die für rhetorische Bauwerke charakteristische Verbindung von Funktionalität und Belehrung ${ }^{69}$.

Bezeichnenderweise finden wir die ersten, nicht mehr dem ephemeren Bereich angehörenden Beispiele der emblematischen Architektur ebenfalls in der römischen Kunst des 17. Jahrhunderts. Ein Cortona zugeschriebener Entwurf für eine Kuppelkirche nach dem Wappen der Chigi ist in diesem Zusammenhang ebenso zu nennen wie Berninis Elephantenobelisk (1667). Parallel zu den von Bernini für Ludwig XIV. projektierten architektonischen Metaphern entwarf Claude Perrault 1665 ein Denkmal in Gestalt der Devise des Sonnenkönigs, und 1712 visualisierte Nicodemus Tessin diese in Form eines Sonnentempels ${ }^{70}$. Die Anwendung dieser Praxis auf eine habsburgische Thematik und im unmittelbaren Umkreis von Fischers römischen Lehrer Philipp Schor belegt ein Entwurf, den dessen Vater 1673 für eine Prunkkarosse des spanischen Botschafters schuf (Abb. 15): Die von den

65) Gerhard Hilleprand S. J., Monumenta Virtutis Austriacae, Invictissimo Romanorum Imperatori Carolo VI. . . a rhetorica Viennensi Calamo \& Mente posita, Wien 1717, S. 113.

66) Zur Wurzel dieser Thematik im Kreis der italienischen Antiquare siehe: SLADEK, Fischer (zit. Anm. 19), S. 156, Abb. 50, sowie ein Thesenblatt von Pietro Cortona und Francisco Spierre nach 1664, das Alexander VII. als neuen Alexander vor dem Berg Arhos zeigt.

67) Johann Bernhard Fischer von ERLACH, Entwurff einer historischen Architektur. Mit einem Nachwort von H. KELler, Dortmund $1988^{5}$, fol. 22, 31 und $49 \mathrm{f}$.

68) Le Monne, Devises (zit. Anm. 63), S. 48.

6) Jacobus Boschius, Symbolographia sive De Arte Symbolica Sermones Septem (. . .), Augsburg-Dillingen 1701 (Reprint Graz 1972), Taf. II/I, XIII u. XI. - Zur emblematischen Funktion der Engelsbrücke siehe: R. Preimesberger, Die Inschriften der Engelsbrücke, in: Kunst in Hauptwerken: Von der Akropolis zu Goya (Schriftenreihe der Universitär Regensburg, 15), hg. von J. TraEGER, Regenburg 1988, S. 199-223.

70) Moseneder, „Aedificata Poesis“ (zit. Anm. 3), S. 139 ff. 
Allegorien des Krieges und des Friedens umgebene Personifikation Spaniens präsentiert nicht nur ein Kastell als dreidimensionales Wappenbild Kastiliens, sondern thront inmitten der Säulen des Herkules mit der königlichen Devise PLVS VLTRA71.

Tatsächlich berichtet Baldinucci 1682 in der Vita Berninis ausdrücklich von dessen rhetorischer Kompetenz $z^{72}$. Der Bildhauer-Architekt habe schon zu Lebzeiten nicht nur als migliore Scultore, e Architetto del suo secolo, sondern auch als gran Teologo und grande Oratore gegolten. Der ingegno Berninis blieb daher nicht auf die cose dell'arte beschränkt, sondern lieferte immer auch concetti nobili und motti acuti. Aufgrund der Auffassung, la Poesia essere una Pittura, che parla, ed all'incontro La Pittura una certa muta Poesia, bemühte sich Bernini bei allen Entwürfen - egal ob Lampe, Statue oder Bauwerk - um einen möglichst guten Concetto. In diesem Zusammenhang habe er auch seinen Schülern empfohlen, dem Beispiel des Redners zu folgen, der zuerst inventiert, dann ordnet, ziert und schmückt:

Nell'opere sue, o grandi, o piccole ch'elle si sussero, cercava, per quanto era in se, che rilucesse quella bellezza di concetto, di che l'opera stessa si rendeva capace, e diceva, che non minore studio, ed applicazione egli era solito porre nel disegno d'una lampana, di quello, ch'ési ponesse in una statua, $o$ in una nobillissima fabbrica. Nel prepararsi all'opere usava di pensare ad una cosa per volta, e davalo per precetto a' suoi Discepoli, cioè prima all'invenzione e poi riflettava all'ordinazione delle parti, finalmente a dar loro perfezione di grazia, e tenerezza. Portava in cid l'esempio dell'Oratore, il quale prima inventa, poi ordina, veste, e adorna, perche diceva, che ciascheduna di quelle operzioni ricercava tutto l'uomo, e il darsi a più cose in un tempo stesso non era possibile 73 .

Für die rhetorische Ambition Fischers und der Wiener Architektur des frühen 18. Jahrhunderts spricht jedoch nicht nur die römische Schulung, sondern auch die Tatsache, daß eine entsprechende Bildung des architectus doctus für den wohl aus dem Hofbauamt des jüngeren Fischer hervorgehenden Architekturprofessor Franz Thomas Rosenstingl (170285) zu einer Conditio sine qua non geworden war. Auch er sah in der Invention und Disposition die erste Leistung des Ingeniums und forderte deshalb die Architekten zu Gelehrsamkeit auf:

Ein Architekt muß auch gut gegründet sein in der Mythologie und sebr vieles gelesen und gesehen haben. Auch mit der Praxis in den Sinnzeichen, Gedanken und mit einem geschwinden Geist begabt sein, sodaß sich ein jedes Gebäude zu dessen Stand, für welchen es gebaut und zu dessen Endzweck es ausgeführt wird, schickt. Dies geht auch hinein in die Heraldik, damit man sich durch das geschlungene Laub der Wappen-Felder nach Standes-Gebühr bediene [. . . . $]^{74}$.

71) Versteigerungskatalog Arnoldi-Lievie, 70 Zeichnungen und Bilder 1590-1913, München 1986, Nr. 7.

$\left.{ }^{72}\right)$ G. SCHRODER, Das freche Feuer der Moderne und das Heilige. Zu Berninis Capella Cornaro, in: Antikenrezeption im Hochbarock, hg. von H. BECK und S. SchulzE, Berlin 1989, S. 193-203.

${ }^{73}$ ) Fiuppo Baldinucci, Vita del Cavaliere Gio: Lorenzo Bernino, Florenz 1682, S. 78, 74 f. und 71. - Zum Dreischritt inventio, dispositio und elocutio in der Kunsttheorie siehe: LeE, Ut Pictura Poesis (zit. Anm. 1), S. 183186.

74) Zitiert in: N. HierL-DeronCo, Je heller ein Ziegl klinget. Franz Thomas Rosenstingl und das Bauen im 18. Jahrhundert, Krailling 1988, S. 212 und 217. 


\section{3. , inventio " und, dispositio}

Die Anleitungen von Bernini und Rosenstingl folgen der traditionellen Auffassung von der Inventio als erstem officium oratoris. Man verstand darunter das Auffinden von Argumenten zum Erschüttern der Affekte, zur Erzeugung von Pathos und Ethos durch schöne oder groteske Bilder ${ }^{75}$. Der dispositio kam dann die Aufgabe zu, die Ergebnisse der inventio in eine sinnvolle Reihenfolge und Ordnung zu bringen. Schon Quintilian verglich diese Ordnung des Rohmaterials zu einer Rede mit der Kunstfertigkeit des Architekten, dem Bau aus dem herbeigeschafften Material Form zu verleihen ${ }^{76}$. Giorgio Vasari verstand in der auf die invenzione folgende disposizione dementsprechend die Lehre von der Komposition und der Proportion des Ganzen und der einzelnen Teile. Diese von der Erfindung nicht immer deutlich zu trennende Aufgabe bedeutet also die eigentliche formale Umsetzung eines vielfach von außen an den Architekten herangetragenen Gedankens oder einer Devise. Fischer war sich dieser zwei Aufgaben seiner künstlerischen Tätigkeit offensichtlich bewußt. Denn die Ansicht des Palais Trautson in der "Historischen Architektur " signierte er voll Stolz Inventée et ordonnée par J. B. Fischer d'Erlachen, während Heraeus in der oben genannten Beschreibung des Burgtores sorgfältig zwischen seiner eigenen Invention und der architektonischen "Ordnung " Hildebrandts unterschied. Die bewußte Verbindung von Inhalt und Form im Werk Fischers soll im folgenden in den Mittelpunkt der Betrachtung gestellt werden, wobei auch mehrere von Sedlmayr, Marsche und Möseneder noch nicht berücksichtigte Quellen und Vergleichsbeispiele einbezogen werden.

Zweck und Ziel künstlerischer Gedanken-Erfindungen war das, was Liechtenstein und Lünig in Zusammenhang mit Kunstkennerschaft als Witz im Sinne von „Pointe ${ }^{*}$ bezeichnet haben. Dabei handelt es sich um einen zentralen Begriff der barocken Rhetorik und Kunsttheorie, nämlich die argutezza 77 . Bereirs 1583 nannte Pierre Langlois als Voraussetzung für die Schönheit (grace) eines emblematischen Bildes, daß es doit estre si ingenieusement inventee qu'elle nous semble parler ${ }^{78}$. Analog dazu bezeichnere der Theoretiker Dominique Bouhours 1673 eine Devise als metaphore peinte of visible qui frappe les yeux; au lieu que celles des orateurs, \& des poetes frappant seulement l'oreille79.

Dementsprechend wurde Berninis plastische Personifikation der Wahrheit von den Zeitgenossen als stupenda Imago und pensiero espresso gepriesen ${ }^{80}$. Genau diese schon in der antiken Rhetorik als sub oculos subiectio bekannte Forderung nach einem „ins Auge springenden Bild“ und einer eindringlichen Gedanken-Erfindung im Sinne der inventio oratoris kennzeichnet auch die Kunstauffassung Fischers. So bezeichnete er den Entwurf für den Hochaltar von Straßengel als ersten Gedanken ${ }^{81}$ und betont auch bei der Publikation der eigenen Werke in der "Historischen Architektur" des Autoris eigene Erfindung.

75) KNAPE, Barock (zit. Anm. 5), Sp. 1300 ff.

76) Quintilian VI, praef. 1: Lemma „Dispositio“, in: Ueding, Historisches Wörterbuch (zit. Anm. 4), 2, Sp. 831.

7) BaUER, Barock (zit. Anm. 57), S. 183 ff. („Concettismo ${ }^{“}$ ).

78) Zitiert in: MOSENEDER, Menestrier (zit. Anm. 59), S. 8.

79) Dominique Bouhours, Les entretiens d'Ariste et d'Eugène, Paris 1673, zitiert in: MOSENEDER, Aedificata Poesis (zit. Anm. 3), S. 141.

oo) Baldinuccl, Bernino (zit. Anm. 73), S. 35 f.

81) Sedlmayr, Fischer (zit. Anm. 9), S. 37 f. 
Fischers Selbsteinschätzung und Leistung als geistreicher Entwerfer und Gelehrter läßt sich vor allem im Zusammenhang mit seinem ersten größeren Werk in Wien, der zur Erinnerung an die Pestepidemie 1679 von Kaiser Leopold I. gelobten Dreifaltigkeitssäule, belegen. Deren heute allgemein anerkannte kunsthistorische Bedeutung als erstes hochbarockes „Gesamtkunstwerk" wird durch eine offizielle Publikation anläßlich der Einweihung 1692 unterstrichen. Die von der kaiserlichen Hofdruckerei veröffentlichte „Beschreibung deß [... ] Pyramidis [...] sambt der [...] allda gehaltener Lob=Predig“ enthält nämlich nicht nur eine ausführliche Beschreibung und Erklärung des Kunstwerkes und der Einweihungszeremonien im Sinne einer Festbeschreibung, sondern behandelt in einer für Osterreich neuen Form ausführlich die künstlerische Genese und den individuellen Anteil der Künstler an Invention und Ausführung dieses marmorsteinenen Gedenckzeichens ${ }^{82}$. Aus dieser Quelle erfahren wir, daß der Ingenieur Hans Bernhard Fischer den Anstoß gab, daß, weil die Säulen bereits auf den Dörfern zu gemein werden wollen, etwas anderes ungemeineres dafür inventiert wurde. Wahrend die newe Invention der Wolkenpyramide dem kaiserlichen Ingenieur [. . .] und Inspectoris der Theatralischen Wercken Lodovico Burnacini zu verdanken war, verrät Fischers Anteil deutlich das Bewußtsein, einen Concetto künstlerisch adäquat umzusetzen. Er forderte nämlich eine Veränderung der schon ausgeführten Basis, damit die ,Triangular figur' beeder Postamente desto mehr ins Gesicht kommen thäte und außerdem nicht mehr ein rundes, sondern , in Cornformitet" der Postamenter cin dreyeckigtes Gländer zu errichten (Abb. 16). Die Ensinn= und Formirung der Concepten für die von Fischer an der architektonischen Basis angebrachten Reliefs erfolgte in enger Zusammenarbeit mit dem Jesuiten und Theologiae Doctor Franz Menegatti (Abb. 8,9). Dem Bericht zufolge hat man nämlich (gleich wie vorhin öffters bey dergleichen Ehrenwerken beschehen) dessen Gutbeduncken, requirieret' und auß vielerley vorgestelten Gedancken die entsprechenden Motive ausgewählt. Das Ergebnis präsentiert sich dementsprechend als inhaltlich wie formal überzeugende Visualisierung der Trinitätssymbolik:

Damit gleich wie alles zu Ehren der Allerbeiligsten dreyen Persobnen gewidmet/ und dessentwegen die ganze ,Figur' auff drey Eck oder Pfeiler außgetheilet ist. Also auch drey ,Inscriptionen" und jeder deren mit drey Worten; Item drey auff dem Glinder immer brennende goldene Lampen=Hertz: auch auß denen in das untere Postament vermeinten sechs Bassi Rilieven, drey nambhaffte Straff = und wiederumben drey nambhafte Gnaden=, Historien' (wie sie sich einer unnd anderer Göttlichen Persohn zuschreiben lassen) auch jedesmahl eine auß dem Alten, die andere auß dem Neuen Testament genommen worden. Jedoch sovil möglich/ eine mit der anderen. und sogar die in dem obern Postament formirende, Emblemata" mit diesen unteren, Historien" ihre, Connexions-Allusion' haben sollet.

Bei der als Hof- und Staatsaktion inszenierten Einweihungsfeier wurden die Zünfte mit ihren Fahnen so am Rand des Platzes aufgestellt, daß es einem vielfarbigen kostbahrem ,Theatro' gleich geseben hat. Von der neben dem Denkmal aufgebauten Kanzel hielt der Jesuit und kaiserliche Hofprediger Ignaz Kriechbaum eine hochgelehrte und trostreiche Predig, in der er sowohl die typologische Gegenüberstellung von Strafe und Gnade als auch die Dreier-Symbolik des Denkmals in Worte bannte: Allda haben wir in allen vorfallenden

82) Beschreibung deß Zu Ehren der Allerheiligsten Dreyfaltigkeit allhie auff dem Graben auffgerichren dreyekkichten weissen Marmorsteinenen Pyramidis sambr der zu Zeit der Einweyhung allda gehaltener Lob=Predig, Wien 1692. - Zur Dreifaltigkeitssäule vgl. auch den Beitrag von Ch. M. Boeckl in diesem Band. 
Nothdurffien/ gemeinen und sonderbaren Anliegen ein weit bewehrteren, lapidem adjutorij, Hilff Schutz= und Schirmstein: so wir anderst die drey Gottliche Persobnen nicht nur eusserlich durch auffgerichtetes Danck= und Denckzeichen/ sondern vilmebr innerlich durch bestindige Andacht/ Vertrauen und Zuversicht demütigst anruffen und verehren werden ${ }^{83}$.

Ähnlich stolz wie über seine Beteiligung an der Pestsäule äußerte sich Fischer im Jahre 1700 in einem Brief an den Freiherrn Bartholotti von Bartenfeld über den Hochaltar von Mariazell (Abb. 2): Es ist ein Werk, dergleichen wenig zu sehen sein ${ }^{84}$. Obwohl Johann Bernhard in diesem Fall schon 1692 den ersten Entwurf und 1702 die Schlußrechnung als Generalunternehmer geliefert hat, wurde das Werk erst dank einer kaiserlichen Stiftung ab 1715 vollendet. Der im ersten Projekt Fischers von einer Dornenkrone umwundene Tabernakel in Form einer Weltkugel als Hinweis auf die Zusammengehörigkeit von Passion und Erlösung stellt zweifellos eine besonders geglückte Verbindung von Inhalt und Form dar ${ }^{85}$. Thema des Altares ist bekanntlich die in die habsburgische Staatsmystik integrierte Kreuzerhöhung ${ }^{86}$, deren Quintessenz der Benediktiner Marian Winger in der Einweihungspredigt 1722 vor dem kaiserlichen Stifter folgend beschrieb:

Kaum ist der eingemenschte Sohn Gottes an dem Creutz=Holtz gestorben/ kaum hat er Ihm das Creutz vor seinen Todt erwählet/ da ist auf einmahl auf ewig alle Schmach und Schand von dem Creutz hinweg gewichen/ da hat sich sein Vermaledeyung in eine Benedeyungl, fons benedictionum; sein Verwerfung in eine Erhöhung, gloria de opprobrijs; alle vorige Peyn und Marter in süsseste Freud und Ergötzlichkeit verwandlet/, vita de morte. A locis infamibus suppliciorum Crux transitum fecit ad frontem Imperatorum : [...] Von der unehrlichen Gerichts=Statt ist nunmehro das Creutz=Zeichen auf die Stirn deren Kaysern gesetzet worden ${ }^{87}$.

Ganz im Sinne eines Theatrum sacrum wird der Betrachter auch von den flankierenden Engeln auf das - nach einer Komposition von Bernini - von Gottvater gehaltene Kruzifix verwiesen und durch die affektgeladenen Gesten Mariä und Johannis unter dem Kreuz zur Compassio aufgefordert. Zur Verdeutlichung der vom Prediger beschriebenen Peripetie präsentierte Fischer das Kreuz genau in der Schwebe zwischen irdischem Schmerz und himmlischer Glorie. Diese horizontale Differenzierung wurde auch durch die Materialikonographie - dunkler Marmor und Silber für das Irdische, heller Marmor und Gold für das Himmlische - veranschaulicht. Dementsprechend wurde das Werk schon 1709 von einem Jesuiten durch ein eigenes Gedicht gewürdigt, wobei die verschiedenen Materialien besonders hervorgehoben wurden ${ }^{88}$.

83) Ignatz Kriechanum S. J., Lapis Jacob oder Stainernes Danck= und Denckzeichen zu Ehren der hochheiligst= unzertheilten Dreyeinigkeit (.. .), Wien 1692, S. 9.

84) SAMMER, Mariazeller Hochaltar (zit. Anm. 48), S. 30.

as) Sedimark, Fischer (2it. Anm. 9), S. 109.

ه6) Der von Matsche (Die Kunst, zit. Anm. 46, S. 126) vermutete Zusammenhang zwischen dem Altar und der habsburgischen Ikonographie aufgrund des damals in der katholischen Kirche nicht allgemein verbindlichen habsburgischen Hoffestes und dem Türkenkrieg Karls VI. wurde in einem kaiserlichen Festgedicht zur Einweihung des Alares ebenso direkr angesprochen wie in der Predigt zu Ehren der kaiserlichen Familie: Aqvila imperialis (...), Steyr 1722.

87) P. Maruan Winger OSB, Festrägliche Predig So folgenden Tag darauf als den 5. Augusti Vor Ihro Römisch=Kayserlich=Königl. Katholischen Majestäten/ Und Beeder Allerdurchleuchtigsten Ertz=Hertzoginnen Elisabetha Und Magdalena In Unterthänigster Aufwartung Kayserlichen Hoffstatd/ und Hoher Adelschafft auß Steyermarckt Vorgetragen, Steyr 1722, o. S.

a) SAMMER, Mariazeller Hochaltar (zit. Anm. 48), S. 29-33. 
Während Sedlmayr beklagte, daß die Ausführung gegenüber dem ersten Entwurf an Qualität verloren habe, spricht Fischers eingangs zitierte Äußerung dafür, daß dabei die grundlegende Invention letztlich ebenso gut oder vielleicht noch deutlicher als beim Vorentwurf umgesetzt wurde. Die wesentlichste Änderung betraf die Reduktion der Säulen, so daß die Architektur dem Betrachter gleichsam mit ausgebreiteten Armen entgegenkommt. Dieser Eindruck eines Trichterportals ${ }^{89}$ konveniert perfekt mit der theologischen Symbolik der Pforte. Die himmlische Ehren=Pforten lieferte beispielsweise nicht nur Titel und Argumentum für eine 1691 gedruckte Predigt von Dr. Johann Ernst de Jamaigne90, sondern wurde direkt mit der Architektur von antiken Tugendtempeln und fürstlichen Ehrenpforten verbunden:

Ich will [. . . ] die Thür weisen; und zwar jene Thür/ so von sich selbsten bezeuget: Ich bin die Thür/ und Pforten/ wer durch mich eingehen wird/ wird erlöset werden (Joh. 10). [. . .] Diese Porten [. . .] ist die Porten der Erlösung [. . . ]; sie ist nicht die Porten des Todes; nicht die Porten der Höllen/ sondern die Porten des Heyls/ die Porten deß Lebens/ die Porten der Seligkeit; durch diese Porten/ und durch keine andere ist der Eingang zur ewigen Glory [. . .]. Christus wird genennet eine Porten, aber nicht eine unbeseeltel unbewegliche Porten/sondern ein Porten/ die selbsten hinein führet/ und hinein leitet. [. . .] Woblan dann die wahre himmlische Ehren=Pforten ist euch gezeuget/ sie ist euch eröffnet/ gehet nur köck hinein/ ehe dann sie verschlossen werde [...]; unser süssester Jesus/ ist unser Tugend = und Ehren=Pforten/ haben wir es erkennet/ so lasset uns/ mit unsern Wercken/ die obne ihme nicht einzugehen vermögen/ durch ihme eingehen/ auf daß wir durch Jhme eingegangen zu seyn/ uns ewig erfreuen. Amen ${ }^{91}$.

Dieser Gedanke des bewußten Hin- beziehungsweise Höherführens des Betrachters kennzeichnet auch Fischers Idealentwurf für Schönbrunn mit seinen zahlreichen Terrassen (Abb. 17). Im Gegensatz zur Beurteilung durch Lorenz als „zumeist ziemlich übèrschätztes Präsentationsstück" ${ }^{92}$ zeigt sich Johann Bernhards Leistung als Concettist und Architekturhistoriker allein schon durch die Tatsache, daß hier bereits zentrale Morive des „Kaiserstils“ Karls VI. vorweggenommen werden. Wie später in der Hofbibliothek sollte die Identifikation des Fürsten mit Apollo und Herkules in erster Linie die Beherrschung von arma et litterae durch den idealen Herrscher veranschaulichen ${ }^{93}$. Hatte Johann Bernhard schon bei diesem Entwurf im achsialen Mittelpunkt der Anlage einen Sonnenwagen plaziert ${ }^{94}$, so bezeichnete die Medaille zur Fertigstellung des Schlosses nach dem zweiten Plan im Jahre 1700 die Residenz Josephs I. ausdrücklich als Sitz der Sonne95. Parallel dazu wurde der schon bei seiner Geburt als Hercules Austriacus gefeierte Römische König 1702 in einem jesuitischen Emblem als Tugendheld vor seiner Residenz porträtiert (Abb. 19) ${ }^{96}$.

a9) Auf den Zusammenhang mit den gleichzeitigen Portalentwürfen hat schon AurenHAMMER, Fischer 1956 (zit. Anm. 20), S. 61, hingewiesen.

90) Der Theologe widmete sein Buch Raimond Regondi, dem Abt des Stiftes Altenburg. Das Stift war eine Tochterabtei von St. Lambrecht, dessen Abt den Mariazeller Altar in Auftrag gab.

9i) Johann Ernest de Jamajgne, Himmlischer Ehren=Saal/ Mit denen aus Götticher Heil. Schrifft gezogenen Figuren gezieret (...) 1. Bd., Würzburg - Frankfurt 1691, S. 1-12.

92) LORENZ, Fischer (zit. Anm. 9), S. 16.

93) Vgl. A. Buck, „Arma et Litterae ${ }^{\star}$ „Waffen und Bildung“. Zur Geschichte eines Topos, Stuttgart 1992.

9) G. Kunoth, Die Historische Architektur Fischers von Erlach, Düsseldorf 1956, S. 224, Abb. $101 \mathrm{~b}$.

95) Kat. Welt des Barock (Ausst. Stift St. Florian), Linz 1986, Nr. 1.40.

96) Franz Hochenburger S. J., Hercules Austriacus. Sive Josephus I (. . .), Graz 1702, Emblem VIII. 
Wesentlicher als die traditionelle Identifikation der Habsburger mit dem Musenführer 97 und dem Tugendhelden ${ }^{98}$ ist meines Erachtens jedoch die besondere räumliche Ausdehnung und hierarchische Höhenstaffelung der Architektur Fischers. Dem optischen Eindruck entspricht nämlich die ikonographische Hierarchie vom Säulenportal mit den apotropäischen Darstellungen des Halbgottes bis zur Quadriga des Sonnengottes über dem Mittelgiebel des Schlosses. Während die Siege des Tugendhelden über Hydra und Zerberus, jene des Apollo über die Python auf dem Brunnen und indirekt auch die kämpfenden Ritter den Kampf des Guten gegen das Böse veranschaulichen, erhebt sich Phöbus-Apollo über der eigentlichen Residenz und damit in dem den Irdischen nicht mehr zugänglichen Bereich der Apotheose. Durch die markanten Brunnenfelsen wird der Schauplatz dieser Psychomachie in Schönbrunn als Bereich der Grotten und der chthonischen Unterwelt ausgewiesen 99. Dieser Gedanke der Läuterung wurde in der oben genannten „Pforten-Predigt“ von Jamaigne 1691 an einem weltlichen Beispiel exemplifiziert:

Allbekandt ist jenes so herrlich/ als sinnreiche Gebäu deß Römischen Rathsmeisters [= Senators]/ Marcelli, welches er zur Verehrung der Tugend und Glory auffgerichtet/ nemlich/ zwey kostbare Tempell welche aber so aneinander gehefftet waren/ daß man den Glory= und Ehren=Tempel nicht ebender betretten kontel man bätte dann vorhin den Tempel der Tugend durchgegangen; dadurch anzudeuten/ daß einiger Weg zu denen Ehren und Glory nicht bevorstebel als durch die Porten der Tugend [.. .]. Dann wie Achilles Bochius zu jenem Tempel die Beyschrifft stellet, ,Virtus Vestibulum est honoris alma; Die Tugend ist der Vorhoft und die Porten zur Ehr und zur Glory ${ }^{100 .}$

Der Prediger bezog sich hier auf ein Emblem des Achille Bocchi von 1555, das eine Herkulesstatue als Bekrönung des Tempels der Tugend zeigte. Eine andere Rekonstruktion dieses antiken templum honoris et virtutis von Giacomo Lauro aus dem frühen 17. Jahrhundert wurde zulezzt von Lavin aufgrund der Verbindung eines Rundtempels und zweier Monumentalsäulen mit der Karlskirche in Verbindung gebracht ${ }^{101}$. Für unseren Zusammenhang ist interessant, daß Lauro die beiden Säulen nicht als jene des Herkules, sondern als jene des Trajan und Antoninus beziehungsweise als Denkmäler für deren Tugenden bezeichnet und die Fürsten ausdrücklich zum Wiederaufbau des Templum virtutis et honoris auffordert:

Dero halben sollen die Fürsten heutigs tags wol ein exempel nehmen, den nun mehr erfalnen und beinabe ganz zu grund gangnen tempel der Tugendt, wieder erbauen: auff das nit jemandts in den tempel der ehren, einigen fues sezze, er sei dan zuvor durch die Pforten der Tugend eingetretten. Dessen uns die Heidnische, und noch der Christlichen lehr nit underwisne keiser und Fürsten genuegsam zeugnus geben. [...] Under disen waren Antoninus und Trajanus,

\footnotetext{
97) Vgl. dazu: F. Polleross, Sonnenkönig und österreichische Sonne. Kunst und Wissenschaft als Fortsetzung des Krieges mit anderen Mirteln, in: Wiener Jb. f. Kunstgeschichte, XL, 1987, S. 239-256.

98) Zur Herkulestradition der Habsburger siehe zuletzt: Matsche, Die Kunst (zit. Anm. 46), S. 343 ff.

99) Vgl. B. Euler-Rolle, Grotten zwischen Kunst und Natur, in: Barocke Natur. Naturverständnis zwischen Spätbarock und Aufklärung, Wien 1989, S, 33-41.

${ }^{100}$ ) De Jamaigne, Ehren-Saal (zit. Anm 91), S. 2 f.

101) I. LAVN, Fischer von Erlach, Tiepolo und die Einheit der bildenden Künste, in: Barock: regional international. Kunsthistorisches Jahrbuch, 25, hg. von G. Pochat und B. WAGNer, Graz 1993, S. 251-274, hier S. 265 f., Abb. 24.
} 
welchen die Roemer nit ueniger wegen ibrer gerechtikeit und guete, als starkhe und manheit haben zwo seilen aufgericht, die noch, zu dern ewigen lob und gedachtnus, gesehen werden 102.

Fischer selbst hat dieses Motiv 1690 bei einem Emblem für den „Triumphbogen der Niederleger “ aufgegriffen: Unter dem Lemma Pandat Alumna wird Joseph I. von Pallas Athene auf den von zwei Säulen flankierten Tempel der Ehre und dessen geöffnete Tugendpforte hingewiesen (Abb. 18) ${ }^{103}$.

Bezeichnenderweise finden wir sowohl die beiden Säulen des Herkules und den steilen Aufstieg in zahlreichen Terrassen als auch die Veranschaulichung des Triumphes des Tugendhelden über die Giganten durch eine Idealarchitektur über künstlichen Felsen beim Entwurf des römischen Architekten Giovanni Francesco Guernerio für die Kasseler Wilhelmshöhe im Jahre 1701 wieder (Abb. 20)104. Die beiden in Rom geschulten BildhauerArchitekten haben damit offensichtlich Konzepte variiert, die Bernini bei den Projekten für Ludwig XIV. ausgearbeitet hatte ${ }^{105} .1665$ plante der römische Architekt die Errichtung eines Amphitheaters zwischen Louvre und Tuilerien. In Abwandlung einer früheren Idee, die Säulen des Trajan und des Antoninus in Rom zusammen aufzustellen, wollte Bernini in Paris zwei Monumentalsäulen mit einem Reiterstandbild des Sonnenkönigs unter dem herkulischen Motto NON PLUS ULTRA kombinieren ${ }^{106}$. Bei der Planung für den Louvre verband der Architekt nicht nur die Sonnensymbolik mit der Herkulesallegorie, sondern auch mit der Visualisierung eines „moralisch-architektonischen Fortschritts ${ }^{\star 107}$. Sollte Berninis Gedanke des Herkules, quale risiede su il monte della fatica che a lo scoglio, bei der Residenz nur metaphorisch durch einen Rustikasockel veranschaulicht werden, so verdeutlichte Menestrier den Concetto 1699 bei einem Feuerwerk zu Ehren des Sonnenkönigs, indem er den Temple de la Gloire als klassische Säulenarchitektur auf einen von Drachen bewohnten Felsen setzte ${ }^{108}$. Im Unterschied zu den gebauten Metaphern in Paris konnten Fischer und Guernerio das ansteigende Gelände nutzen, um den beschwerlichen Weg der Tugend zum Tempel der Glorie auch realiter nachvollziehbar zu machen. Mit dieser gleichsam profanierten und umgekehrten Idee der Wolkenpyramide bildete der Premier projet

102) JaCoBus Lauro, Antiquae urbis splendor (. . .), Rom $1641^{2}$, Tab. 30.

103) Bestätigt wird diese Interpretation durch eine Darstellung der Aufnahme eines Freimaurerlehrlings in den Tempel der Tugend: C. Limpricht, Der Salomonische Tempel als typologisches Modell, in: P. NAREDi-RaINER, Salomos Tempel und das Abendland. Monumentale Folgen historischer Irrtilmer, Köln 1994, S. 277, Abb. 171. Beim Triumphbogen 1699 präsentierte Fischer Joseph 1 . in einem Rundtempel, der durch die Inschrift deudich als Templum gloriac ausgewiesen war.

104) Giovanni Francesco Guernerio, Delineatio Montis a Metropoli Hasso-Cassellana Uno Circiter Milliari Distantis (...), Rom 17262. - G. WINTER, Der Heros im Garten - Gedanken zum Kasseler Herkules, in: Herakles/Herkules I. Metamorphosen des Heros in ihrer medialen Vielfalt, hg. von R. KRAY und ST. OETTERmaNN, Basel - Frankfurt/Main 1994, S. 111-130.

i05) Als Vermittler zwischen Fischer und dem Pariser Projekt Berninis wird meist der Mannheimer Entwurf von Jean Marot angenommen: SedlmaYr, Fischer (zit. Anm. 9), S. 52 f. - MOSEneder, „Aedificata Poesis“ (zit. Anm. 3), S. 159.

$\left.{ }^{106}\right)$ Dieses Motiv wurde 1717 bei einer Medaille zu Ehren von Karl VI. aufgegriffen: Lavin, Fischer von Erlach (zit. Anm. 101), S. 267, Abb. 26.

${ }^{107}$ ) I. Lavin, Bernini's Image of the Sun King, in: Past - Present. Essays on Historicism in Art from Donatello to Picasso, Berkely - Los Angeles - London 1993, S. 138-200 und 288-302.

108) P. BuRkE, Ludwig XIV. Die Inszenierung des Sonnenkönigs, Berlin 1993, S. 145 ff., Abb. 54. 
pour la Venerie Imperiale das weltliche Gegenstück zur „ungemeinen Invention“ der Pestsäule ${ }^{109}$.

Das Schönbrunnprojekt führt darüber hinaus in der Hauptachse eine (allerdings nur fiktive) geographische Symbolik vor, erscheint doch die Sonnenquadriga im Osten, während die Säulen des Herkules das westliche Ende der Welt markierten. Man wird in diesem Zusammenhang an die Verse erinnert, die Heraeus später den kaiserlichen Edelknaben vortrug:

In jenem grossen Reich, das sich von Osten nennt,

Das, wie der Sonnen = Lauf, gar keine Grenzen findet,

Als die durch Westen hin der Aufgang wieder kennt; [. . .]

Die Kaiser=Burg mußt' andre Wunder sebn:

Europens letzate Grenz' in Ost und West umfangen;

Die Cran Hispaniens auf Hungarns Balken stehn;

AufNeapels Königs= Thron den Böhmischen Löwen prangen [. . .]110.

Tatsächlich beabsichtigte Fischer mit seinem eindrucksvollen Perspektiventwurf wohl die Veranschaulichung der geographischen und der historischen Dimension der habsburgischen Herrschaft ${ }^{111}$. Ebenso wie die Spiralreliefs die beiden Herkulessäulen eindeutig als Nachfahren der römischen Triumphalsäulen ausweisen ${ }^{112}$, veranschaulicht das Residenzgebäude den Bezug zu den römischen Imperatoren, da dessen architektonische Struktur und Gliederung Fischers Rekonstruktion der Domus aurea des Nero entspricht ${ }^{113}$. Die Veranschaulichung der Stellung des Regierenden Welt-Monarchen in zeitlicher und räumlicher Hinsicht, das heißt einerseits die Translatio Imperii von den antiken Weltreichen der Babylonier, Perser, Griechen und Römer an die Habsburger, andererseits der mit dem spanischen Erbe verbundene Anspruch auf eine Herrschaft plus ultra in allen vier Erdteilen, war bereits seit den sechziger Jahren des 17. Jahrhunderts geläufiges Gedankengut der bildlichen und literarischen Panegyrik114. Es läßt sich zwar nicht eindeutig nachweisen, ob Fischer bei seiner Darstellung der Vier Weltmonarchien auf dem linken Brunnen in Schönbrunn tatsächlich schon mit dem erst 1691 als Erzieher Josephs I. angestellten Historiker Wagner von Wagen-

109) Die etwa 1644 von Pietro Sforza Pallavicino in einem Rhetoriktraktat beschriebene Entwicklung des menschlichen Geistes von den fondamenti di pietre rozze bis zum alto e maraviglioso edificio (NoeHles, zit. Anm. 3, S. 200) hat Bernini bei den Brunnenentwürfen für die Piazza Navona und Piazza della Minerva (Herkules?) künsclerisch umgesetzt. - Zur Weiterführung dieser Gedanken bei Fischers Bau in Frain siehe: F. Polleross, „Virtutum exercitia sunt gradus ad gloriam ${ }^{*}$. Zum concetto des Ahnensaales in Frain an der Thaya, in: Tagungsbericht der "Frainer Begegnung 1995 (in Druck).

110) Herazus, Gedichte (zit. Anm. 56), S. 226 and 230. - Auch bei der Festdekoration im Palais Liechtenstein hat Heraeus 1718 Apollo und Herkules als Sinnbilder für die kaiserlichen Siege im Osten und Westen vorgeführt: MATSCHE, Die Kunst (zit. Anm. 46), S. 359.

111) Es sei in diesem Zusammenhang vor allem auf die in ihrer perspektivischen Monumentalität vergleichbare Ansicht der "Sinesischen Kaiser Burg zu Peking" verwiesen, deren Vorhöfe laut Fischers Beschreibung nach den 4 Enden der Welt ausgerichtet waren: FisCHER, Historische Architektur (zit. Anm. 67), fol. 96.

112) Sснмпт, Schönbrunn (zit. Anm. 34), S. 41 f., verwies in diesem Zusammenhang auf die Tatsache, daß die Habsburger sich nicht nur als Nachfahren des Herkules, sondern auch der Colonna betrachtet haben, deren Säulensymbolik Fischer wohl von Rom her vertraut war.

113) SCHмrт, Schönbrunn (zit. Anm. 34), S. 18 ff.

114) F. POLeross, „Sol Austriacus" und "Roi soleil“. Amerika in den Auseinanderserzungen der europäischen Mächre, in: Kat. Federschmuck und Kaiserkrone. Das barocke Amerikabild in den habsburgischen Ländern (Ausst. Schloßhof), Wien 1992, S. 54-84, hier S. $63 \mathrm{ff}$. 
fels kooperierte115, aber die vier Hauptregiment nach des Allmächtigsten gnädiger Verordnung waren ein traditionelles Thema habsburgischer Ikonographie116. Diese Propagierung der Reichsidee wird etwa im 1669 aufgeführten und 1680 in Breslau publizierten Trauerspiel Sophonisbe des Daniel Caspar von Lohenstein (1635-1683) in allegorischer Form zu Ehren Leopolds I. vorgetragen. Im letzten Akt treten das Babylonische, das Persische, das Griechische und das Römische Reich auf, um ihr Scheitern gegenüber dem Römischen Reich Deutscher Nation einzugestehen, das der Prophezeiung nach den ganzen Erdball (also vor allem auch die amerikanischen Länder der spanischen Linie des Hauses Habsburg) beherrschen wird:

Doch wird mein Schluß erst treffen ein

Wenn Deutschland wird der Reichs-Sitz sein

Mein fermes Auge siehet schon

Den österreichischen Stamm besteigen

Mit grösserem Glanz der Römer Thron.

Schau eine neue Welt sich zeigen!

Weil ihm ein allzu enges $Z$ iel

Alcidens Säule werden will. [. . .]

Europa, Asia, Afrika, Amerika. [... ]

Der ist ein Herr der Welt zu beißen/

Vor dem wir alle vier knien.

Nimm Osterreich den Siegeskranz bin 117.

Die im Herkulesbrunnen en miniature vorgeführte Translatio Imperii war also in Fischers Gesamtentwurf durch den fiktiven Aufstieg von den Säulen des Herkules im „Okzident" bis

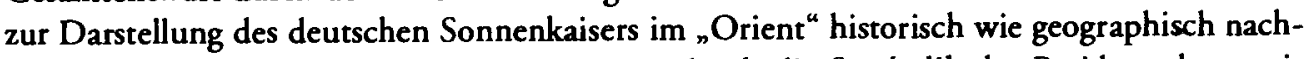
vollziehbar. Gestützt wird diese Interpretation durch die Symbolik der Residenz der persischen Könige in Isfahan. Im Manuskript der "Historischen Architektur ${ }^{*}$ beschreibt der Architekt diese nämlich nicht nur als la place la plus grande et la plus reguliere qu'il y ait au monde, sondern verdeutlicht die geographische Dimension auch durch die Beischriften ORIENS im Hinter- und OKZIDENS im Vordergrund der symmetrischen Anlage. Die historische Dimension wird in der Legende ebenfalls deutlich zum Ausdruck gebracht: Diese prächtige von Cyro erbaute Residenz der Könige von Persien hat Alexander M. eindschern Lassen 118.

Die im utopischen Projekt für Schönbrunn angelegten universalen Concetti hat Fischer wenig später beim "Triumphbogen der fremden Niederleger" anläßlich der Krönung Josephs 1 . in kompakter Form durch die Verbindung von Monumentalsäulen und Weltkugel vorgeführt ${ }^{119}$. Ein zeitgenössischer Bericht schließt dementsprechend mit den Worten: $E t$

115) Sedlmayr, Fischer (zit. Anm. 9), S. 246 ff. - Schmitt, Schönbrunn (zit. Anm. 34) S. 182/Anm. 171.

116) LeONhart Wurfbain, Relationes Historicae (. . .), Nürnberg 1636, S. 1.

117) Lohenstein, Sophonisbe, Vers 675-688, zitiert in: W. Neuber, Plus ultra - Die Überbierung der Antike durch die Entdeckung der Neuen Welt. Amerika in der deutschen Panegyrik des 17. Jahrhunderts, in: Federschmuck und Kaiserkrone (zit. Anm. 114), S. 185-193, hier S. 188.

118) KUNOTH, Historische Architektur (zit. Anm. 94), Abb. 102.

119) Siche zuletzt: MOSENEdeR, „Aedificata Poesis“ (zir. Anm. 3), S. 160-163. 
sic Austria Erit In Orbe Ultima!'120 1711 wurden die Triumphalsäulen von Fischer beim Trauergerüst für Joseph I. wieder aufgegriffen (Abb. 28), wobei die Beschreibung von Heraeus erläutert, daß diese wie dergleichen Colossalische Geschichts-Säulen als zu Rom von Trajano und Antonino Pio zu sehen sind [. . . ] die glorreichen Taten des Kaisers abbilden ${ }^{121}$.

Unter Josephs Nachfolger erhielt das Motiv der Doppelsäulen zusätzliche und konkreter auf den Herrscher bezogene Bedeutungen. Da die Devise Plus ultra das Sinnbild der spanischen Monarchie und nicht zuletzt ihrer überseeischen Besitzungen war, finden sich die beiden Säulen des Herkules mit bekrönenden Globen gemeinsam mit der aufgehenden Sonne bereits auf einem Porträt Karls als Hispaniarium et Indiarum Rex von Johannes Blommendaal und Philibert Bouttats aus der Zeir um 1703/1705 (Abb. 24). Anläßlich der Wahl des Habsburgers zum Römischen Kaiser wurde dieses Motiv zu einem Sinnbild der Doppelherrschaft im Sinne des Ahnen Karl V. gedeutet, zum Beispiel auf einer Medaille Auff die höchst erfreuliche Wahl Ihro Königl. Majestät CAROLI III König in Spanien und Indien etc. zum Römischen Kayser von Christian Wermuth. Der Avers zeigt das Bildnis. Die andere Seite stellet das Römische und Spanische Reich/ unter zweyen, Toscanischen' Säulen vorl welche durch die über denen Capitelen befindlichen Wappen unterschieden, und vermittelst einer Ketten/ an welcher die Caroli V. und jetziger Kayserl. Majestät/ Carali VI. Bildniß schweben/ vereiniget sind/ mit der Jabre $=Z a h l 1711$ in sich haltenden Uberschrift: $s I C$ tanDeM $p L V s$ VLtra.

So steiget man im Helden = Lauff

Die Ehren=Staffeln böher auff.

Diese, Invention' ist genommen/ aus Caroli $V$, bekannter ,Devise', deren beyden ,Herculis"Säulen/ mit der Beyschrift: PLVS VLTRA. Weilen kein Römischer Kayser/ Teutscher,Nation" ausser Carolo V. und jetziger Kayserl. Majestät/ zugleich Römischer Kayser und König in Spanien gewesen. 122

Eine neue Sinnschicht ergab sich durch das von Karl VI. gewählte kaiserliche Motto Constantia et Fortitudine, da diese beiden Tugenden ebenfalls durch die Säulen symbolisiert wurden. Ein von Heraeus als stumme Tichterey bezeichneter emblematischer Kupferstich verbindet alle diese Motive ebenso miteinander ${ }^{123}$ wie eine zur Kaiserhuldigung 1712 in Nürnberg geprägte Medaille (Abb. 25): Die beiden toskanischen Säulen werden nicht nur als jene des Herkules beziehungsweise als Sinnbild der weltweiten Herrschaft Karls V. präsentiert, sondern die Inschriften verweisen auf die Devise Karls VI. und die beiden Kronen auf dessen Herrschaft im Reich und in Spanien. Die Inschrift PLVS VLTRA CAROLVM CAROLVS stellt den Bezug zwischen Herkules und den beiden Habsburgern schließlich als eine historische Steigerung dar.

Dieser Aspekt kennzeichnet auch das Programm der ab 1715 von Fischer errichteten Karlskirche in Wien (Abb. 26), verweisen doch die Monumentalsäulen dieser kaiserlichen Votivkirche laut Heraeus als "stumme Redner" allegorisch ebenfalls auf die Devise des

${ }^{120}$ ) Ausführlich= und lesenswürdige Beschreibung (...) der Wahl, als Krönung JOSEPHI (...), Frankfurt $1711^{2}$, S. 19.

121) Heraeus, Inscriptiones (zit. Anm. 54), S. 196.

122) Ausführliche Beschreibung Der Crönung Ihr. Röm. Käyserl. Majest. CAROLI VI (. .), Leizig 1712, S. $22 \mathrm{f}$.

123) Moseneder, ${ }_{n}$ Aedificata Poesis“ (zit. Anm. 3), S. 163, Abb. 204. - Mntsche, Die Kunst (zit. Anm. 46), S. 310 ff., Abb. 36 f. 
Stifters: Columnae muta et secundaria tantum significatione symbolum fundatoris loquantur. Man hat die beiden Triumphalsäulen zu Recht auch mit den vor dem Tempel in Jerusalem aufgestellten Säulen Jachin und Boas in Zusammenhang gebracht, die ebenso wie die Devise des Kaisers das Motto Damit er nicht stürze symbolisieren ${ }^{124}$. Darauf bezieht sich etwa ein Emblem der Grazer Jesuiten zu Ehren Ferdinands II. (dem Erbauer des von Fischer stuckierten Mausoleums) um 1600. Es zeigt den Tempel von Jerusalem als Zentralbau mit Kuppel sowie zwei Säulen und zwei Obelisken (Abb. 22)125.

Die Triumphsäulen der Karlskirche sollten im Sensus literalis zunächst einer Idee von Leibniz zufolge Karl V. und dem hl. Karl von Flandern als Vorgängern des regierenden Herrschers gewidmet werden, wurden schließlich aber mit Szenen aus der Vita des Titelheiligen der Kirche und Namenspatrons des Kaisers, Karl Borromäus, geschmückt. Beide Aspekte der Ikonographie, der Bezug auf das Volk Israel und die bewußte Vermischung von kaiserlichem und himmlischem Pestpatron, waren schon vor Baubeginn angesprochen worden, nämlich in der Predigt des dem Jesuitenorden angehörenden Hofpredigers Franz Xaver Brean anläßlich des festlichen Gelöbnisses zum Kirchenbau im Jahre 1714:

David baute einen Altar an eben jenem Orth, allwo er den Göttlichen Straff=Engel das Schwerd sabe in die Schoyd stecken, schlachtete auff diesem Brand = und Fried $=O$ Pffer. Hierauff wunde der Herr versöbnet, und die schwere Plag von Israel abgewendet. Als eben dieser Engel am allermehristen wider uns darein schluge, und die Straff am böchsten ware, hat höchst benentes Gelübd [des Kaisers] dem Allerhöchsten nicht einen, sondern in einem herrlichen Gottes=Hauß mehr Altär angelobet, umb auff diesen das unschuldigste Gottes Lamb als ein unendliches Versöhnungs=Opffer obne Unterlaß zu schlachten. Bald darauf spürten wir die Göttliche Erbarmnuß, die Straff finge an nachzulassen [. . .]. Weilen aber die Flüchtigkeit unseres Lebens, auch die Danckbarkeit auff der Welt abstürzet, sollen die herrliche Kirchen=Mäuren, welche zu euren Ehren [der Pestheiligen] das geheiligste Wort eines Kaysers Gott hat angelobet, so lang sie stehen, der gantzen Nach=Welt ein Denck=Zeichen segn, der Andacht und Gotsseeligkeit CAROLI auff Erden, gegen CAROLUM in dem Himmel, und hingegen des Schutzes und der mächtigsten Vorsprechung CAROLI von dem Himmel gegen CAROLUM auff Erden ${ }^{126}$.

Die Ikonographie der Karlskirche muß also unter dem Aspekt der Typologie gesehen werden. Ebenso wie bei der Pestsäule (Abb. 8, 9) betrifft dies zunächst theologisch die Dialektik von Altem und Neuem Testament, von Strafe und Gnade. Die Typologie der bewußt als Symbol des gesamten habsburgischen Reiches errichteten Kaiserkirche ist jedoch vor allem historisch-panegyrisch auf Wien als neues Jerusalem, Rom und Konstantinopel sowie Karl VI. als neuen Salomon, Augustus und Konstantin ausgerichtet ${ }^{127}$.

Ebenso wie beim ersten Entwurf für Schönbrunn ist aber nicht nur die mehr oder weniger traditionelle Symbolik zu beachten, sondern die eigentliche Aussage erhellt sich erst

124) Zur Ikonographie der Karlskirchen-Säulen siehe zuletzr: P. NAREDI-RAINER, Johann Bernhard Fischer von Erlach und Johann Joseph Fux - Beziehungen zwischen Architektur und Musik im österreichischen Barock, in: Pоснат - WAGNER, Barock (zit. Anm. 101), S. 275-290, hier S. 276-279. - LAVIN, Fischer von Erlach (zit. Anm. 101), S. 264-267. - MATSCHE, Die Kunst (zit. Anm. 46), S. 201-205.

125) G. LeskY, Frühe Embleme aus der Steiermark, Graz 1973, S. 18 f.

126) Franz Xaver Brean S. J., Danck=Prodig. Vor Ihro (. . .) Majestärten, dero gantzen Hoff=Statt (...) Wegen abgewendeter Straff der gifftigen Seuch nach einem hoch=feyerlichen Birt=Gesang In des Heiligen Errz=Martyers Stephans Dom=Kirchen (...), Wien 1714, S. 14 u. 19 f.

${ }^{127}$ ) SedLmarr, Fischer (zit. Anm. 9), S. 174-184. 
in der künstlerischen Umsetzung durch Fischer. Das architektonische Charakteristikum der Karlskirche ist bekanntlich deren bewußte Verbindung antikisierender Elemente - der Jesuit Keller spricht ausdrücklich von der Übertragung der Trajansäule und der Fassade des templum Jovis et pacis von Rom nach Wien - mit barocken Lösungen, wobei meist Madernos und Berninis Fassadenentwürfe für St. Peter, Borrominis S. Agnese in Piazza Navona oder die Pariser Minoritenkirche von François Mansart als Anregungen genannt werden ${ }^{128}$. Parallel zu Sedlmayrs Analyse der „Schauseite vor der Schauseite“, mit der Unterscheidung zwischen einer hinteren modernen Architektur (Kuppelbau und Turmpavillons) und einer vorderen antikisierenden Schicht (Tempelhalle und Säulen)129, scheint mir auch eine andere Interpretation dieses Sachverhaltes denkbar. Diese entspricht nicht nur dem horizontalen Aufbau der möglichen Vorbilder, sondern vor allem Fischers Kompositionsweise bei anderen Bauten. Sowohl bei den Triumphbögen und beim "Lustgartengebäude “ als auch beim Projekt für eine sternförmige Kapelle und bei der Salzburger Kollegienkirche gibt es nämlich eine durch ein ausgeprägtes Gebälk zusammengefaßte Hauptzone, auf die Kuppeln, Türme und Aufsätze gesetzt werden, die sich vielfach auch durch einen gegenläufigen Grundriß von ihrer Basis abheben. Bei der Karlskirche könnte also der Portikus mit den beiden Durchfahrten und den Säulen analog zum "Triumphbogen der Niederleger“ als antik-römische Basis interpretiert werden, auf die eine römische-katholische Kuppel und Glockenpavillons aufgesetzt sind. Tatsächlich wird der Turmpavillon auf dem Titelkupfer von Keller zu einem echten Triumphbogen umgewandelt und gemeinsam mit einer Säule als Pars pro toto für die Karlskirche präsentiert ${ }^{130}$. Eine solche Interpretation korrespondiert mit der schon von Sedlmayr hervorgehobenen Tatsache, daß die bewußt antikisierenden Elemente der Architektur einem modernen und christlichen Heroen gewidmet sind, dem Pestpatron Karl Borromäus, dessen Fürbitte zur Rettung Wiens von der Pest auf dem Giebel der Säulenhalle erscheint. Fischer selbst war dieser Gedanke der Christianisierung der heidnischen Antike von der Trajansäule her vertraut:

Vor Alters hat die oberste Spitze eine, Statwam Pedestrem' des Kaysers, Trajani' von verguldetem Erz 19 Schuh boch getragen/ welche in der Rechten die Welt=Kugell in der Linken den Szepter gehalten. An deren Stelle der Pabst Sixtus V. als das glorreicheste, Trophaeum' des von den Christen überwundenen Hegdnischen Antichristischen Roms/ die Statue des obersten Apostels gestellet 131 .

Ein in diesem Sinn formal und inhaltlich mit der Karlskirche aufs engste verwandtes Projekt hatte Fischers Kollege Carlo Fontana für Rom entwickelt: eine von der Statue der santa Fede Cattolica trionfante bekrönte Kuppelkirche im Kolosseum als Zeichen des christlichen Triumphes der Märtyrer (Abb. 23). Ebenso wie in anderen Fällen sollten dadurch die

129) Siche zuletzt: Lavin, Fischer von Erlach (zit. Anm. 101), S. 264 f.

129) H. SedumaYR, Die Schauseite der Karlskirche, in: Ders., Epochen und Werke, 2, München 1985², S. 174187.

130) Matsche, Die Kunst (zit. Anm. 46), Abb. 155. - Auf die ikonographische Funktion der - praktisch nutzlosen - Durchfahrten als Seitenteile eines Triumphbogens verweist auch die formale Übereinstimmung mit dem Triumphbogen des Augustus in der Historischen Architektur: Fischer. Historische Architektur (zit. Anm. 67), Taf. 59.

13!) Fischer, ebenda, fol. 68. 
Profani Edificii Antichi, dedicati d falsi Numi, [. . . convertiti e tramutati in Onore del nostro Dio, ed à Gloria dé più rinomati Eroi della Fede ${ }^{132}$. Der Entwurf wurde zwar erst 1725 publiziert, die Idee könnte Fischer aber schon aus seiner römischen Zeit bekannt gewesen sein, da die ersten Planungen dafür im Gefolge des Heiligen Jahres 1675 entstanden ${ }^{133}$. Tatsächlich sollte dieser Gedanke der aemulatio, also der Überbietung des jüdischen und heidnischen Altertums durch das Christentum, in Wien zunächst auch durch die den Portikus flankierenden Statuen der hll. Petrus und Paulus ausgedrückt werden (Abb. 26). An ihre Stelle traten jedoch die Skulpturen der Ecclesia und der Synagoge, also der traditionellen Typologie des Alten und Neuen Bundes. Heraeus, der wesentliche Konzeptor der Karlskirche, hatte diesen Aspekt bereits in einem Gedicht anläßlich der Erbhuldigung der niederösterreichischen Stände im Jahre 1712 in aller Deutlichkeit zum Ausdruck gebracht. Der aufgrund seines ungarischen und spanischen Königstitels als apostolische und katholische Majestät bezeichnete Kaiser wurde dabei als direkter und legitimer Nachfolger der biblischen Könige apostrophiert, da das Königreich Jerusalem noch im Spanischen Titel stehet wegen Sicilien. Angesichts der Sündhaftigkeit der Herrscher Israels habe Gott die Herrschaft jedoch Karl VI. anvertraut, der David und Salomon übertreffen würde. Diese Vermischung der biblischen und der profanen Typologie kulminiert in den Versen:

Des Tempels Schatten-Werk blieb nur in Juda stecken.

Des reinen Opfers Dienst, den Carl von Ost und West

Auf Apostolisch hegt und auf Katholisch schützt

Bleibt, wie des Adlers Macht, auf ewig unterstützt.

Mit diesem Hinweis auf die Aeternitas des Imperium Romanum Christi bezog sich Heraeus ausdrücklich auf die Prophezeiung des Daniel von den vier Weltreichen: In den Tagen dieser Königreiche wird Gott des Himmels ein Reich erwecken (die Kirche des neuen Bundes), das in Ewigkeit nicht wird zerstört werden; und sein Königreich wird keinem anderen Volk übergeben werden. Dan. 2. V.44134.

Es kann also kein Zweifel daran bestehen, daß die Karlskirche als theologische und künstlerische Verwirklichung des im Salomonischen Tempel nur schattenhaft präfigurierten Hauses des Allmächtigen beabsichtigt war. Bestätigt wird diese These durch eine Leichenpredigt der Breslauer Jesuiten auf Karl VI.:

Er, Salomon, richtete auf zwey Säulen im Vorhoff des Tempels: und als er die Säule zur rechten Hand gestellet, ,vocavit eam nomine Jachin; so nennete er sie mit Nahmen Jachin. Imgleichen stellete er auch die andere Säul auf zur lincken Hand, ,vocavit nomen eius Booz; und er nennete ihren Nahmen Booz. Das Wort Jachin heißet Fortitudo, Stärke. Durch solche Benahmung dieser zweyen Säulen [. . . bat Salomon dieses geurunschen: ,Dei fortitudo confirmet hanc domum!' die Stärke Gottes erhalte, oder befestige dieses Haus! Was bey dem jüdischen König Salomon ein Wunsch gewesen, daß wäre bey dem Römischen Kayser Carl di Sach, der viel besser die herrliche Kirch des Heiligen Caroli Borromei, Prudentia et Fortitudine, durch seine Klugheit, und Stärke befestiget, als Salomon den Vorhoff des Tempels mit steinernen Säulen,

132) Carlo Fontana, L'Anfiteatro Flavio, Rom 1725, S. 160.

133) H. Hager, Carlo Fontana's Project for a Church in Honour of the "Ecclesia Triumphans" in the Colosseum, Rome, in: Journal of the Warburg and Courtauld Institutes, 36, 1973, S. 319-337.

134) Zitiert in: Matsche, Die Kunst (zit. Anm. 46), S. 283-289. 
welche Kirch, als ein herrliches Ehren=Zeichen der Carolinischen Gottseeligkeit dastehet, und diese anrühmet 135 .

Den Beweis für eine solche typologische Interpretation der Karlskirche bietet schließlich Fischer bei der Beschreibung des Salomonischen Tempels:

Daß in dem Tempel des alten Bundes der Altar nach Westen/ wie die Altäre in den Kirchen des neuen Testaments vor Alters gemeiniglich nach Osten/ gerichtet gewesen; Solches deutet vermuthlich an die Verbergung der damals noch nicht aufgegangenen Sonne einer vollkommenen Offenbahrung. Wie die Christen hengegen/ nach dem aufgehabenen Schatten $=$ Werk/ das volle Licht des Evangelii und des Glaubens dadurch andeuten wollen ${ }^{136}$.

Das in einer vergoldeten Stuckgloriole und durch die indirekte Beleuchtung des Chores doppelt strahlende Wort $J A H W E$ über dem Tabernakel der Karlskirche verweist also wohl direkt auf die Sonnensymbolik des Tempels in Jerusalem. Noch deutlicher wurde dieser Zusammenhang in der gleichzeitig von Fischer errichteten Breslauer Kurfürsten- beziehungsweise Sakramentskapelle veranschaulicht: Dort erscheint die "Sonne der Gerechtigkeit" nämlich über der Bundeslade und zwei Vertretern des Alten Bundes ${ }^{137}$.

Ausgehend von der allegorischen Bedeutung der Karlskirche hat Sedlmayr auch die Hofbibliothek unter diesem Gesichtspunkt analysiert, wobei sich zunächst ebenfalls die Säulen als Ansatzpunkt boten (Abb. 30) ${ }^{138}$. Diese Interpretation der Säulen als "gebaute Devisen“ wurde von Möseneder und Matsche aus ikonologischen Überlegungen bestätigt ${ }^{139}$. Bisher unbeachtet blieb jedoch die architektonische Parallele zum Trauergerüst Josephs I. in der Augustinerkirche, das nachweislich eine Verdoppelung der Trajan- und Antoninussäule darstellte (Abb. 28). War der Architekt dort aufgrund des gotischen Raumes genötigt, die vier das kaiserliche Monument umgebenden mittelalterlichen Stützen in antikisierende Säulen zu verwandeln, so war es angesichts der kaiserlichen Säulendevise nur naheliegend, diese Idee in der Hofbibliothek zum formal-ikonographischen Concetto des Raumes weiter zu entwickeln ${ }^{140}$. Darüber hinaus sind vermutlich auch die rund um das Standbild Karls VI. aufgestellten Globen Teil dieser Emblematik ${ }^{141}$. Tatsächlich wurden die zwei Säulen auf dem Globus nicht nur 1732 bei einem Festgerüst in Neapel als Sinnbild Karls VI. monumentalisierr ${ }^{142}$, sondern auch auf der Michaelerfassade der Wiener Hofburg des jüngeren

135) Franz Mersch, Carl dises Nahmens Der Sechste Römischer Kayser Fortitudine et Constantia (. . ) bey gehaltenem Leich=Gepräng (. . .) vorgestellet, Breslau 1740.

136) FischER, Historische Architektur (zit. Anm. 67), fol. 12v.

${ }^{137)}$ R. Hołownin, Fischers Werke in Schlesien, in: Polleross, Fischer (zit. Anm. 9), S. 177-209, hier S. 180, Abb. 61.

138) Sedlmayr, Fischer (zit. Anm. 9), S. 246 ff.

139) Moseneder, „Aedificata Poesis“ (zit. Anm. 3), S. $166 \mathrm{ff}$. - F. Matsche, Die Hofbibliothek in Wien als Denkmal kaiserlicher Kulturpolitik, in: Ikonographie der Bibliotheken (Wolfenbüttler Schriften zur Geschichte des Buchwesens, 17), hg. von C.-P. WARNCKE, Wiesbaden 1992, S. 199-233, hier S. 224 f.

$\left.{ }^{140}\right)$ Gleichsam eine formale Zwischenstufe bilden die ebenso wie beim Trauergerüst mit dorischen Kapitellen versehenen und glatte Gewölbe tragenden Säulen des Vestibüls im Palais Trautson: LoRENZ, Fischer (zit. Anm. 9), Abb. $132 \mathrm{f}$.

14i) Vgl. dazu: F. Polleross, „Austrie Est Imperare Orbi Universo“. Der Globus als Herrschaftssymbol der Habsburger, in: W. KROMER (Hg.), 1492-1992: Spanien, Osterreich und Iberoamerika, Innsbruck 1993, S. 3550 .

${ }^{142}$ ) Kat. Barock in Neapel. Kunst zur Zeit der österreichischen Vizekönige, Wien - Neapel 1993, Nr. 129/VII (mit Abb.). 
Fischer sollten laut Albrecht als kaiserliches Emblem zweye Säulen Plus Ultra des Caroli V. in Bildhauerey aufgestellt werden zu beeden Seiten des Globi. Das Motiv der beiden Säulen bezog sich jedoch auch auf das Motto Arte et martel Ex utroque Caesar, das im Bibliotheksprogramm von Albrecht wörtlich genannt und 1741 bei einem Trauergerüst der Grazer Jesuiten zu Ehren Karls VI. aufgegriffen wurde ${ }^{143}$. Eine Visualisierung dieser Thematik finden wir etwa auf dem Titelblatt eines Werkes von Athanasius Kircher (Abb. 27), der mit dem Kaiserhof in enger Verbindung stand und den Fischer in Rom persönlich kennenlernen konnte. Das 1672 publizierte Buch war zugleich Fürstenspiegel und Biographie des am Hofe Philipps II. tätigen Prinzenerziehers Honorata Juan. Auf dem Titelkupfer präsentiert Minerva die Säulen der Weisheit und der Kriegstüchtigkeit als Haupteigenschaften des christlichen Fürsten. Ein Schriftband erläutert die architektonische Allegorie144: Die Weisheit ist der Grundpfiiler aller großen Dinge, die kriegerische Tiuchtigkeit der Anfang und die Herrlichkeit berïhmter Geschlechter ${ }^{145}$.

Analog dazu verweisen bei der Hofbibliothek nicht nur die beiden Säulenpaare auf die Devise Arte et marte, sondern auch deren programmatische und durch die Fresken Grans veranschaulichte zweipolige Anlage146. Tatsächlich wies Fischer von Erlach in der „Historischen Architektur " ausdrücklich auf die entsprechende Stellung Karls VI. als Auftraggeber für Kriegs-Bau-Kunst und ,Civil-Architectur' hin ${ }^{147}$. Zwischen den beiden der Weisheit und der Kriegstüchtigkeit gewidmeten Flügeln befindet sich nun die Ruhmeshalle der Habsburger als eines der von Kircher genannten "berühmten Geschlechter" als formaler sowie ikonologischer Mittelpunkt der Architektur. Die durch eigene Satteldächer hervorgehobene Gliederung des Gebäudes in drei Baukörper veranschaulichte die inhaltliche Dreiteilung des Bücher-Palastes auch nach außen (Abb. 29). Diese Übereinstimmung von Inhalt und Form kulminiert im Zentrum der Anlage: Der ovale Grundriß des Kuppelsaales entspricht genau der Bahn der Planeten um die Sonne, so daß die Aufstellung der Statue Karls VI. in ihrem Mirtelpunkt dessen Rolle als Musenführer noch unterstreicht ${ }^{148}$. Tatsächlich hatte Heraeus schon 1718 bei der Festdekoration zum Geburtstag des Kaisers im Palais Liechtenstein die Kreisform des antiken Circus als Sinnbild der Ekliptik zu Ehren CAESARI AUGVSTO/

143) W. BuchowIEcKI, Der Barockbau der ehemaligen Hofbibliothek in Wien, ein Werk J. B. Fischers von Erlach, Wien 1957, S. 94. - Beim Trauergeruist symbolisierten die Darstellung einer Kunstsammlung und eines Zeughauses die Constantia im Frieden und die Fortitudo im Krieg.

i4) Schon früher hat ein Emblem auf Karl V. damit visualisiert, daßß der Rubm seiner Kaiserhernschaft, gestützat auf diese beiden Saulen wie auf die dos Hercules, niemals zusammenbrechen kanm. Siehe: Emblemata, hg. von A. Henkel und A. SChONE, Sturtgart 1967, 2, Sp. 1197 f.

145) Kat. Universale Bildung im Barock. Der Gelehrte Athanasius Kircher, Rastatt 1981, Nr. 1.20 u. 1.24. Seit seit seiner Berufung als Hofmathematiker 1633 durch Ferdinand II. stand der Jesuit in Kontakt mit dem Wiener Hof. Eine engere Verbindung ergab sich mit Ferdinand III., der mit Kircher nicht nur korrespondierte, sondern 1652 auch dessen Werk „Oedipus aegyptiacus" finanzierte. Das 1679 veröffentlichte Werk „Turris Babel“ widmete der Jesuit Kaiser Leopold I.

146) Ausführlich dazu: Marsche, Hofbibliothek (zit. Anm. 139), S. 208 ff.

147) FISCHER, Historische Architektur (zit. Anm. 67), fol. 4r. - Die Gegenüberstellung von zivilen und milizürischen Aufgaben war nicht nur ein Grundprinzip der barocken Architekturtheorie, sondern auch ein Hauptaspekt fürstlicher Ikonographie. So standen im Rittersaal der königlichen Residenz zu Berlin im Deckenfresko „Arte et Ingenio" mit dem Plan des Schlosses und "Fortezza" mit dem Plan des Zeughauses einander gegenüber. Siehe: L. WIESINGER, Deckengemälde im Berliner Schloß, Frankfurt/Main - Berlin 1992, Abb. 50-52, 70-75.

149) A. KreUL, "Regimen rerum" und Besucherregie. Der Prunksal der Hofbibliothek in Wien, in: Polleross, Fischer (zit. Anm. 9), S. 210-228. 
CAROLO VI./ ORBIS SOLI BENEFICO aufgegriffen ${ }^{149}$, und diese universale Symbolik kehrt in einer Leichenpredigt wieder:

Ist die Sonn der Größte auß Allen von der Allmacht Gottes hervor gebrachten Planeten/ ist CAROLO gewesen auß Gnaden Gottes der Allergrößte auß allen Herren und Monarchen. [.. .] Wie kan ich Ihne dan besser [. . . ] vortellen/ als in dem Glanz der Sonnen/ als eine Durchleuchtigste Sonn? Es ist ohne dem der einem Römischen Kayser allein zuständige Titul deß Aller $=$ Durchleuchtigsten von der Sonn hergehollet/ gestaltsam auß allen Geschöpfen keine das Aller=Durchleuchtigste ist/ dan die Sonn 150.

Die Regiam Solis oder die Burg der Sonnem die Fischer 1716 vor dem Palais Schwarzenberg errichtete, entsprach mit ihrer dreigeteilten Fassade - ein von zwei Flügelbauten flankierter Globus - nicht nur formal jener der Hofbibliothek, sondern auch inhaltlich: $A n$ beyden Seiten seynd zwey Pavillons [...]/ welche die Kriegs= und Friedenszeiten auf die neue Landes Sonne deuten 151. Es ist daher wohl auch kein Zufall, daß die Görtin der Weisheit am Mittelpavillon der Hofbibliothek mit der Quadriga des Sonnengottes Unwissenheit und Laster vertreibt. Der immer wieder angesprochenen Parallele zwischen den Ovalräumen der Karlskirche und der Hofbibliothek liegen vermutlich auch die gleichen Vorstellungen vom "Tempel der Weisheit" bezichungsweise dem "Tempel der Sonne“ als Zentralbau zugrunde ${ }^{152}$. Die Zusammengehörigkeit der beiden von Fischer entworfenen Bauten wird jedenfalls auf der Allegorie der Bautätigkeit Karls VI. unmißverständlich zum Ausdruck gebracht (Abb. 10): Die beiden Haupttugenden des Bauherren, der Andachts Eyfer und die Kayl: Weißheit, weisen jeweils mit einer Hand auf die Kuppel der Karlskirche und der Hofbibliothek.

\section{4. , elocutio}

Ebenso wichtig wie die guten Ideen einer Rede war die sprachliche Gestaltung der in der inventio gefundenen und in der dispositio geordneten Gedanken durch die virtuose Beherrschung der Schmuck- und Wirkungsformen, die sogenannte elocutio ${ }^{153}$. Von den klassischen vier Stilqualitäten, den virtutes elocutionis (sprachliche Korrektheit, Klarheit, Schönheit und Angemessenheit) wurde vor allem das Decorum zu einer zentralen Kategorie der Kunsttheorie in Renaissance und Barock ${ }^{154}$. Ciceros Meinung, daß nicht ein Stil für jeden Fall und jeden Hörer, für jede beteiligte Person und jede Situation geeignet ist, führte zur Regel, den anspruchsvolleren, den schlichteren und ebenso den mittleren Stil je nach dem, was man

149) Herafus, Inscriptiones (zit. Anm. 54), S. 108 ff. - Matsche, Die Kunst (zit. Anm. 46), S. 359.

150) Franz Xaver Pfyffer: Schmertzlichster Untergang Der Aller-Durchleuchtigsten Sonn (. . .) Caroli VI Großmächtigsten Römischen Kaysers (. . .), Augsburg 1740, S. 4.

151) Heraeus zitiert in: Matsche, Die Kunst (zit. Anm. 46), 2, S. 538, Anm. 1356.

152) Einen Sonnentempel über kreisförmigem Grundriß hat Fischer aufgrund einer Anregung von Bellori bei seiner Darstellung von Ninive rekonstruiert: FisCHER, Historische Architektur (zit. Anm. 67), fol. 37. - Zur biblischen Tradition vgl. vor allem die Darstellung auf dem Titelblart der Tempelrekonstruktion von Villalpando: Naredi-Ruiner, Salomos Tempel (zit. Anm. 103), S. 104 f. - Zur Parallele zwischen der Hofbibliothek und Tessins Apollo-Wissenschaftstempel siehe: MOSENEDER, Aedificata Poesis (zit. Anm. 3), S. 170 f.

153) J. KNAPE, Elocutio, in: UedING, Historisches Wörterbuch (zit. Anm. 4), 2, Sp. 1022-1083.

144) U. Mildner, Decorum: Malerei, Architektur, in: Ebenda, Sp. 434-451. 
behandelt, auszuwählen (De oratore 1Il, 210-212). Auf diesen Angemessenheitsvorschriften basiert die Theorie der Stilarten mit ihrem dreiteiligen System des stilus humilis, stilus mediocris und stilus gravis ${ }^{155}$, die vor allem Poussin in seinen Überlegungen zum Modusproblem in der Malerei behandelt hat ${ }^{156}$. In der Architekturtheorie wurde die Frage der Stillagen durch Sebastiano Serlio behandelt, der in seinem Traktat (1545) auf Vitruv zurückgriff. Auf diesen Überlegungen beruht etwa die stilistische Differenzierung von scena tragica und scena comica ${ }^{157}$. Fischers szenische Reliefs der Pestsäule bilden offensichtlich eine direkte Umsetzung dieser Lehre. Die bildparallele Darstellung des Abendmahles in einem antikisierenden Raum ist in diesem Zusammenhang nicht nur aufgrund der Analogie zur Darstellung gleichen Themas von Poussin interessant ${ }^{158}$, sondern auch aufgrund der typologischen Gegenüberstellung zum Relief des Paschamahles (Abb. 8, 9). Denn hier wird das Geschehen ebenfalls bühnenartig vorgeführt, wobei die Architekturkulisse räumlich und stilistisch klar akzentuiert wird ${ }^{159}$. Vor allem die Zuordnung des neutestamentlichen Geschehens zur klassischen Säulenarchitektur und jene der alttestamentlichen Präfiguration der Eucharistie zur bescheidenen Raumgestaltung mit Stuck ist wohl nicht zufällig. Wie sehr die Überlegungen der französischen Maler auch in Architektenkreisen verbindlich waren, bezeugt eine Stelle in dem 1700 in Hamburg publizierten Werk „Die zum Vergnügen der Reisenden geöfnete Baumeister=Academie ${ }^{\star}$. Weil nämlich Malerei und Bildhauerei mir der Architektur so eng verbunden, sei auch bei den Gemälden das Decorum zu beachten, daß die Bilder solche Kleidungen/ die Bäume solch Laubl die Gebäude solche. Ordononance' und Verzierung bekommen/ als sie in dem Land und zu der Zeit gehabt/ da die Geschicht, passiret. Dieses hat le Brun in seinen Gemablden von Alexandro, welche theils auf dem Louvre, theils zu Versailles sind/ wobl in acht genommen.

Die Lehre vom Decorum betraf aber nicht nur die Darstellung der Historien, sondern auch die zeremonielle Gegenwart. Dieser Aspekt wurde von Karl Srieler 1686 für den rhetorischen Bereich folgend formuliert: Eine besondere Art der Rede will bei Freunden, eine besondere bei Fremden und Feinden, eine andere bei Mächtigen und Vornehmen, eine andere bei Schwächeren und Geringeren angewendet werden. Die Zeit, Gelegenheit, der Ort, die Absicht und dergleichen Zustände, geben auch jedesmal eine Veränderung der Schrift an die Hand, welche ohne Klugheit, Vorsicht und geläuterte Beurteilung nicht beobachtet werden kann 160 . Analog dazu hatte die barocke Architektur und Ausstattung dem standesgemäßen Decorum

15s) Vgl. dazu: F. BOTTNER, Rhetorik und barocke Deckenmalerei. Überlegungen am Beispiel der Fresken Johann Zicks in Bruchsal, in: Zeitschrift des deutschen Vereins für Kunstwissenschaft, 43, 1989, S. 49-72, hier S. 51 .

156) K. SPANG, Dreistillehre, in: UedING, Historisches Wörterbuch (zit. Anm. 4), 2, Sp. 921-972, hier $954 \mathrm{f}$.

157) Serlio unterscheidet zwischen der altertümlichen komischen Szene für Bürger und den klassisch gebildeten Häusern der grandi personaggi für die Tragödie: Tutte l'Opere d'Architettura et Prospetiva di Sebastiano Serlio, Venedig 1619 (Reprint Ridgewood 1964), II. Buch, fol. 45 f.

158) $\mathrm{Zu}$ den Einflüssen der Rhetorik auf Poussin und seine modi, insbesondere in der auch von Bernini geschätzten Sakramentenserie siehe: A. MÉrot, Les modes, ou le paradoxe du peintre, in: Kat. Nicolas Poussin 1594-1665, Paris 1994, S. 80-86.

159) Zu den ${ }_{n}$ classical and academic tendencies “ dieser Reliefs sowie den römischen Einflüssen (Raffael, Poussin und Sacchi) siehe: Ch. Theuerkauff, Johann Ignaz Bendl: Sculptor and Medalist, in: Metropolitan Museum Journal, 26, 1991, S. 227-275, hier S. 245-247.

160) Zitiert in: KNAPE, Barock (zit. Anm. 5), Sp. 1307. 
zu entsprechen ${ }^{161}$. Karl Eusebius von Liechtenstein verwies um 1670/75 direkt auf diesen Zusammenhang zwischen Zeremoniell und Stil beziehungsweise Decorum und Modus, als er in seinem "Architekturtraktat" runde und polygonale Grundrisse für einen Palast als unschicklich ablehnte. Die runde Form nehme der Fassade die Magnificenz und das schenste Ansehen und lasse das Gebäude kurz und gebogen erscheinen, was dem grossen Ansehen hechst zuwider sei. Das gleiche gelte für vieleckige Grundrisse, die nur bei einem Lusthaus oder Loggia in einem Walt oder Thiergarten verwendet werden dürfen ${ }^{162}$. Das Angemessenheitspostulat betraf sowohl die Grundstruktur als auch die Proportionen der Säulenordnung und die Quantität der Zierformen. Schon Vitruv hatte die unterschiedliche Verwendung der Säulenordnung der Tempel in Entsprechung zu den darin verehrten Göttern gefordert. Auf diese Austheilung gewisser Ordnungen/ nach Beschaffenheit der Götter und Göttinnen bezog sich Fischer etwa bei der Rekonstruktion des Tempels der Diana in Ephesos ${ }^{163}$.

Ein besonders anschauliches Beispiel für das Angemessenheitspostulat zur Zeit Fischers liefert der 1687 erschienene "Wienerische Tugendspiegel“ des Erhard Weigel. Er beschreibt die Tugend der Decentia (Gemäßßthätigkeit) als standesgemäße Repräsentation und zeigt sie als Personifikation mit Maßstab vor den verschiedenen Säulen. Diese sind gemäß ihrer Ordnung unterschiedlich hoch und von der niedrigsten bis zur höchsten mit den entsprechenden herrschaftlichen Insignien geschmückt (Abb. 6) ${ }^{164} .1702$ wurden die Stillagen auch vom Theoretiker Johann Christoph Sturm sozial definiert:

Die Geziemenheit oder Wobl-Anständigkeit besteht vornemlich darin, daß die Wohnungen mit des Wohnberm Zustand übereinkommt; daß je nach dem Zweck des Hauses alle Zierraten dahin abzielen und solchen gleichsam mit Fingern andeuten; daß nachdem das ganze Gebäude prächtig oder schlecht angegeben worden, alle Teile und Stücke mit demselben darinnen übereinstimmen [. . . und] die gebrauchten [Säulen-] Ordnungen [. . ] mit dem Stand und Würde des Bauberrn oder Bewohners übereinkommen ${ }^{165}$.

Nur wenige Jahre später wurde die Anwendung dieser Prinzipien durch Fischer von Erlach gewürdigt: 1708 berichtete Johann Christoph Volckamer bei einer Beschreibung des Schlosses Schönbrunn, daß der Architekt dabei aufgrund der Funktion als kaiserliches Lustschloß alles mit solcher Zierlich- und Kostbarkeit angeordnet habe, daß die Hobeit des Majestätischen Besitzers gar deutlich zu erkennen stehet ${ }^{166}$. Die hier verwendeten Begriffe "Zierlichkeit" und "Kostbarkeit“ sind identisch mit den von Karl Eusebius von Liechtenstein gebrauchten Bezeichnungen „Annehmlichkeit“ und „Prächtigkeit" und verweisen auf quantitative und qualitative Kriterien des Decorum. Fischer verwendete in Schönbrunn eine Kolossalordnung, die die eineinhalb Hauptgeschosse zusammenfaßt - beim Mittelrisalit als Vollsäulen, sonst als

161) U. SCHOTTE, „Ordnung “ und „Verzierung“. Untersuchungen zur deutschsprachigen Architekrurtheorie des 18. Jahrhunderts, Phil. Diss., Heidelberg 1979, S. $118 \mathrm{ff}$.

162) Fleischer, Karl Eusebius (zit. Anm. 32), S. 180 f.

163) Fischer, Historische Architektur (zit. Anm. 67), fol. 29r.

164) E. Berger, Baukunst und Moral im Barock - Zu einigen zeitgenössischen Titelillustrationen, in: Kunsthistoriker, IV, 1987, S. 13-20, hier S. 17, Abb. 3-8.

165) Johann Chrustoph StuRM, Marhesis juvenalis, Nürnberg 1702, zitiert in: SCHUTtE, Architekturtheorie (zit. Anm. 161), S. 121.

166) Johann Christoph Volckamer, Nürnbergische Hesperides, Nümberg 1708, 2. Bd., fol. D3a, b. 
Pilaster. Die Anwendung der "mittleren “ ionischen Kapitellformen erklärt sich hingegen daraus, daß das Gebäude laut Fischer "nur" ein königliches Jacht=Haws war ${ }^{167}$.

Die tatsächliche Bedeutung dieser Frage läßt sich an zwei Bauten Fischers nachweisen, die bisher nicht unter diesem Aspekt beachtet wurden: die böhmische Hofkanzlei und das Palais Trautson. Beide entstanden kurz hintereinander, 1708/1709, und besitzen das gleiche klassizistische Fassadenschema. Der reiche plastische Schmuck des Amtssitzes des böhmischen Hofkanzlers - Hermenpilaster beim Portal, Giebel über den Fenstern des Piano Nobile, Säulenordnung beim Mittelfenster mit dem königlichen Wappen, Lisenen an den Ecken etc. - wurde daher als Gegensatz zur Grundform interpretiert, der das Schema "vollkommen verschlinge und dessen $\operatorname{Sinn}$ ins Gegenteil verwandle ${ }^{4}{ }_{168}$. Tatsächlich entsprach aber die Quantität des Ornamentum an diesem königlichen Bauwerk nur der Qualität der verwendeten Säulenordnung, also der Composita, die allein Bauten von höchstem Rang vorbehalten war ${ }^{169}$. Besonders deurlich wird dies aus der Tatsache, daß die Fassade der Hofkanzlei anläßlich der Geburt Erzherzog Leopolds 1716 zusätzlich mit ephemeren Skulpturen, Reliefs, Säulen etc. geziert wurde und - laut Heraeus - Basilicam Romanam repraesentavit 170 .

Der Palast des Grafen Trautson sollte dem ersten Entwurf zufolge wie das kaiserliche Jagdschloß nur mit einer ionischen Ordnung gegliedert werden (Abb. 31). Diesen Qualitätsunterschieden waren nicht nur die bekrönenden Figuren - hier die böhmischen Könige, dort die Götter der klassischen Mythen -, sondern auch die Proportionen angepaßt: War beim Mittelrisalit des vorstädtischen Palais das Verhältnis von Breite zur Höhe etwa gleich groß, so besitzt die Hofkanzlei wesentlich schlankere Proportionen. Als der Obersthofmeister jedoch während der Bauzeit, am 14. März 1711, in den Reichsfürstenstand erhoben wurde, mußte auch das Decorum seiner Residenz diesem Faktum Rechnung tragen: Beim Mittelrisalit wurde die ionische daher durch eine komposite Pilasterordnung ersetzt. Deren schlankere Proportionen erforderten jedoch eine Erhöhung des Giebels, so daß es zu den unschönen Gebälküberschneidungen kam ${ }^{171}$, die von den Architekturhistorikern als ${ }_{n}$ gewollte Härte" und dynamisches Durchdringen zweier Baublöcke mißverstanden wurden ${ }^{172}$. Den Beweis dafür liefert uns die Abfolge der Fassadenansichten: Zeigt der 1710 datierte eigenhändige Stich der „Historischen Architektur“ den ursprünglichen Entwurf mit ionischer Ordnung und Grafenkrone über dem Wappen, so gibt die 1713 vom jungen Fischer gezeichnete Ansicht den tatsächlich ausgeführten reicheren Schmuck und die heraldische Fürstenkrone wieder, kaschiert aber die Überschneidung, die erst auf Salomon Kleiners Stich aus den zwanziger Jahren sichtbar wird (Abb. 32).

Vor dem Hintergrund der Stilfrage in der Rhetorik muß meines Erachtens auch die dezidierte Entscheidung des Kaisers beziehungsweise seiner Kunstberater für die beiden

${ }^{167)}$ In der Palladio-Ausgabe von 1698 wird die Jonica u. a. für Landschlösser, Garten- und Landgebäude empfohlen: ScHUTTE, Architekrurtheorie (zit. Anm. 161), S. 127.

168) Sedumayr, Fischer (zit. Anm. 9), S. 144 f.

169) Vgl. ScHOTre, Architekrurtheorie (zit. Anm. 161), S. 128.

170) Heraeus, Inscriptiones (zit. Anm. 54), S. 141 ff.

171) Einen ähnlichen Widerspruch zwischen sozialem Decorum und ästhetischer Norm findet man auch beim Palazzo Farnese: WARNCKE, Rhetorik der Architekrur (zit. Anm. 2), S. 614.

172) P. Prange, Das Palais Trautson - cine „ungemeine Architecture“, in: Pantheon, LII, 1994, S. 101-119, hier S. 103, Abb. 4. - M. KRAPF, Palais Trautson, Wien $1990^{2}$, S. 25 f. 
Fischer und gegen den zweiten Hofarchitekten Hildebrandt gesehen werden. Schon beim Wettbewerb um die Karlskirche (1715) zog der Herrscher Johann Bernhards Entwurf denjenigen Hildebrandts und des kaiserlichen Theaterarchitekten Galli-Bibiena vor. 1726 wurde dann der Bau des Reichskanzleitraktes der Hofburg, den Hildebrandt 1723 begonnen hatte, auf Befehl des kaiserlichen Generalbaudirektors Joseph Emanuel übertragen. Hildebrandt wurde damit von dem um 25 Jahre jüngeren und auch sonst vom Kaiser bevorzugten Fischer de facto aus seiner Stellung als Erster Hofarchitekt verdrängt ${ }^{173}$. In der Tat steht Hildebrandts dekorativ-flächiger Stil mit seinem Einfluß auf die bürgerliche Bautätigkeir im Gegensatz zum "hohen“, römisch-palladianischen Stil der Fischer ${ }^{174}$. Angesichts der stilistischen Unterschiede der Kontrahenten war die Entscheidung in Wien zweifellos eine bewußt getroffene ästhetische Wahl175, die sich auch anhand der Pläne flir die Michaelerfront der Hofburg aufzeigen läß $t^{176}$. So hatte Hildebrandt für die Hauptfassade der kaiserlichen Residenz zur Stadt einen fast kasernenartig schlichten Kanzleibau mit dreieinhalb Geschossen vorgesehen, der nur im Zentrum durch einen überkuppelten Einfahrtszylinder, eine Lisenengliederung und eine Statuenbalustrade geschmückt werden sollte (Abb. 33). Schon in einem ersten Gegenentwurf übernahm Joseph Emanuel zwar die wesentliche Grundstruktur, ersetzte aber das eher bescheidene Portal durch einen monumentalen Triumphbogen und bereicherte die schmucklosen "Kasernenfassaden" durch eigene Risalite mit kolossaler Säulenordnung (Abb. 34). Die gleiche Entwicklung läßt sich etwas später in Klosterneuburg feststellen, wo das Stift zu einer kaiserlichen Residenz umfunktioniert werden sollte. Auf Anordnung des Hofbaumeisters Fischer mußte der Bauleiter Donato Felice d'Allio neue prächsige und kostbare Entwürfe schaffen mit kuppeln und einer prächtigen galerie sowie vielen kostbaren verzierungen an der Fassade ${ }^{177}$. Tatsächlich brachten genau diese Formen in der Architektur jene Magnificentia zum Ausdruck, die im Genus grande der Rhetorik durch reichen Schmuck (Ornatus), bewußte Anreicherung (Amplificatio), Fülle (Copia) und Abwechslungsreichtum (Varietas) erzielt wurde ${ }^{178}$.

Dementsprechend befand sich die Magnifizenz nicht nur unter jenen Tugenden, die der junge Erzherzog Karl am Beispiel seiner Vorfahren und biblischen Vorbilder lernen sollte ${ }^{179}$,

173) F. Mutsche, Zur Planungs- und Baugeschichre des Reichskanzleitraktes der Wiener Hofburg, in: Wien und der europäische Barock Akten des XXV. Internationalen Kongresses für Kunstgeschichte, 7, hg. von H. FIL LTZ und M. PIPPAL, Wien - Köln - Graz 1986, S. 31-49.

174) Auf diesen Unterschied hat zuletzt J. Garms, Kaiser - Kirche - Adel - Architekten. Wien und Neapel: Vergleiche und Verbindungen, in: Kat. Barock in Neapel (zit. Anm. 142), S. 94 u. 100, hingewiesen.

173) Den Zeitgenossen war diese grundsätaliche stilistische Alternative nicht nur bewußt, sondern vielfach geradezu eine Frage des Kulturkampfes der Klassizisten Bellori, Campbell und ihrer französischen Kollegen gegen Borromini, Guarini und deren Nachfolger: Perouse DE MONTClos, Larchitecture à la française (zit. Anm. 8), S. 240 u. 262 - J. Summerson, The Classical Language of Architecture, London 19933, S. 8-12.

176) Zur Baugeschichte siehe: R. Bosel - Ch. BeNEDIK, Kat. Der Michaelerplatz in Wien. Seine städtebauliche und architektonische Entwicklung, Wien 1992, S. 66 ff., Nr. 30-33.

17) Informazione des Architekren zitiert in: H. WEIGL, Stift Klosterneuburg - Der „österreichische Escorial“". Von der ersten barocken Neuplanung zur Klosterresidenz Karls VI., in. Die Krone des Landes, Ausstellungskat., Klosterneuburg 1996, S. 75-98, hier S. 78-81.

178) Vgl. dazu das Kapitel „Magnificentia": Zur historischen Semantik eines barocken Grundbegriffes" bei A. Ch. Gampp, Santa Rosalia in Palestrina. Die Grablege der Barberini und das ästhetische Konzept der „Magnificentia ", in: Römisches Jahrbuch der Bibliotheca Hertzianz, 29, 1994, S. 343-368, hier S. 346-350.

179) Marumi Oharn, THEATRUM AUSTRLACUM: An illustrated Speculum Principis for Archiduke Karl of Austria, in: Jissen Women's University Aesthetics and Art History, 9, 1994, S. 1-25. 
sondern galt den Zeitgenossen schon im Schloß Schönbrunn Josephs I. verwirklicht (Abb. 19). Als Utheber der kaiserlichen Bautätigkeit wird diese im wahrsten Sinn des Wortes fürstliche Eigenschaft schließlich im Kuppelfresko der Hofbibliothek dargestellt: die Kayl. Prächtigkeit in einem mit Perlen gestickten Kleide, und Ihre Haare mit Kostbahren Geschmucke glanzend, sambt dem an der Hals=Ketten gehefften goldenen Herzel so das Kayl: zu Gutthaten geneigte Gemüth Bedeutet, wird von Winkelmaß, Pinsel und Bildhauereisen sowie dem Symulacrum der drei Grazien begleitet, die die Schönheit der, Architecturae, Picturae et Sculpturae', welche in der Aufführung des, Bibliothec $=$ Baues beobachtet worden ist, versinnbildlichen. Gehalten wird das Modell der Bibliothek hingegen von Inventio und Executio. 180 In einem Huldigungsgedicht des Jesuiten Georg Grill anläßlich der Hochzeit Maria Theresias im Jahre 1736 wird die maiestas der Architektur ausdrücklich als Hinweis auf den kaiserlichen Stifter ausgewiesen:

Du wirst vielleicht fragen, durch welchen Stifter sich dies Haws erhebt,

und möchtest erfahren, welchen Herren es ehrt?

Gesetzt, es entbehrte einer Inschrift, wirst du doch an seiner Würde

selbst ablesen, daß es das große Werk des erhabnen Kaisers ist.

Diesen, den die Musen als Gebieter verehren und lieben,

ehrt es auch und will ihn als Gebieter lieben.

Wenn du den Bau betrachtest, er ragt auf mit hohen Räumen

und blickt auf die übrigen Häuser, hehre Gebäude, herab. ${ }^{181}$

Die soziale Interpretation ästhetischer Phänomene in der Wiener Architektur des 18. Jahrhunderts wird auch im Traktat von Franz Rosenstingl klar zum Ausdruck gebracht:

Die Zierde auszubreiten bestehet darinnen, wann alle Theile insgemein nach der Dignität und Hoheit des Herrn appliciret werden [...]. Es ist aber noch eine Zierde, welche durch die Kunst und gebührende Proportion denen Augen dargestellet wird; [ . . ]. Was aber die Proportion seye, wird durch die fünff Ordnungen deren Säulen [.. . ] deutlich erkläret 182.

Der klassische Stil der beiden Fischer war jedoch offensichtlich nicht nur aufgrund seines Ornatus der von Karl VI. und seinen Beratern gewünschte Modus zum Ausdruck imperialuniversaler Majestas, sondern besaß als „Kaiserstil“ direkten ikonographisch-formalen Verweischarakter ${ }^{183}$. So hat Joseph Emanuel bei der Michaelerfront die von Hildebrandt über-

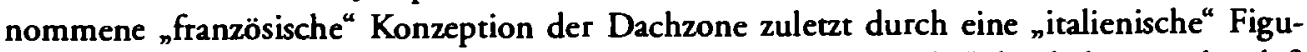
renbalustrade ersetzt und mit dieser „römischen Architektursprache" deutlich gemacht, daß Wien mit gleichem Recht Neu=Rom genannt wird als vormals Constantinopel 184. Dieses Prinzip entspricht wohl dem rhetorischen Vergleich, der etwa 1718 von Mannling als besonders elegante Form der Zierlichkeit im ,Stylo bezeichnet wurde. Als Beispiele nennt er folgende in der Rede über einen Fürsten gebräuchliche Formulierungen: Er war ein Herkules im Arbeiten. [.. .] Er war ein Salomon unserer Zeiten ${ }^{185}$. Analog dazu hat der ältere Fischer

180) Codex-Albrecht zitiert in: BuchOWIEckI, Hofbibliothek (zit. Anm. 143), S. 96.

181) Übersetzung von KLECKER-Mersich, Nationalbibliothek (zit. Anm. 46), S. 50 f.

182) HierL-Deronco, Rosenstingl (zit. Anm. 74), S. 212.

183) Matsche, Die Kunst (zit. Anm. 46), S. 304 ff. - F. B. Polueross, Zur Repräsentation der Habsburger in der bildenden Kunst, in: R FeuchtmUUeR - E. KovAcs $\left(\mathrm{Hg}_{\mathrm{g}}\right.$ ), Welt des Barock, Wien - Freiburg - Basel 1986, S. 87-104, hier S. 100-102.

184) Heraeus zitiert in: Matsche, Die Kunst (zit. Anm. 46), S. 301.

185) Mannung, Expediter Redner (zit. Anm. 38), S. 203. 
schon drei Jahrzehnte früher beim ersten Entwurf für Schönbrunn sowie bei den Triumphbögen des Jahres $1690^{186}$ die „altrömische Architektursprache “ verwendet, wie auch die italienische Sprache am Kaiserhof von Leopold I. gefördert wurde, da sie auf einige art mitten in Teutschland sein Königreich über Rom und Italien zu verstehen gibt ${ }^{187}$. Die auf profunder historischer Kenntnis basierende Architektursprache der beiden Fischer erfüllte darüber hinaus auch die von der Rhetorik geforderte sprachliche Korrektheit (latinitas):

Die Alten, die das, was sie sagen wollten, noch nicht auszuschmücken wußten, haben sich ja auch fast alle klar und deutlich ausgedrückt. Wer sich nur ihre Sprache angewöhnt, wird nicht einmal, wenn er den Wunsch hat, anders reden können als korrekt (Cicero, De oratore III, 39).

Tatsächlich wurde der jüngere Fischer 1722 von Karl VI. ausdrücklich deswegen angestellt, weil er in der heutigen Neuen so wobl als der dermablen fast in Abgang gekommen alt Römischen architektur erfahren war ${ }^{188}$. Ebenso wie der Hofarchitekt Fischer setzte damals auch der Hofkomponist Johann Joseph Fux diesen stylus antiquus (oder gravis) im Gegensatz zum stylus modernus (oder luxurians) gezielt ein, etwa bei der wohl für die Karlskirche bestimmten und dem Kaiser gewidmeten Missa Canonica a Capella ${ }^{189}$. Die dahinterstehende Kunstpolitik und Ästhetik des Wiener Hofes wurde um 1720 durch das Motto ANTIQUOS REVERENTIA NOVOS AEQUITATE (Verehrung des Alten, Anerkennung des Neuen) auch programmatisch formuliert. Diese Worte erscheinen nicht nur als persönliche Devise von Carl Gustav Heraeus auf dem Titelblatt seiner kaiserlichen „Inscriptiones“ (Abb. 41) und seiner Porträtmedaille von Benedikt Richter, sondern auch als Revers der Preismedaille der kaiserlichen Akademie im Jahre 1731190. Deren Direktor, der Maler Jacques van Schuppen, hatte schon 1725 auch das Titelblatt für das Kontrapunkt- und Kompositionslehrbuch des oben genannten kaiserlichen Hofkomponisten Fux, "Gradus ad Parnassus", entworfen ${ }^{191}$, womit sich der Kreis wieder schließt. Es kann also kein Zweifel daran bestehen, daß die Architektur des „Kaiserstils“ der beiden Fischer nicht nur ikonographisch, sondern auch formal von einem bewußten Historismus gekennzeichnet ist. Die zentrale Rolle der Karlskirche in diesem Zusammenhang wurde zuletzt von Lorenz mit dem Hinweis auf ähnliche Lösungen aus der Architekturtradition der Accademia di San Luca relativiert ${ }^{192}$. Eines der schon von Sedlmayr genannten Vergleichsbeispiele, Filippo Juvarras Superga-Kirche in Turin, ist zwar durch den gleichen italo-französischen Klassizismus geprägt wie Fischers Werk, die historisierende Collage mit Triumphsäulen findet sich bei Juvarra aber nur in Form von gezeichneten Architekturcapricci und Bühnenbildentwürfen ${ }^{193}$. Die einzige echte Parallele zur Kaiserkirche, Carlo Fontanas oben genannter Plan für

186) Der direkte Bezug zur römischen Triumphalarchitektur wird vor allem durch den Vergleich mit dem Bogen Strudels deutich: Haselberger-Blaha, Triumphtore (zit. Anm. 50), S. 70.

187) Casimir Freschơt, Relation von dem Kayserlichen Hofe zu Wien aufgesezz von einem Reisenden im Jahre 1704, Köln 1705, S. 54.

198) Matsche, Die Kunst (zit. Anm. 46), S. 305.

189) Naredi-RaINer, Fischer von Erlach (zit. Anm. 124), S. $281 \mathrm{ff}$.

190) Kat. Georg Raphael Donner 1693-1741, Wien 1993, S. 628 ff., Nr. 195 f. u. 199.

191) Kat. Pegasus und die Künste, hg. von C. BrINK und W. Hornbostel, Hamburg 1993, S. 227, Nr. IV.59.

192) Lorenz, Fischer (zit. Anm. 9), S. 133.

193) Vgl. H. A. Mrllon, Filippo Juvarra: New Drawings, in: An Architectural Progress in the Renaissance and Baroque. Sojourns In and Out of Italy (Papers in Art History from The Pennsylvania State University, VIII/2), hg. von H. A. Millon und S. Scott Munshower, Pennsylvania 1992, S. 566-609. 
eine Kuppelkirche im Kolosseum (Abb. 23), bestätigt hingegen die Sonderstellung der Karlskirche ebenso wie ihre römischen Wurzeln ${ }^{194}$. Konnte sich das Papsttum beim Bau der Triumphalkirche im Kolosseum auf die antiken Ruinen berufen, so bedurfte es im imperialen Wien historisierender Architekturzitate, um den gleichen legitimatorischen Anspruch des Kaisertums zu veranschaulichen.

\section{5. ,memoria' und, imitatio"}

Für die planmäßige Absicht dieser Architekturcollagen spricht auch, daß der formale Historismus in beiden Fällen mit einer wissenschaftlichen Betrachtung der Vergangenheir einherging ${ }^{195}$. Heraeus trug dieser Tatsache Rechnung, indem er Fischer gerade im Zusammenhang mit der Karlskirche als eifrigen Liebhaber der antiken Kunst (antiqüe artis cultori sedulo) lobte19. Es ist wahrscheinlich auch kein Zufall, daß die Anfänge des Fischerschen "Kaiserstils" zeitlich genau mit der Einrichtung einer (kaiserlichen) Kunstakademie (1688/92) und der geplanten Gründung eines "Collegium Imperiale Historicum" unter dem Protektorat von Leibniz (1689) zusammenfallen ${ }^{197}$.

Dem 1686 für den Thronfolger erstellten Erziehungsprogramm zufolge sollte Joseph I. nämlich die Geschichte der eigenen Familie und Länder genaustens kennenlernen, um darin Gottes Vorsehung fuir das Haus Osterreich zu sehen ${ }^{198}$. Zu diesem Zweck wurde 1691 Hans Jacob Wagner von Wagenfels als instructor in historicis et politicis des Thronfolgers berufen ${ }^{199}$. Wie oben ausgeführt, war schon Fischers erster Entwurf für Schönbrunn durch seine Verweise auf die vier Weltreiche einerseits in die architekturhistorischen Unternehmungen des Architekten und andererseits in die habsburgische Hofhistoriographie eingebertet. Nachweisbar ist eine solche direkte Verschränkung spätestens im Zusammenhang mit Fischers Triumphbögen des Jahres 1690 . Als nämlich bei der Aushebung der Fundamente in der Wiener Innenstadt römische Münzen gefunden wurden, hat die Festbeschreibung dieses Ereignis als Huldigung der Antike vor dem regierenden Römischen Kaiser gewürdigt und dessen tugendhaften Kampf in Ost und West mit jenem des Kaiser Gratianus verglichen (Abb. 21)200.

Den Kulminationspunkt dieser Bestrebungen bietet die Compendieuse Universalgeschichte des P. Matthias Fuhrmann aus dem Jahre 1734 mit dem bezeichnenden Titel ${ }_{n} \mathrm{Alt}=$ und Neues Oesterreich", eine ,Chronologisch" $=$ historische Beschreibung vom Ursprung des alten

194) Man hat in diesem Zusammenhang von der „più formidabile collage dell'architettura barocca” gesprochen: Maria Cristina Buscioni, Matrici berniniane nell'opera di Johann Bernhard Fischer von Erlach, in: SpagnesiFagiolo (zit. Anm. 30), S. 661-672, hier S. 671. - Die architektonische Gegenüberstellung des alt-heidnischen und modern-christlichen Rom finder sịch später auch bei einem Maler-Architekten der Accademia di San Luca: M. KIfNE, „Redende Capricci“ von Giovani Paolo Pannini, in: Zeitschrift für Kunstgeschichte, 57, 1994, S. $440-445$.

195) Fontanas Publikation über das Kolosseum (zit. Anm. 132) hatte den Charakter einer Dissertation.

196) HeRAEUS, Inscriptiones (zit. Anm. 54), S. 76.

197) RINCK, Leopold I. (zit. Anm. 39), S. 50.

198) Programm von Rummel zitiert in: ScHMITT, Schönbrunn (zit. Anm. 34), S. 67 f.

199) A. CoRETH, Osterreichische Geschichtsschreibung in der Barockzeit (1620-1740), Wien 1950, S. 24 f.

${ }^{200}$ ) Arcus Triumphalis, Leopoldo Magno Eleonorae Augustae Josepho Glorioso a senaru populoque Viennensi positus, et emblematibus ornatus, Wien 1690. 
Nordgau und, Pannonien' bis zur Regierungszeit Karls VI. Die Entwicklung der Austria Romana wird sowohl durch die Darstellung römischer Relikte wie dem Triumphbogen in Carnuntum als auch durch zahlreiche Landkarten und Münzbilder der Kaiser illustriert. Ebenso wie das Titelblatt mit den vor antiken Ruinen postierten Personifikationen Pannoniens und Osterreichs bringt auch das Vorsatzblatt zum ersten Buch mit der Gegenüberstellung der Münzbildnisse des DIVVS AVGVSTVS PATER und des CAROLVS VI NOVVS AVGVSTVS die eschatologisch-typologische Konzeption deutlich zum Ausdruck (Abb. 37).

Die direkte architektonische Umsetzung solcher Gedanken bildet die Hofbibliothek, in deren Stiegenhaus damals zahlreiche römische Spolien aufgestellt und in die Wände eingesetzt wurden ${ }^{201}$. Wie Möseneder und Matsche ausführlich dargelegt haben, ist das ganze von Albrecht konzipierte Programm dieses kaiserlichen Wissenschaftszentrums auf die „Translatio studii“ ausgerichtet ${ }^{202}$, worauf die Porträts griechischer und römischer Gelehrter ebenso verweisen wie die Fresken der "Schule von Athen" (Abb. 39). Die Darstellungen von Alexander dem Großen und Julius Cäsar als Liebhaber und Förderer der Wissenschaft dienen dabei ausdrücklich zum anzeichen Unsers grossen Caroli, der, so bald Er von seinen Feinden die Friedens $=$ Ruhe erobert, Sich auf seiner Länder $=$ und Volker=nutzbare und Kunstmässige Unterhaltungen begeben ${ }^{203}$. Gleichsam en miniature wird das Argumentum der „Translatio studii“ im Kuppelfresko von der Allegorie der Geschichts=Kunst und Chronos vorgeführt: Die Zeit hält eine Skulptur des Ptolemäus als wolte Sie diesen König, und ersten Aufrichter der Bücher=Samblungen in der Gleichnuß gegen Unseren, Restauratorem ' emeueren. Daneben befinden sich die Bildnisse des Kaisers Maximilian I., welcher Anno 1495 einen ziemlichen anfangsgrunde der Wiennerischen Hof $=$,Bibliothec'zu wegen gebracht, sowie des ungarischen Königs Matthias Corvinus, dessen nach Wien verbrachter Bücherschatz noch beute ein vornehmes, Monumentum Doctrinae' abgibet ${ }^{204}$. Genau dieselbe Thematik, welcher das 1730 von Daniel Gran vollendete Fresko gewidmet ist, wurde schon 1729 in einer Dissertation der Wiener Universität unter dem programmatischen Titel „Bibliothecae Veterum Deperditae In Augusta Vindobonensi Caesarea Instauratae“ vorgeführt (Abb. 38). Diese Geschichte der Bibliotheken reicht dementsprechend von der Büchersammlung Salomons und der Alexandrina des Ptolemäus über die Bibliotheken in Athen und Rom, darunter die von Julius Cäsar und Tiberius Claudius auf dem Palatin errichteten Bibliothecas Graecas \& Latinas, bis zur Einrichtung der Hofbibliotheken in Wien und Budapest unter Maximilian I. und Matthias Corvinus. Der von Karl VI. errichtete Musenpalast habe nunmehr alle diese vom Schicksal der Zeit zerstörten Bibliotheken wieder zu neuem Leben erweckt: Sic scilicet, dum Augustissimi Majones Veterum Bibliothecas, fatorum injurid deperditas, in Vindobonensi Caesarea incredibili studio restaurdrunt; supra omnia fata constituit Carolus in omne aevum duraturas ${ }^{205}$. Ein direkter Zusammenhang zwischen dieser jesuitischen Dissertation und der Architektur ergibt sich vor allem dadurch, daß in dieser Publikation die älteste Ansicht der Fassade veröffentlicht wurde (Abb. 29).

201) BUCHOWrecki, Hofbibliothek (zit. Anm. 143), S. 56-61.

202) MOSENEDER, „Aedificata Poesis“ (zit. Anm. 3), S. 166-170. - Matsche, Hofbibliothek (zit. Anm. 139), S. $203 \mathrm{ff}$.

203) Albrechr-Codex zitiert in: Buchowreckl, Hofbibliothek (zit. Anm. 143), S. 107.

204) Ebenda, S. 100.

205) Ignaz Greiner S. J., Bibliothecae Veterum Deperditae in Augusta Vindobonensi Caesarea Instauratae (. . .), Wien 1729, S. 81. - Vgl. KueCKer-Mersich, Der Prunksaal (zit. Anm. 46), S. 52 ff. 
Dieses über einzelne historisch-ikonographische Verweise hinausgehende "Einbeziehen einer historischen Sicht bei der Wahl der künstlerischen Mittel des Architekten selbst " und damit als "Bestandteil einer auf diese Weise legitimierten und legitimierenden Kunst" ${ }^{\text {" zeigt }}$ sich jedoch nicht nur bei der Karlskirche und Hofbibliothek, sondern auch und vor allem

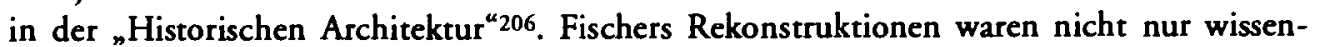
schaftlich auf der Höhe der Zeir und in enger Beziehung zur Numismatik entstanden, sondern wurden $1724 \mathrm{im}$ „Mercure de France" ausdrücklich als ebenso wegen ihrer utilité dans la science de l'architecture, comme aussi pour l'Histoire, les Antiquitez of l'explication des anciens Auteurs angepriesen ${ }^{207}$. Im Vorwort seines Werkes betont der Architekt ausdrücklich, man solle in Historischen Vorstellungen nicht alles [.. .] auf eine aus blossen Erzehlungen geholete Bildungs=Krafft ankommen lassen, sondern die Augen selbst [...] zu Rathe ziehen und durch solches Anschauen das Gedächtnis stärken 208. Bei vielen Stichen gibt Fischer daher Münzen und Zeichnungen mit derselben Sorgfalt als Quellen an wie literarische Zeugnisse. Die Bildhaftigkeit war nun nicht nur ein grundlegendes Prinzip der barocken Rhetorik, sondern kam auch in der Historiographie des 17. Jahrhunderts zur Anwendung 209. Athanasius Kircher und Giovanni Pietro Bellori, die in diesem Sinne in der zweiten Jahrhunderthälfte umfangreiche Kupferstichwerke ägyptischer, römischer und außereuropäischer Monumente publizierten, haben Fischer diesbezüglich zweifellos ebenso beeinflußt wie durch ihre Interpretationen und Antikensammlungen.

In diesem Zusammenhang muß auch ein bisher wenig beachtetes Kuriosum erwähnt werden: ein $840 \times 210 \mathrm{~cm}$ großer und 1698 in Wien publizierter Kupferstich ${ }_{n}$ Arbor Monarchica Repraesentans Omnes Universi Orbis Monarchas“ (Abb. 35). Die auf historischer Literatur von Plutarch und Herodot über Otto von Freising bis zu Lipsius und unmittelbar zeitgenössischen Werken basierende Publikation präsentiert eine umfassende Weltgeschichte von der Schöpfung bis zu Leopold I. nach dem System der vier Weltmonarchien. Das dem Kaiser und seinen beiden Söhnen gewidmete Werk sollte durch sein ungewöhnliches Format ermöglichen, daß alles in Einem eröffneter zuersehen wäre, damit wiederumb in Gedächtnis gebracht wird die Allmacht deß Allerhöchsten/ [. . . indeme er alle Monarchen/ Könige und andere gecrönte Häupter/ Philosophos/ auch Historiam universalem [...] seinen rechtmässigen Sitz/ und Wohnungs=Platz gibet ${ }^{210}$. Ganz im Sinne der Ars memorativa ging es also darum, alle dise so berrliche geschribene Bücherl durch disen Monarchen=Baum auff einmal eröffneter vorzustellen [...] und in Gedächtnis zu bringen. Der Autor stand mit dieser Idee zweifellos in der Tradition mnemotechnischer Werke. So ordnete Buno in seiner Geschichte der vier Weltmonarchien (1672) jedem Herrscher und jeder Epoche ein Sinnbild zu, darunter Salomon den Tempel und Cecrops die Stadt Athen, während der eine Generation jüngere ${ }_{n}$ Atlas historique ${ }^{u}$ die sieben Weltwunder als Zeugnisse der vier Welt-

${ }^{206}$ ) W. OECHSLIN, Fischer von Erlachs „Entwurff einer historischen Architectur“: die Integration einer erweiterten Geschichtsauffassung in die Architektur im Zeichen des erstarkten Kaisertums in Wien, in: Fillitz-Pippal, Wien und der europäische Barock (zit. Anm. 173), S. 77-81, hier S. 79. - Matsche, Die Kunst (zit. Anm. 46), S. 278-283.

${ }^{207)}$ Mercure de France, Paris Mai 1724, S. 951.

208) FISCHER, Historische Architektur (zit. Anm. 67), Vorrede fol. 4r.

${ }^{209)}$ F. HASKEL, History and Images. Art and the Interpreration of the Past, New Haven - London 1993, S. $91 \mathrm{ff}$.

210) Wilhelm Wolfgang PrXmer, Arbor Monarchica (. . .), Wien 1698. 
monarchien präsentiert ${ }^{211}$ (Abb. 36). Die monumentale „Arbor Monarchica“ von 1698 ist jedoch für uns deswegen von besonderem Interesse, da sie vom kaiserlichen Hofkriegsrat Wolfgang Wilhelm Prämer verfaßt wurde, der vor Fischer den ersten Versuch einer illustrierten Architekturgeschichte Wiens unternommen hatte ${ }^{212}$.

Die panegyrisch-didaktische Absicht des Werkes geht aus der Widmung an den jungen Erzherzog Karl deutlich hervor, wenn es heißt, daß dieser schon de $\beta$ grossen Kaysers Tito vortreffliche Lieb gegen die Armen/ deß Kaysers Trajani grosse Zuneigung der Gelehrten/ deß Antonini $P_{i j}$, und deß grossen Kaysers LEOPOLDI [... .] Sanffmütigkeiten erkennen lasse. Darüber hinaus zeige er auch wie ein anderer Alexander Magnus [. . .] wie man durch dessen Lehr die Soldaten und Untergebene zu lieben habe. In der $1712 \mathrm{zu}$ Ehren von Karl als Potentissimo Rey de las Hespañas y universo Emperadore dela America y nuevo Mundo publizierten spanischen Neuauflage wurde noch einmal betont, daß die Fähigkeit zu herrschen, aus nichts anderem als den Lehren der Geschichte erwachse: los aciertos del Giovierno de donde nacen, sino es della leccion de las Historias? 213

Die wichtigste Funktion der literarischen und architektonischen „Denk-Male“ vergangener Zeiten war also die Aufgabe, die Erinnerung an die Bauherren und ihre Tugenden wachzuhalten. Diese Gleichsetzung von Architektur und Ruhmestaten, gebauter und geschriebener Memorie entsprach auch der Auffassung von Fischer, wenn er schreibt, die Architektur der Semiramis in Babylon habe den Namen der Königin nicht weniger verewiget/ als die übrige Helden = Thaten/ so ihr zugeschrieben werden ${ }^{214}$. Die Interpretation von Architektur als Stein gewordene Tugend basiert auf der etwa vom Jesuiten Jacob Boschius 1701 vertretenen Auffassung, daß Tugend und Kunst die gleiche geistige Wurzel hätten: Nam animi pars altera bonis artibus instruenda est, altera exornanda virtutibus ${ }^{215}$. Boschius' Sinnbild-Enzyklopädie ist für uns besonders wichtig, da sie dem sechszehnjährigen Erzherzog Karl gewidmet wurde (Abb. 4). Im Vorwort verweist der Jesuit daher - ebenso wie Prämer auf die Kenntnis der Geschichte als Basis der Erziehung des jungen Fürsten:

Du vergrößerst die Dauer deines Lebens um so mehr, wie du jegliche zu erinnernde Geschehnisse früherer Zeiten so im Geiste erfaßst, daß du auch damals gelebt zu haben scheinen kannst. Und du hast nicht genug daran, alles in geistiger Erinnerung zu bewahren, sondern wenn du alles das mit Fleiß auch in deinen Gedanken gründlich erwägst, und, welches der höchste Nutzen der Geschichte ist, aus den Zeugnissen der geschehenen Ding dir ein Beispiel fir die zu tuenden nimmst.

Diese Gedächtnisleistung ist also die Voraussetzung für das kluge Handeln des Herrschers in der humanistischen Tradition: Historia Magistra Vitae. „Das Prinzip ist die Eschatologie: Die memorative Einverleibung der Geschichte soll ihn zum Herrscher über Vergan-

2ii) Johannes BUNo, Historische Bilder/ Darinnen IDEA HISTORIAE UNIVERSALIS, Eine kurtze Summarische Abbildung Der fürnehmsten Geist= und Weltlichen Geschichte durch die vier Monarchien (. . .), Lüneburg 1672. - Vgl. dazu die Vorträge von Thomas Rahn und Gerhard F. Strasser beim Symposion des Instituts für die Erforschung der Frühen Neuzeit „Ars memorativa II“ im November 1995 in Wien.

$\left.{ }^{212}\right)$ H. TieTze, Wolfgang Wilhelm Praemers Architekturwerk und der Wiener Palastbau des XVI. Jahrhunderts, in: Jahrbuch der kunschistorischen Sammlungen des Allerhöchsten Kaiserhauses, 32, 1915, S. $343-402$.

213) WILHelm Wolfgang PrXMeR, Arbor Monarchica, Wien 1712.

214) Fischer, Historische Architektur (zit. Anm. 67), fol. 17r.

215) Boschius, Symbolographia (zit. Anm. 69), Widmung o. S. 
genes machen, auf daß er tüchrig werde, die Zukunft zu beherrschen. ${ }^{\text {216 }}$ Die Widmungsrede des Jesuiten an den späteren Kaiser bietet also aufgrund ihrer geschichtsphilosophischen Konzeption den zentralen Erklärungsansatz für die Werke Fischers: Tatsächlich bindet die "Historische Architektur" die Baukunst nicht nur in eine theologisch-universale, heilsgeschichtliche Geschichtsvision ein ${ }^{217}$, sondern besitzt auch eine offensichtlich direkt auf Karl VI. bezogene Auswahl der Motive, wie vor allem die Ansicht des unscheinbaren Amphitheaters von Taragona und jene der Wasserleitung in Karthago (2. Buch, Tab. I und II) beweisen. Die Zeichnungen für das angeblich von Cäsar errichtete spanische Bauwerk sowie das in derselben Stadt befindliche Grabmal der Scipionen stammen von dem von Karl mit der Bauaufnahme der römischen Antiquitären beauftragten Militärarchitekten Matthias Anton Weiß, während die afrikanische Ansicht von Karl V. und von Karl VI. als Tapisserie in Auftrag gegeben wurde ${ }^{218}$. Aber auch die ägyptischen und chinesischen Altertümer lassen sich in ein habsburgozentrisches Weltbild integrieren ${ }^{219}$.

Die von Fischer rekonstruierten antiken Denkmäler der ${ }_{n}$ Historischen Architektur ${ }^{\text {" wa- }}$ ren also die historischen und künstlerischen Exempla und Präfigurationen für die Monumente des "Kaiserstils", so wie Salomon und David, Cäsar und Augustus in der Widmung des Werkes als Vorbilder für Karl VI. genannt wurden ${ }^{220}$. Es war daher nur folgerichtig, daß die von den beiden Fischer und anderen Architekten für den Kaiser errichteten Bauten schon zu Lebzeiten ebenso als Monumenta virturis interpretiert wurden wie die antiken Vorbilder. Die Verherrlichung der Bautätigkeit Karls VI. als Ausdruck seiner Tugenden wurde nicht nur in einer von Albrecht entworfenen und von Daniel Gran gemalten Allegorie veranschaulicht (Abb. 10)221, sondern auch von Franz Keller 1733 in einer illustrierten Publikation unter dem programmatischen Titel „Augusta Carolinae Virtutis Monumenta seu Aedificia a Carolo VI [... . posita“ ausführlich dargelegt ${ }^{222}$. Bereits 1717 hatte jedoch ein anderer Jesuit, Gerhard Hilleprand (1682-1747), ein ähnliches Werk mit dem Titel "Monumenta Virtutis Austriacae [. . . a Rhetorica Viennensi [.. . ] posita" verfaßt ${ }^{223}$. Ebenso wie bei Keller wird der direkte Bezug zur Antike hergestellt, da damals Denkmäler

216) NeUBer, Locus (zit. Anm. 62), S. 366 f. - Vgl. dazu auch den Vortrag "Domänen des Gedächtnisses. Zum Verhältnis von bistoria, memoria und prudentia und ihrer Bedeutung für die frtihneuzeitliche Herrschaftstheorie" von Anita Huber beim Symposion „Ars memorativa II“ (zit. Anm. 211).

217) OEChSLIN, Fischer (zit. Anm. 206), S. 79. - KunOth, Historische Architektur (zit. Anm. 94), S. 223 f.

211) KUNOTH, Historische Architektur (zit. Anm. 94), S. 224 f.

219) Die Betonung der ägyptischen Monumente spiegelt vielleichr den „Ägyptischen Plan ${ }^{\alpha}$ des Leibniz wieder, d. h. die Idee der Beherrschung des Nahen Ostens durch die Habsburger. Siehe: Hotownin, Schlesien (zit. Anm. 137), S. 196. - Die exotische Komponente als Ausdruck der kaiserlichen Universalizät finden wir um 1680 2. B. durch Chinoiserien (neben den vier Weltmonarchien) auf einem Bernsteinthron sowie chinesischen Handschriften, die als Geschenke aus Berlin nach Wien kamen. Siehe: W. BAER, Ein Bernsteinstuhl für Kaiser Leopold I. Ein Geschenk des Kurfürsten Friedrich Wilhelm von Brandenburg, in: Jb. d. Kunsthist. Slgn., 78, 1982, S. 91-138 - E. KrafT, Christian Menzels chinesische Geschenke für Kaiser Leopold I., in: Schloß Charlottenburg - Berlin - Preußen (Festschrift für Margarete Kühn), hg. von M. SPERLCH und H. BORSCH-SUPAN, München - Berlin 1975, S. 191-202.

220) Matsche, Die Kunst (wie Anm. 46), S. 278-283.

221) B. KAISER - J. KRASSER, „Bauen ist ein schöner Lust ... . Ein Gedankenspiel zum Bauen im Barock und heute, in: Kat. Lust \& Leid. Barocke Kunst, Barocker Alltag (Ausst. Trautenfels), Graz 1992, S. 357-362, hier S. 359 (Abb.).

222) Matsche, Die Kunst (zit. Anm. 46), S. 386-427.

${ }^{223)}$ Kat. Welt des Barock (zit. Anm. 95), S. 71, Nr. 1.28 (Abb.). 
errichtet wurden, um der Nachwelt tugendhafte Vorbilder zu überliefern: An Atheniensis primi omnium, ut immortali nomine, ac Fame dignos in effigie servarent, claris, of Posteris in exemplum proponerent, claris Heroibus, of vel arte, vel bello Victoribus posuerint ex aere, argento, auro statuas 224. Neben einem Reiterdenkmal in der Hofburg und einem Triumphbogen führt das teilweise in Streitgesprächen aufgebaute Werk auch einen schon erwähnten Colossus Ad Rhodii similitudinem Carolo V. an (Abb. 12), der die Constantia Occidentem und die Fortitudine Orientem des Kaisers veranschaulichen sollte. Nach dem Vorbild von Julius Cäsar oder Gottfried von Bouillon solle Theodosius M. in Carolo VI. redivivus das antike Weltreich auf christlicher Grundlage erneuern.

Parallel zu ihrer pädagogischen Funktion für den Herrscher dienten die Illustrationen der „Historischen Architektur ${ }^{4}$ auch als Vorbilder für die Künstler. Ebenso wie die von Fischer als Quellen verwendeten Münzen sollten die Stiche als redende Zeugen dazu beitragen, die alles verstörende Zeit und gäntzliche Vernichrung der Denk=Male alter Gebäude abzubalten, und sich dadurch sowohl um die Gedächtnis der Rubm=wrïrdigen Urbeber, als um die Kunst=begierige Nach-Welt verdient zu machen. Es war also offensichtlich Fischers Absicht, neben der Tanslatio Imperii eine Translatio studii et artium und kunsthistorische aemulatio zu propagieren. Dieser Aspekt wird bereits bei der ersten Beschreibung, nämlich jener des Salomonischen Tempels, deutlich:

Angeseben leicht zu behaupten/ daß die in den letzten, Seculis', samt andern abgestorbenen Künsten/ gleichsam wieder lebendig gewordene Römische Bau=Kunst ibre Vollkommenheiten/ und die sogenannte Corinthische Ordnung zu erst nach dem Salomonischen Bau durch die ,Phonicier von den Griechen entlehnet 225.

Die von Fischer angestrebre Beforderung sowohl der Wissenschaften, als der Künste beruht dementsprechend darauf, den Geschmack der Landes=Arten [. . . gegeneinender zu halten, und das Beste zu erwäblen, [. . .]. Ist nun gleich worinn gefehlet: So hat derjenige, der es besser machet, dennoch dem Anfanger den Vortheil zu danken, daß man ihm durch Vor $=$ Arbeit zu besserem Nachsinnen Anleitung gegeben ${ }^{226}$. Mit diesen Worten bezog sich der Architekt offensichtlich auf die Nachahmungslehre, wie sie in der Rhetorik etwa von Quintilian vertreten wurde:

Es kann nämlich nicht bezweifelt werden, daß ein Großteil der Kunstfertigkeit auf Nachahmung beruht. [...] Doch gerade dies, was uns das Verfahren auf allen Gebieten um soviel leichter macht, als es fur jene war, die nichts nachzuabmen hatten, bringt, wenn es nicht mit Vorsicht und kritisch angewandt wird, Schaden 227.

Die Nachahmungslehre dominierte auch die Rhetorik der römischen Jesuiten und fand auf diese Weise Eingang in die Kunsttheorie eines Bellori und Poussin. Letzterer bezog sich direkt auf Agostino Mascardis Buch „Dell'arte historica" (Rom 1636) ${ }^{228 .}$

224) Hilleprand, Monumenta Virturis (zit. Anm. 65), S. 36.

225) FisCHER, Historische Architektur (zit. Anm. 67), fol. 4v und 12r - Vgl. dazu: OECHSUN, Fischer (zit. Anm. 206), S. $78 \mathrm{f}$.

228) Ebenda, fol. $5 r$.

277) Quintilian, Institutio oratoria X, II. Buch, 1 u. 3. - Vgl. dazu das Kapitel „L'imitation“ bei: LeE, Ut Pictura Poesis (zit. Anm. 1), S. 21-37.

2an) E. Cropper, „La più bella antichitz̀ che sappite desiderare": History and Style in Giovan Pietro Bellori's "Lives", in: Kunst und Kunsttheorie 1400-1900 (Wolfenbüttler Forschungen, 48), hg. von P. Ganz u. 2., Wolfenbüttel 1991, S. 145-173, hier S. 151 f. - Vgl. C. GoldsteIn, A New Role for the Antique in Academies, in: Antikenrezeption im Hochbarock, hg. von H. BECK und S. SCHulzE, Berlin 1989, S. 155-171. 
Auf dieselben kunstheoretischen Wurzeln muß wohl auch der ${ }_{n}$ Historismus ${ }^{\star}$ und der „Klassizismus“ der Wiener Kunst seit der Gründung einer kaiserlich geförderten Kunstakademie im Jahre 1688 zurückgeführt werden ${ }^{229}$. Tatsächlich verweist Franz Rosenstingl später ausdrücklich auf die Ars memorativa als zweite Basis des künstlerischen Ingeniums:

Das Anderte [ist] die Gedächtnis und seben, wie in denen Altertbümern die noch stehende Wercker und Rudera [= Ruinen], wie hoch die Bau-Kunst gestiegen zur selben Zeit, nach welcher wir heuntiges tages noch allezeit zu lernen haben. [. . .] Die Historien sind Zeugen der Zeiten, ein Licht der Wabrheit, ein Leben des Gedalchtnisses, und ein Bote der Antiquitäten; denn in diesen wird man erfahren, daß ein,Architectus" sich zu allen Wissenschaften wenden muß [. . .]. Dieses ist genugsabm zu ersehen, da die Wunder der Welt mit höchster Verwunderung zu Rom aufgefuibret worden, und die Antiquitäten annoch darauf weisen, auch in verschiedenen Authoribus zu lesen, als Theatra, Amphitheatra, Mausulaea, Triumph Bögen, die Columna Trajani, Columna Antonini, die Obelisci oder Flamm Säulen, die Colossi, die Thermae, die Tempeln, der Pantheon, die Egyptische Pyramiden und so weiter. Sogar die heylige Schriff rühmt zwei Männer sebr, welche künstlich im bauen, und allen arbeiten waren [...]. Die Griechen haben die Ehre, daß sie durch ibren unermüdeten Fleiß und obnausgesetzte Bemühung die erste Ideam der Architektur erfunden [. . . ] $]^{230}$.

Ebenso wie Fischer griff offensichtlich auch Rosenstingl hier direkt oder indirekt auf die antike Rhetorik zurück. Denn sein Lob der Geschichte findet sich nicht nur in der Einleitung und auf dem Titelblatt eines Buches über das Römische Reich des Salzburger Benediktiners Otto Aicher von 1691231, sondern gibt Ciceros Charakterisierung der Geschichte als vornehmste Aufgabe der Rhetorik wörtlich wider: Historia vero testis temporum, lux veritatis, vita memoriae, magistra vitae, nuntia vetustatis, qua voce alia nisi oratoris immortalitati commendantur? (De oratore, II, 36.)

\section{6. ,conclusio}

Es ist naheliegend, daß die Programmberater der kaiserlichen Bauten, die Hofgelehrten Carl Gustav Heraeus und Conrad Adolph von Albrecht, die Theorien der Gedächtniskunst und Emblematik ebenso beherrschten wie die Jesuiten im Umkreis des Hofes. Es bleibt aber noch die Frage zu beantworten, ob Fischer selbst mit den Grundsätzen der Rhetorik vertraut war. Wenn Johann Bernhard nicht schon in Rom mit der emblematischen Funktion von Architektur bekannt wurde, so geschah dies zumindest sofort nach seiner Rückkehr nach Osterreich. Denn auf einem unter seiner Leitung um 1688 entstandenem Emblem des Grazer Mausoleums versinnbildlichen die zwei Säulen vor einem Palast die Söhne Kaiser Leopolds I., Joseph und Karl, und damit die genealogische Standhaftigkeit des ${ }_{\text {Hauses }}$

229) Tatsächlich bildete der 1692 erfolgte Ankauf von Gipsabgüssen nach römischen Statuen eine der Voraussetzungen der Wiener Akademic: Koller, Strudel (zit. Anm. 45), S. 96-110. - Ein direkter Einfluß der Ideen Belloris scheint zur selben Zeit bei Strudels Nachbarn in der Rossau, dem Fürsten Liechtenstein, nachweisbar: F. Polleross, Utilità, Virtù e Bellezxa. Fürst Johann Adam Andreas von Liechtenstein und sein Wiener Palast in der Rossau, in: Osterr. Zeitschrift f. Kunst und Denkmalpflege, XLVII, 1993, S. 36-52.

230) Hiert-DeronCo, Rosenstingl (zit. Anm. 74), S. 212 u. 217.

231) Otto Aicher OSB, Historia Quartae Monarchiae Sacra et Profana (. . .), St. Gallen 1691. 
Österreich" ${ }^{232}$. Zwei Jahre später entwarf beziehungsweise zeichnete der Architekt die Embleme für die beiden Triumphbögen zum Einzug der kaiserlichen Familie. In zwei Fällen griff Fischer dabei auf Architekturmotive zurück: bei der Darstellung des Templum virtutis et gloriae (Abb. 18) sowie bei der Imago des Memnon-Kolosses.

Die Theorien der Emblematik und Poetik, also der gemeinsame Einsatz von Wort und Bild, Sinnlichkeit und Verstand im Sinne der Rhetorik, waren Fischer offensichtlich nicht nur aufgrund der in Beziehung zur zeitgenössischen Impresen- und Emblemkunst stehenden Arbeiten Berninis vertraut ${ }^{233}$. Denn in der ${ }_{n}$ Historischen Architektur ${ }^{*}$ verweist der Architekt darauf, daß die Bildtafeln deshalb mit Texten erläutert werden, weil Abbildungen/ als stumme Redner/ eine redende Mahlerey erfordern. Weil eine von diesen ohne die andere sich nicht deutlich genug zu erkennen giebet ${ }^{234}$. Mit diesen Worten greift der Architekt einen der Grundsätze der Emblematik auf. Denn diese forderte die Verbindung von Bild und Text, imago und scriptura, da ersteres allein zu allgemein und unbestimmt bliebe: le Mot cest a la Figure, qui est comme la matiere of l'etrofe de la Devise. Il reserre of détermine ce qu'elle a de vague, of d'indifferent: il reduit sa maniere de signifier universelle of suspendue, a une signification particuliere of arrestée 235 .

Einen deutlicheren Beweis für die These von der Architektur des „Kaiserstils“ als gebaute Rhetorik und Fischers bewußte Verbindung von Rede- und Baukunst liefert uns aber die Porträtmedaille des Architekten von Benedikt Richter aus dem Jahre 1719 (Abb. 42). Deren Rückseite zeigt als persönliches Emblem Architekturversatzstücke unter dem Motto DOCENT ET DELECTANT. Die damit als theoretische Basis der Architektur Johann Bernhard Fischers von Erlach ausgewiesenen Methoden des docere und delectare waren nämlich genau die von Cicero und Horaz formulierten und seit Leon Battista Alberti in der neuzeitlichen Kunsttheorie bekannten genuin rhetorischen Intentionen ${ }^{236}$. Der französische Theoretiker Charles Batteux hat dementsprechend die Architektur gemeinsam mit der Rhetorik als dritte Kategorie zwischen den "mechanischen " und den "schönen " Künsten bezeichnet: Die dritte Klasse enthält diejenigen Künste, die den Nutzen und das Ergetzen zugleich zur Absicht haben. Die Notdurfft hat sie erfunden, und der Geschmack hat sie vollkommen gemacht. Sie halten das Mittel zwischen den anderen beiden, und sind aus Nutzbarkeit und Vergnügen zusammengesetzt 237 .

Diese "funktionalistische" Analogie zwischen Rede- und Baukunst findet sich aber ebenfalls schon bei Cicero:

Tempel und Hallen stützen sich auf Säulen, doch liegt in ihnen ebensoviel Würde wie Nützlichkeit. Nicht Schönheit, sondern zwingende Notwendigkeit schuf den berühmten Giebel des Kapitols und der übrigen Tempel. Denn als man der Erwägung, wie das Wasser von beiden Seiten des Dachs abfließen könnte, Rechnung getragen hatte, da stellte sich die Würde als Folge der Nützlichkeit des Tempelgiebels ein, so daß es scheint, als würde das Kapitol, sogar wenn es im

232) KoDOuTsCH, Mausoleen (2it. Anm. 44), S. 351, Abb. 21.

233) Zu den "Wort-Bild-Synthesen" Berninis und seines Umkreises siehe: R. PreamesBerger, Berninis Capella Cornaro. Eine Bild-Wort-Synthese des siebzehnten Jahrhunderts? Zu Irving Lavins Bernini-Buch, in: Zeitschrift für Kunstgeschichte, 49, 1986, S. 190-219, hier S. $213 \mathrm{ff}$.

234) FisCHER, Historische Architektur (zit. Anm. 67), fol. 12.

235) LE Morne, Devises (zit. Anm. 63), S. 143 f.

236) LEE, Ut Pictura Poesis (zir. Anm. 1), S. 71-75 („L'instruction et la délectation“).

237) Charles Batteux, Einleitung in die Schönen Wissenschaften, Bd. I, Leipzig 1762, S. 10 f. 
Himmel stünde, wo es nicht regnet, obne Giebel keinen wïndevollen Eindruck machen. Das trifft dann auch auf alle Teile der Rede zu, daß Nützlichkeit und fast Notwendigkeit eine gewisse Art von Reiz und Anmut im Gefolge haben (De oratore III, 180-181).

Auch wenn Fischers Devise "nur" das Bestreben verraten sollte, in seiner Baukunst Nützlichkeit und Schönheit zu verbinden, so hat er zweifellos einen Wettstreit mit der Antike für sich entschieden: Denn der von Cicero als Exemplum eines eloquenten Architekten genannte Baumeister des Zeughauses in Athen, Philon, soll seine Zeitgenossen mehr durch seine Redekunst als durch sein Können als Architekt überzeugt haben (Cicero, De oratore I, 62). Wie eine Bestätigung dieser Aussage wirkt die Installation des vom Akademiedirektor van Schuppen gemalten Bildnisses des Hofarchitekten in der Kaiserloge der Karlskirche: Mit der linken Hand weist Fischer auf den Grundriß der Kirche, mit der Rechten wendet er sich im Gestus des Rhetorikers direkt an den Betrachter und unterstreicht damit seine Autorschaft an der Architektur des Ortes ${ }^{238}$.

238) I. SeVterun, Baumeister und Architekten. Studien zur Darstellung eines Berufsstandes in Porträt und Bildnis, Berlin 1992, S. 67 f. (Abb.), Kat.-Nr. 144.

Abbildungsnachweis: Abb. 1: Nach F. BorSI, G. L. Bernini, Stuttgart - Zürich 1982. - Abb. 2, 3, 7, 13, 31, 32, 35: Institut für Kunstgeschichte der Universität Wien. - Abb. 4, 14: nach Boschrus, Symbolographia (zit. Anm. 69). - 5: Nationalmuseum Stockholm. - Abb. 6, 11, 12, 16, 17, 19, 24, 25, 28, 29, 37, 38, 40, 41: Archiv des Verfassers. - Abb. 8, 9, 30: Bundesdenkmalamt Wien. - Abb. 10: Foto Jare, Graz. - Abb. 15: Versteigerungskatalog Arnoldi-Lievie, München 1986. - Abb. 18, 33, 34: Graphische Sammlung Albertina, Wien. - Abb. 20: E. BerCKenhugen, Barock in Deutschland: Residenzen, Berlin 1966. - Abb. 21, 23, 26, 36, 39: Osterreichische Nationalbibliothek, Wien. - Abb. 22: nach LesKr, Frühe Embleme (zit. Anm. 125). - Abb. 27: nach: Universale Bildung im Barock, Rastatt 1981. - Abb. 42: Kunsthistorisches Museum Wien. 

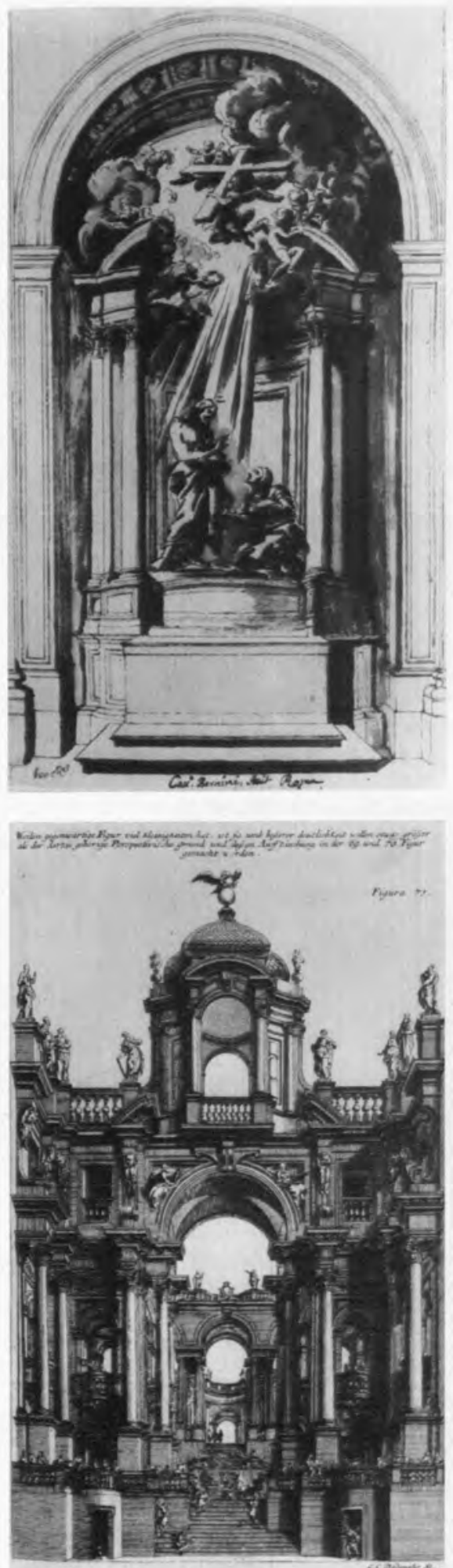

1. Gian Lorenzo Bernini, Entwurf für die Alaleona-Kapelle in SS. Domenico e

Sisto in Rom,

um 1648

2. J. B. Fischer v.

Erlach, Hochaltar in Mariazell, Radierung von Chr. Engelbrecht und J. A. Pfeffel, nach 1696

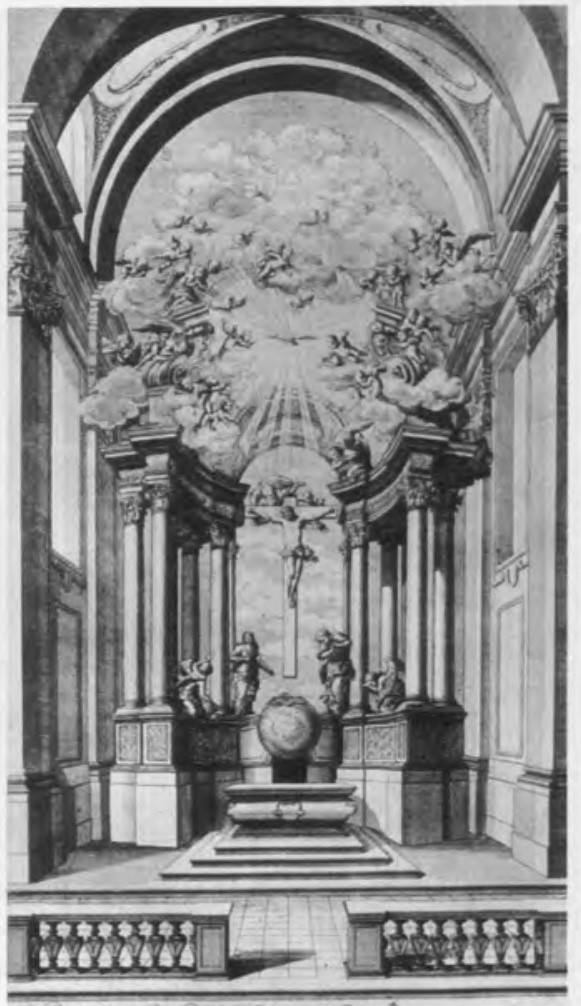

3. Andrea Pozzo, Teatro delle Nozze di Cana

(Trattato I, 71), 1693

4. Apotheose Erzherzog Karls, Kupferstich von Johann Georg Engelbrecht, 1701

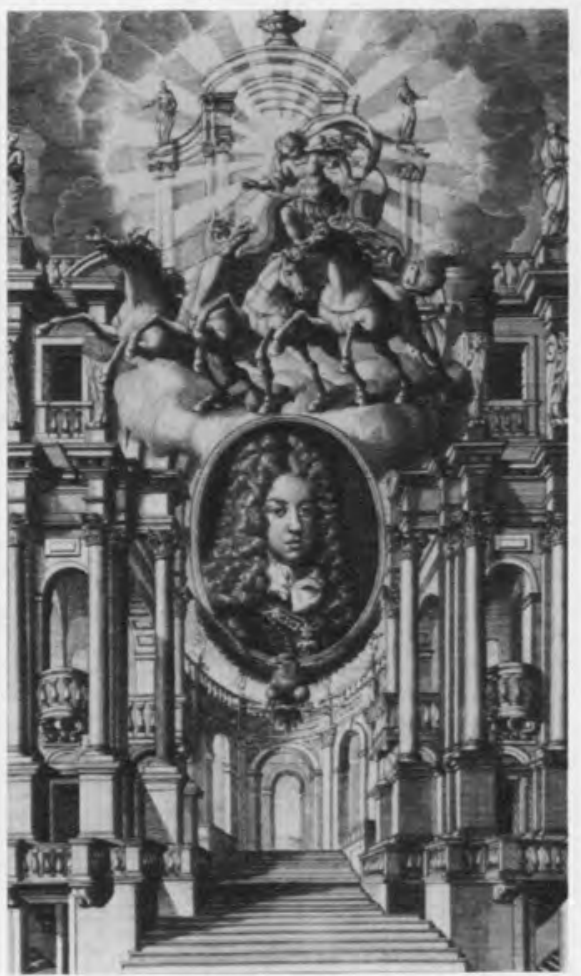




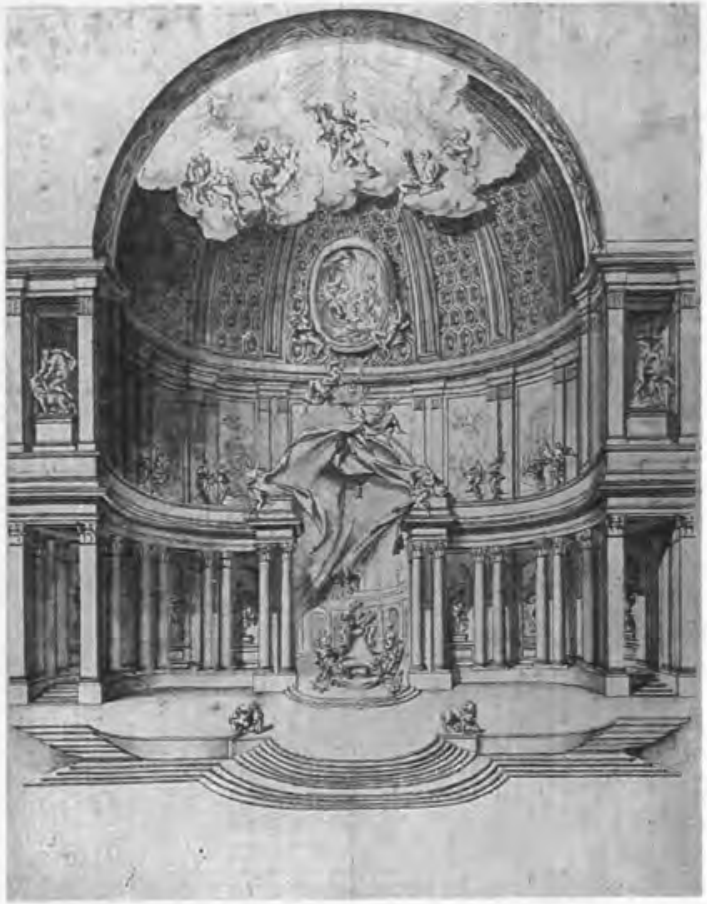

5. Entwurf für einen Thronsaal, Nicodemus Tessin d. J. nach Abrahamo Paris, Stockholm, Nationalmuseum
DECENTIA. N. g. b.

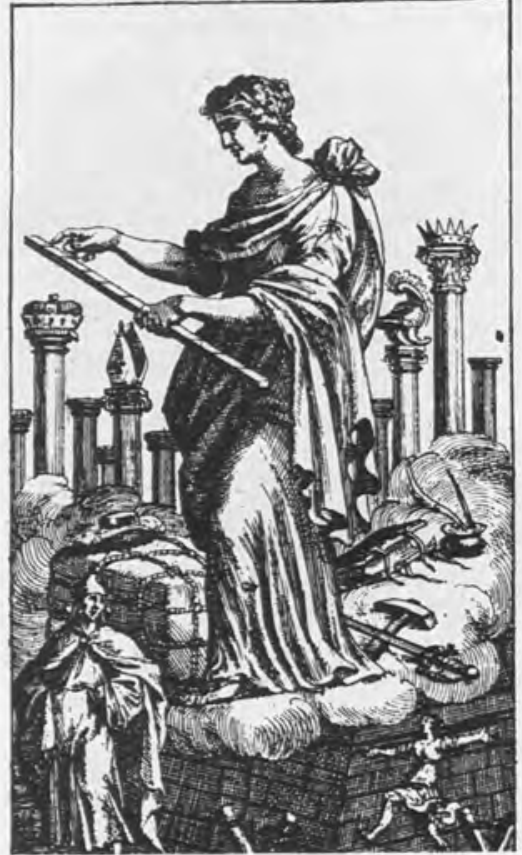

6. Allegorie der Decentia, Radierung in:

E. Weigl, Wienerischer Tugendspiegel, 1687

7. Karl Eusebius von Liechtenstein, Schloß Plumenau, Kupferstich von J. A. Delsenbach

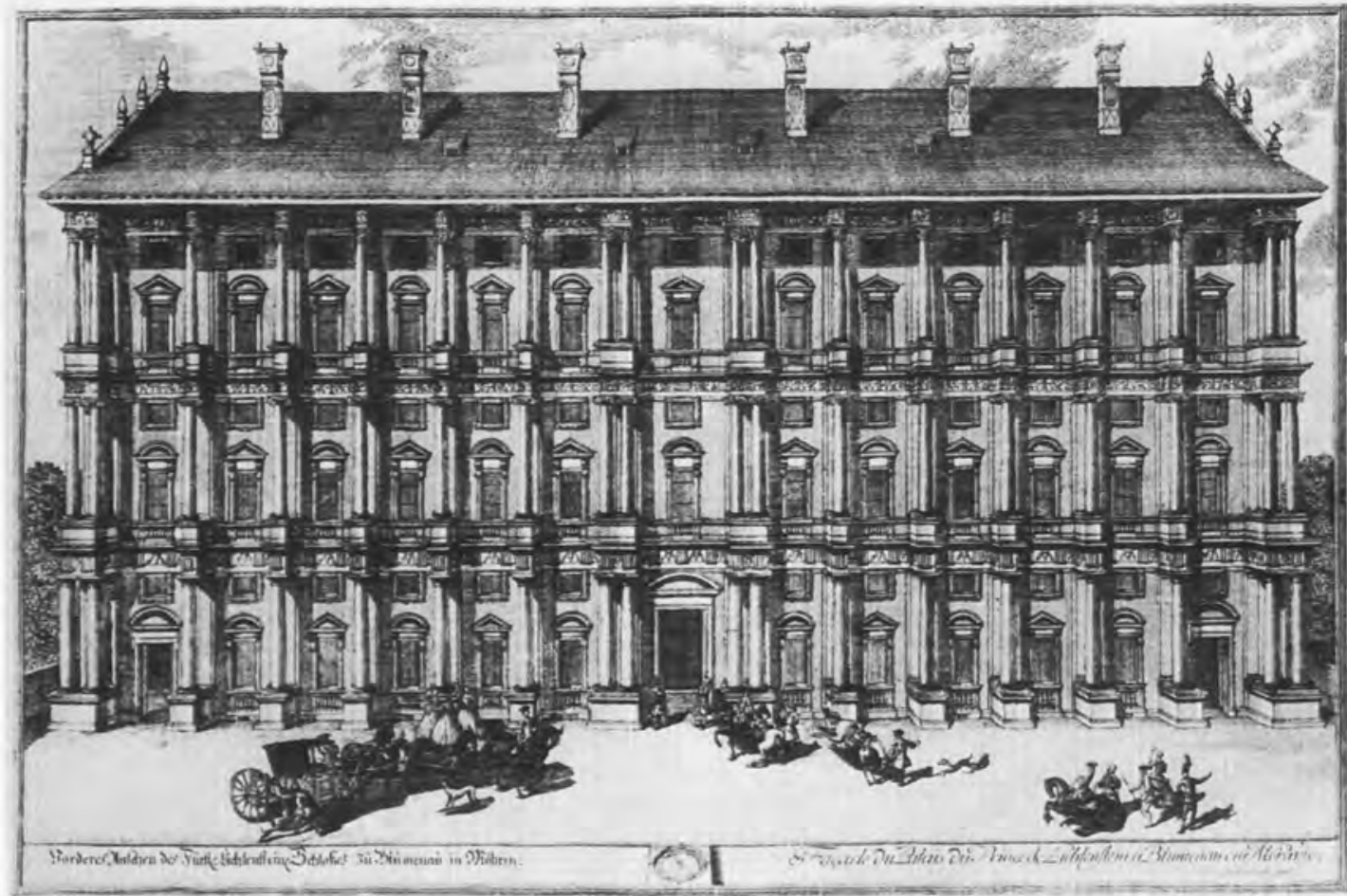



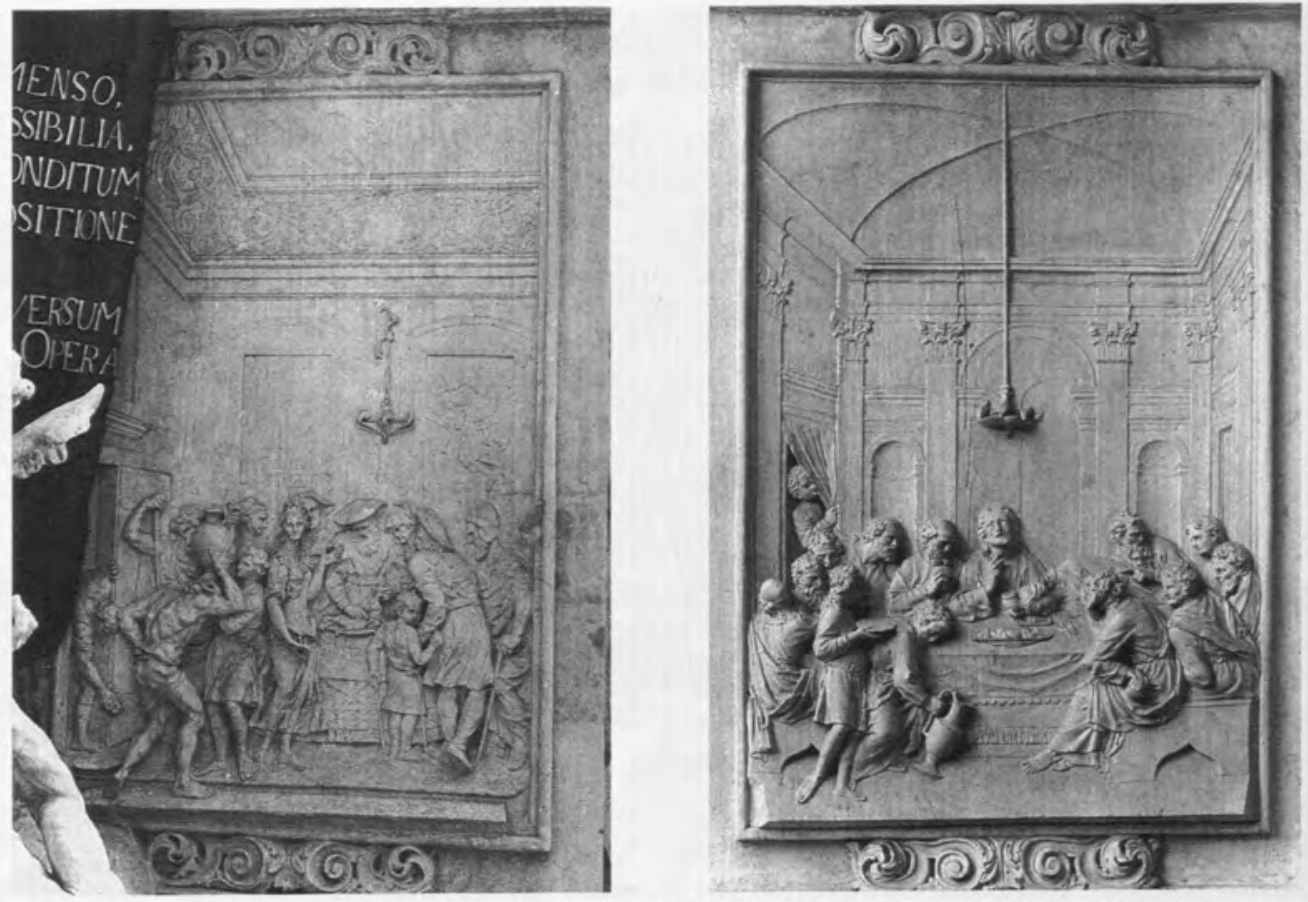

8, 9. J. B. Fischer u. Johann Ignaz Bendl, Paschafest u. Letztes Abendmahl, Reliefs der Pestsäule, Wien, Graben, 1688/89

10. Allegorie auf die Bautätigkeit Karls VI., Ölskizze von Daniel Gran nach einer Zeichnung im Codex Albrecht, um 1730, Graz, Schloß Eggenberg

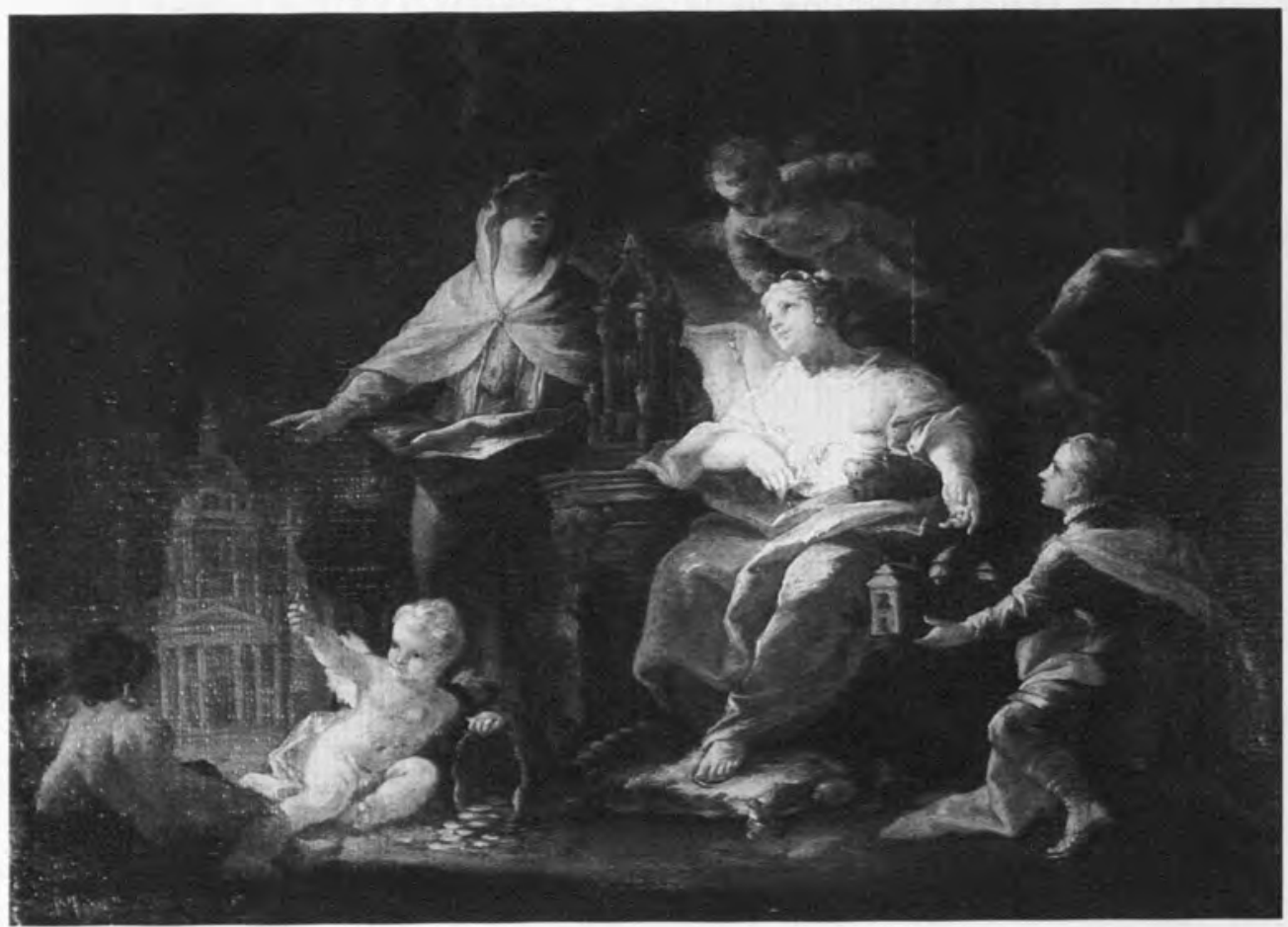




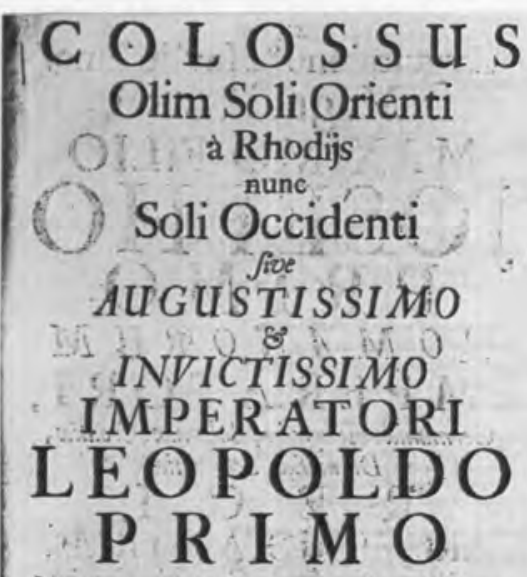

\section{Gloriofifsimum vitæ cur-}

füm abfolventi erectus ,

Dumfubmiffiffimadevotionein Ecclefia SocietaTIS JESU

OLOMUCII. Die 8.9. 10. Jumij.

DefVNCto MonarCha Jufta perfolverentur,

pro publici Luedûs Incremento propofitus;

11. Leopold I. als Koloß von Rhodos, Leichenpredigt der Jesuiten in Olmütz, 1705

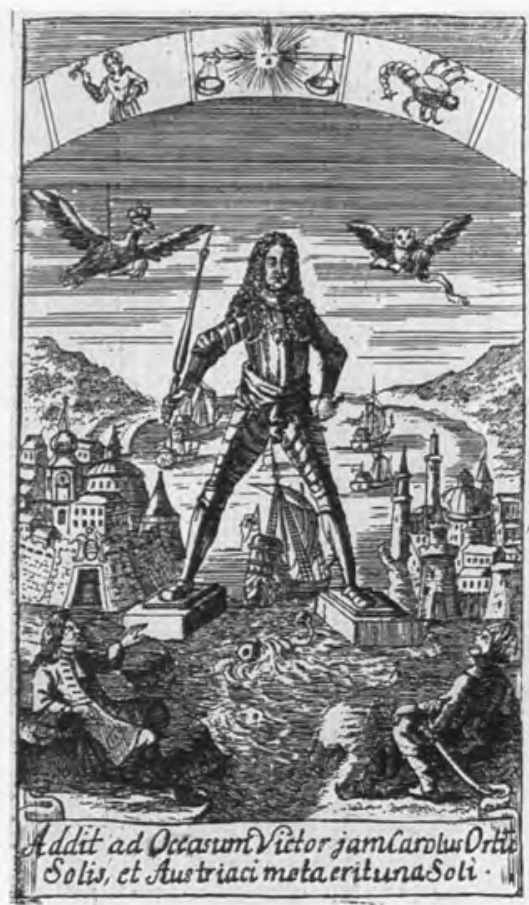

12. Karl VI. als Koloß von Rhodos, Radierung in: J. G. Hilleprand, Monumenta

Virtutis Austriacae, 1717

13. Der Berg Athos als Denkmal Alexanders des Großen, Kupferstich von J. B. Fischer v. Erlach, 1721

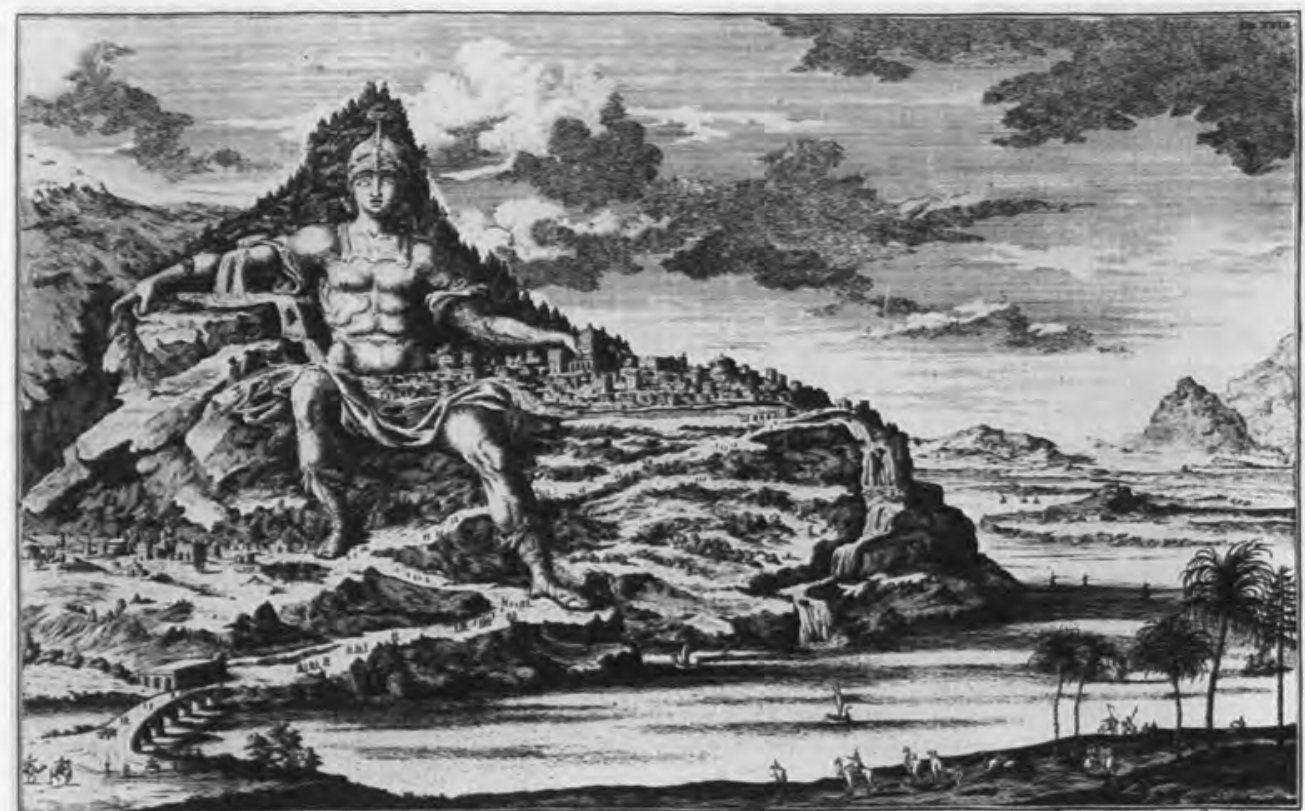

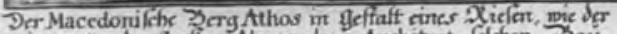
Dinocrates, Des ffrothere Alecanders Architect, folchen Sari

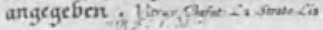

Le Colovge du mont. tchas en Macedoine felon le dengein que on firma Dinocrate trehitecte au grand tlexañore $\operatorname{cosec} x$

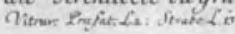




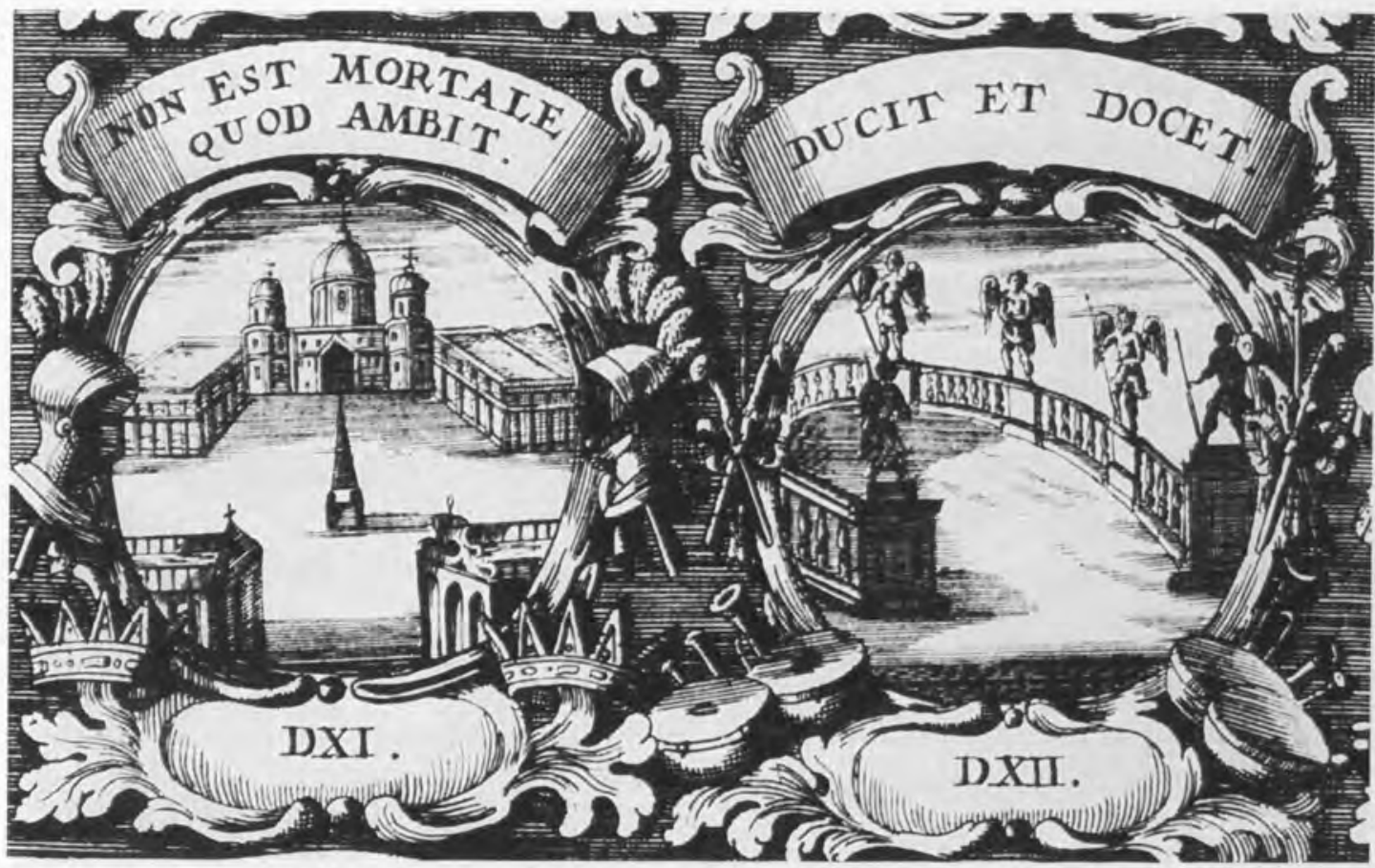

14. Embleme mit den Kolonnaden von St. Peter und den Skulpturen der Engelsbrücke von Bernini, 1701

15. Giovanni Paolo Schor, Entwurf für einen Prunkwagen des spanischen Botschafters, 1673 , Kunsthandel

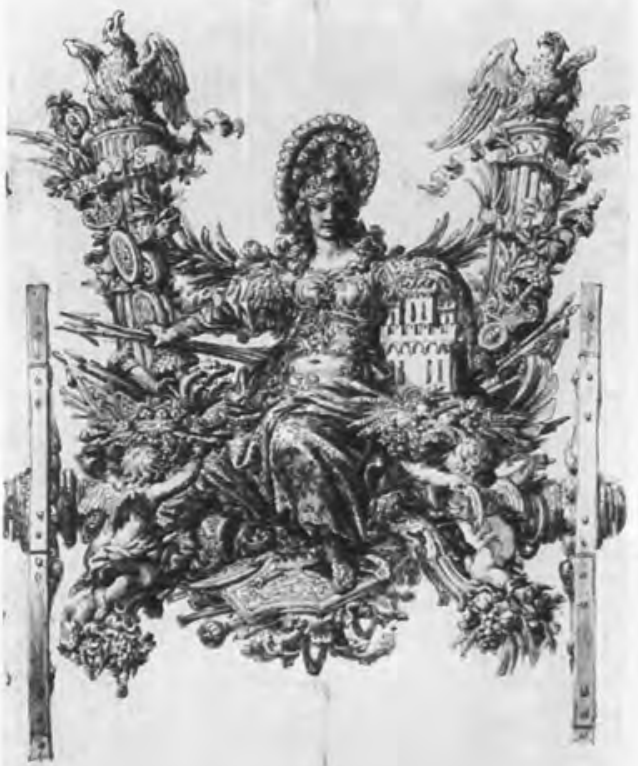

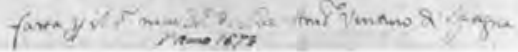

16. Ludovico Burnacini, Johann Bernhard Fischer u. a., Wien, Graben, Pestsäule, Kupferstich, 18. Jh.

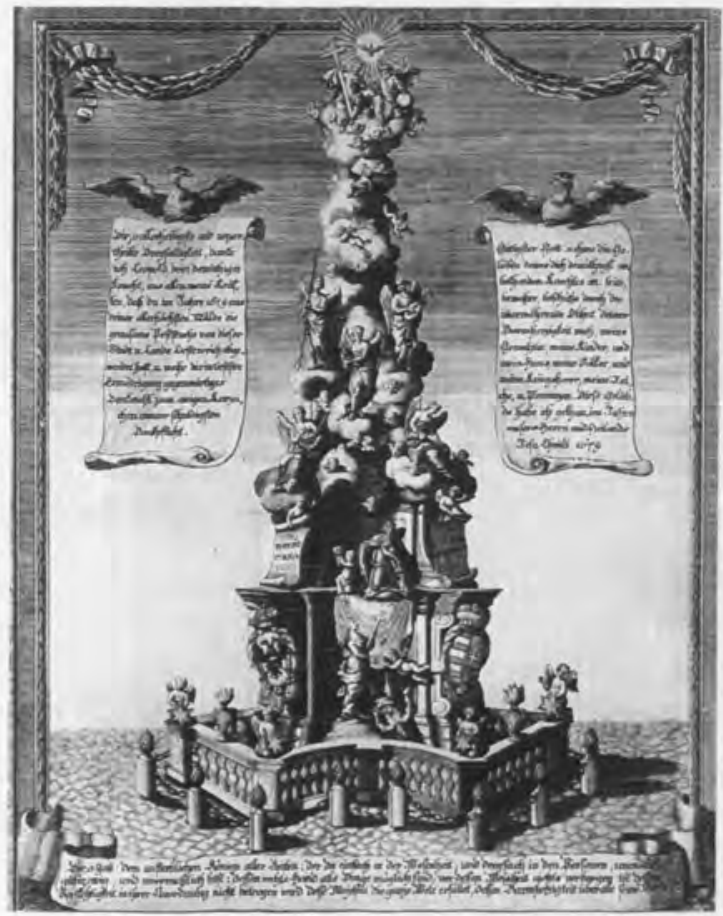




\section{Sh}

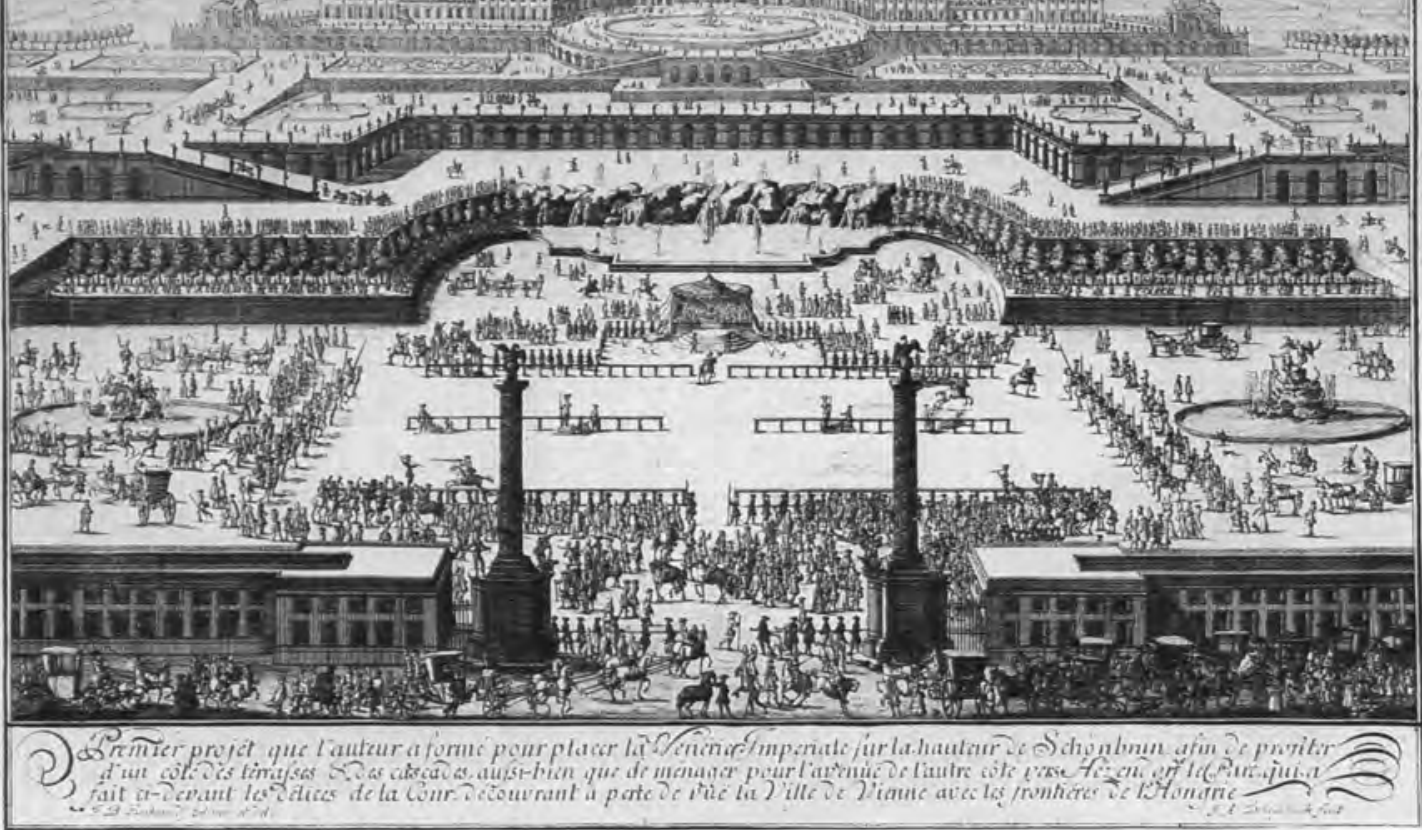

17. J. B. Fischer v. Erlach, Erster Entwurf für Schönbrunn, um 1688, Radierung von J. A. Delsenbach

18. Templum virtutis et honoris, Triumphbogen d. Niederleger, J. B. Fischer, 1690, Wien, Albertina

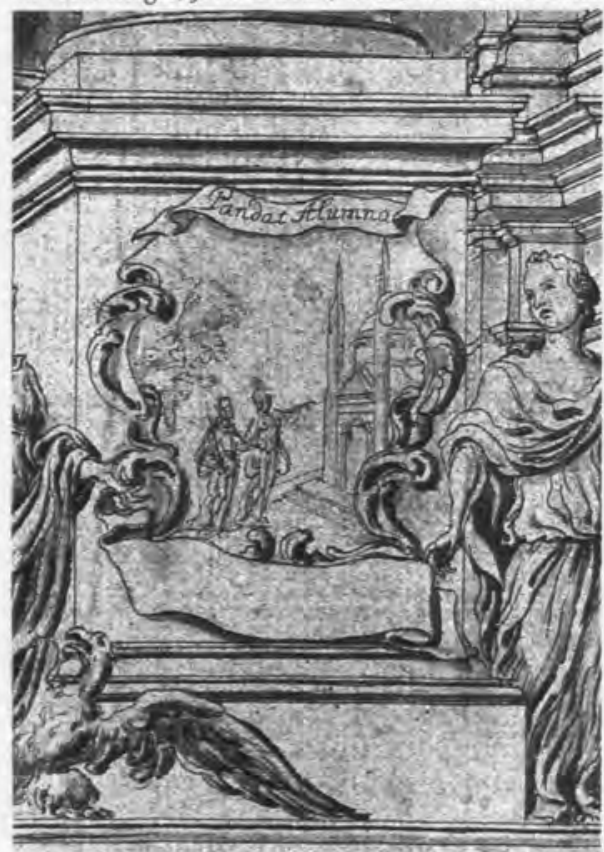

19. Joseph I. als Herkules Austriacus in Schönbrunn, Kupferstich von A. Trost, 1702

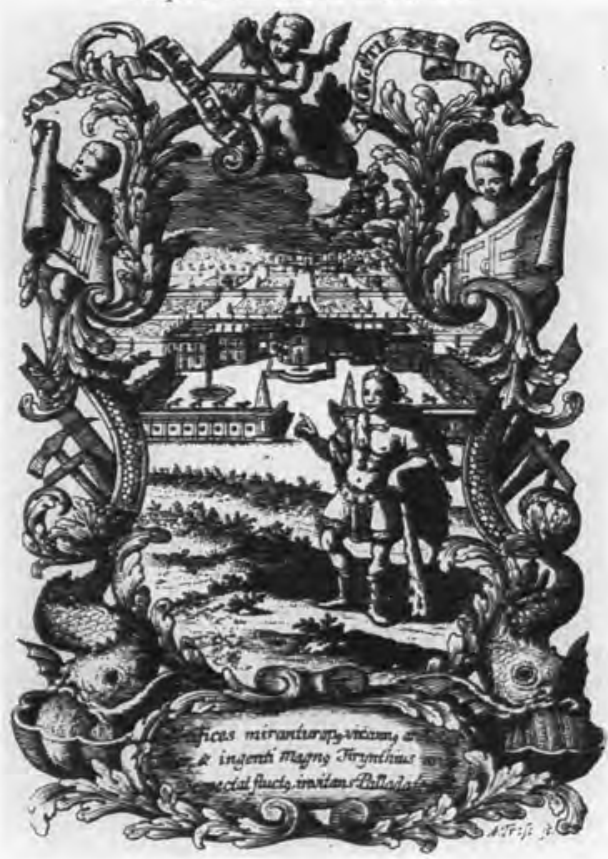




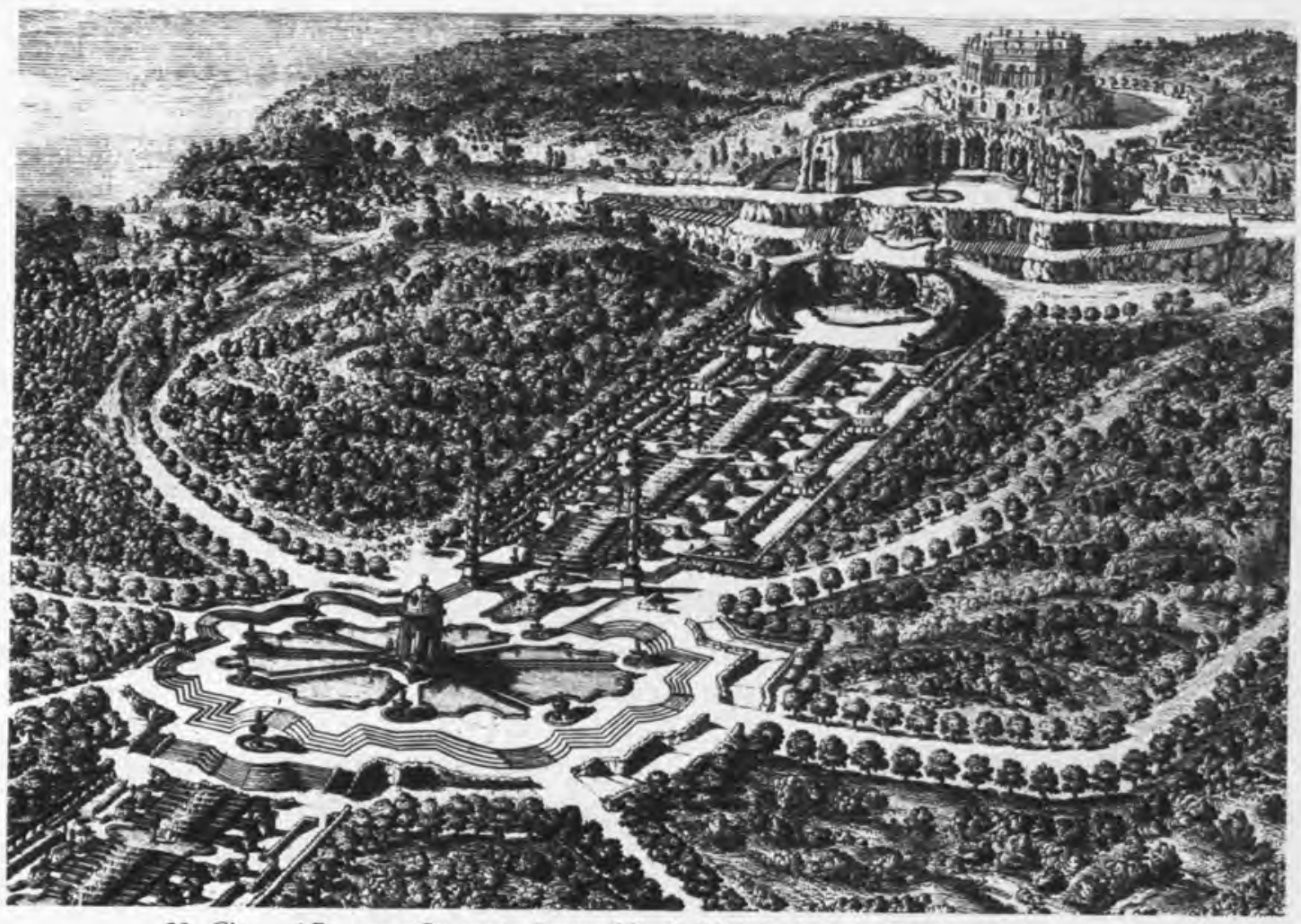

20. Giovanni Francesco Guernerio, Entwurf für die Wilhelmshöhe in Kassel, 1701, Ausschnitt

21. Beschreibung der römischen Münzfunde anläßlich d. Errichtung d. Triumphbögen in Wien, 1690

participant, fed bionc eternitatior defedtum compenfant fidelium Jubditoran animi ; Tua enim gloria \& ut cum Nazanio loquanuar : cuus vultus aboleri non poteft, univerforum pectoribus infixus eft, noc commendatione cera aut pigmentorum fucis retinetur, fẹd defiderio efflorefcit animorum,una demum LEOPQ LDI $M A$ ANI oblivio totries Ayrie accafus. Ut vel a co sitelliges, nom prives in animis noftris perituram lavids T we memoriam, quam Aw-

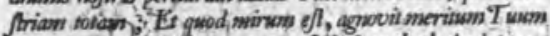
Romena of bis, dian aperto prafécti fecande legionis hamis. lo locum, ceffit ad exfrniendum bwop Majeftati 'Twee arcum

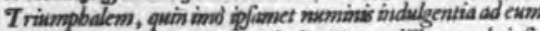
illuf framdum concurrere vifa $f l$, dum in predilio tumulo inferius appofita veterion lonperatorum -numifimata detexir, qua ad preteritorum prafentiumque geftanum ac Sacratiflimx Majeftatis Tive glarian clare videntur alludere.

\section{(12) (19)}

bu boc numifinate fefe offert Gens Flavia, \& in gente Fla via Domus Avy/triacs, quia ficut referente Swetrono incertum diu \& quafi vagum Imperium fufcepit, firmavitque tandem gens Flavia, tta divjis Eletionum votis Richardo emente, Alpborfo vero ambiente incertum diu \& quafi viagum

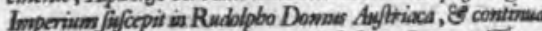

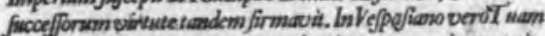
Auguftiffime Imperatoot predentian vencrari convent, quia ficat ille Hijpoum exercitum, qui Galbam, Pretoria num, qui Ottonem, Germanum, qui Vitellisim elegeranis, $E$ grptiacis ac Syriacis legiomibus survit ad binperij Jalutem, ita

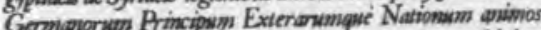
faluber

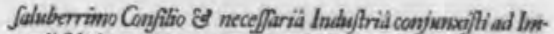

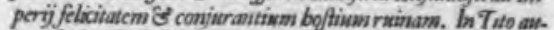
tem Cefore JOSEFHUL Magnefinies in Romanoran Regem s/jomprum, telte enim Spartianolmperatorum fili, qui ad Regnum deftinabantur, Cxfares nuncupari, hodieque Germanorum Regem ita appellamus, Serenilf?

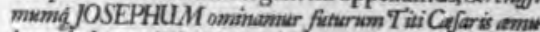
hum, id $\mathrm{g} / \mathrm{t}$ populi delicias, orbis Amorem, Timore ad $f 6$. los boftes 80 cos, qui fe anory indigmos probuat, conroer 6 .

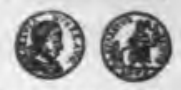

In boc Numijimate expreffum fpettamus Grationon, 8 in Gratiano Tuam Auguftiflime Imperator pietatem ac for titudinem, pietatem, quia Grationsus futt narrante Cufpinionso, Princeps planè religiofus ab adolefeentia, qui mente pura \& immaculabili confcicntia DEU M fummum veneratus cft, que verba Sacratiffimx Majeftati Twe convenuire nullhw ambrigit : fortibudinem vero, quis ficut $G$ ins tiansis referente Baronio imsuentiom ab Occidente Aleman. monum quadrayinta, vel wt aljijvolent, feptsagyita milliacom. milo prialio delevit, Gosbos verd ab Orienite iffi Comfantinopoli ingnemtes proffigervit, tanta cum unimi fortitudine, wt Reparator Reipublicx vocatws fient, fic Auguftiflime Imperator boftes tam ab Occidente, quàm Oriente, bivic etiam

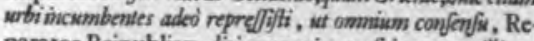
parator Reipublicx dici merears; ; confpirroenunt illi an. daciam immensâ. fuggereute potentia incertam Inpenty perni ciem, fed nonne manifeftum eft, wt cum Ptimio ad Trajanum loquanur; fiquid adverfi cadat, tuis laudibus tuisó; ) ?( ) $:($ virtu- 


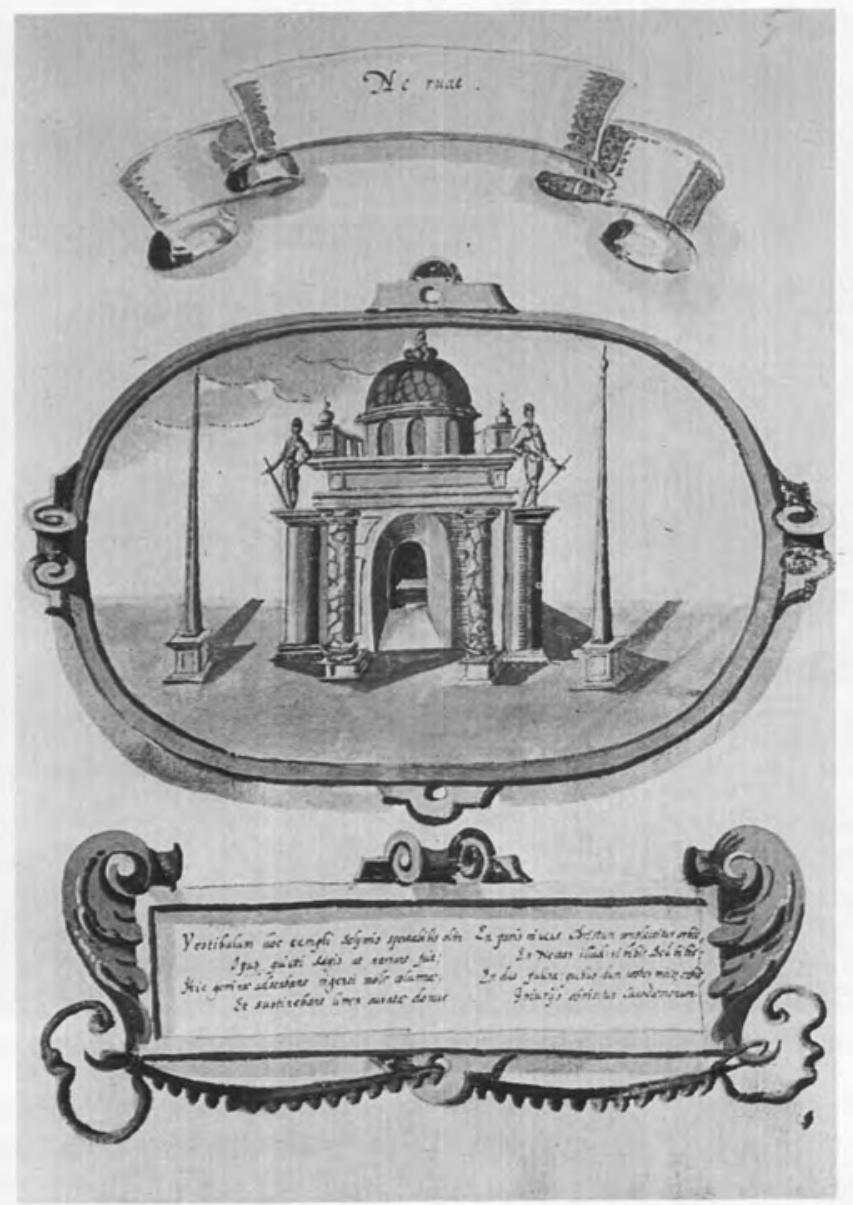

22. Der Tempel in Jerusalem mit den beiden Säulen, Emblem der Grazer Jesuiten, um 1603

23. Carlo Fontana, Entwurf für eine Kirche im Kolosseum, 1725, Ausschnitt

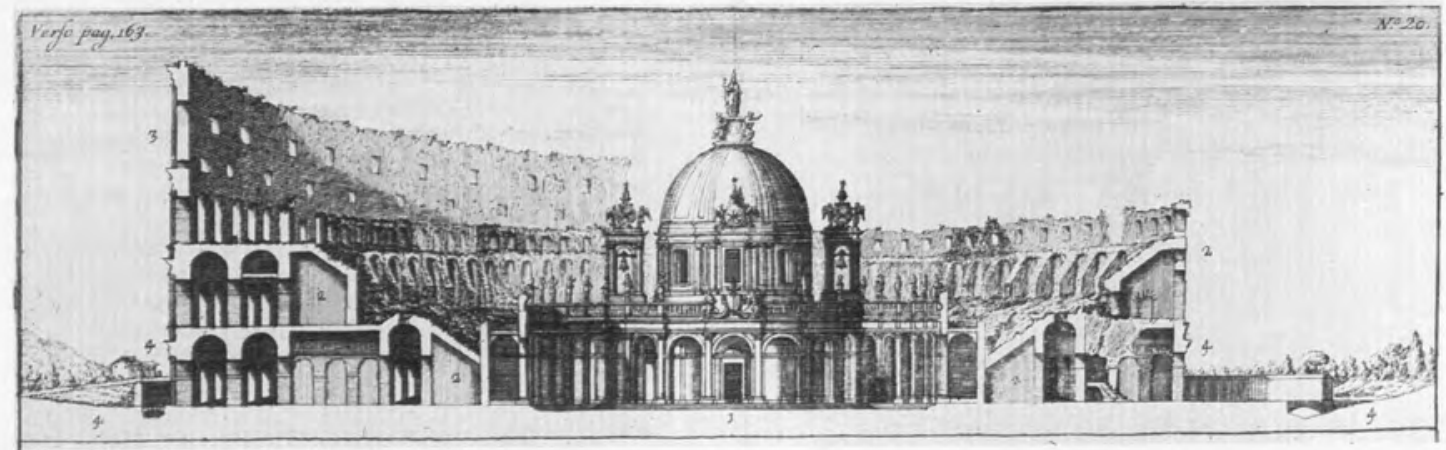




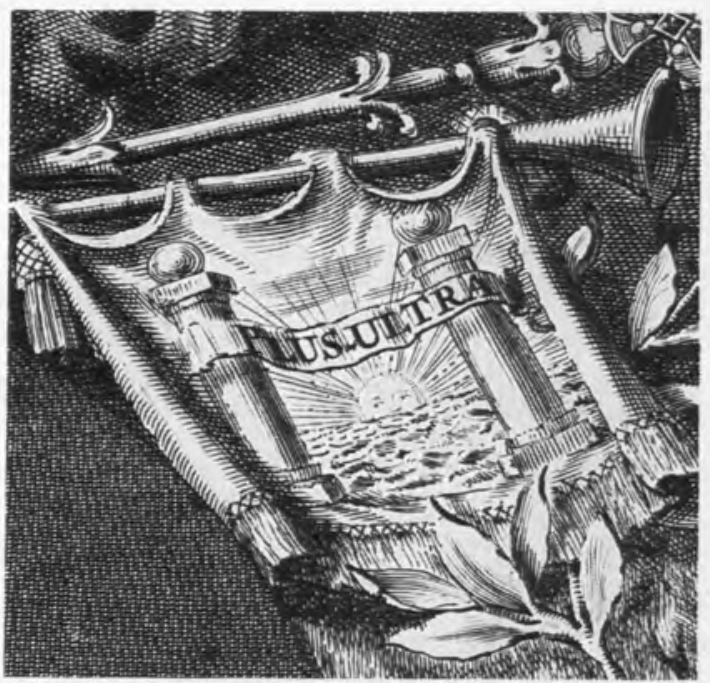

24. Devise Karls als spanischer König, Radierung v. J. Blommendaal u. Ph. Bouttats, um 1703/5, Ausschnitt

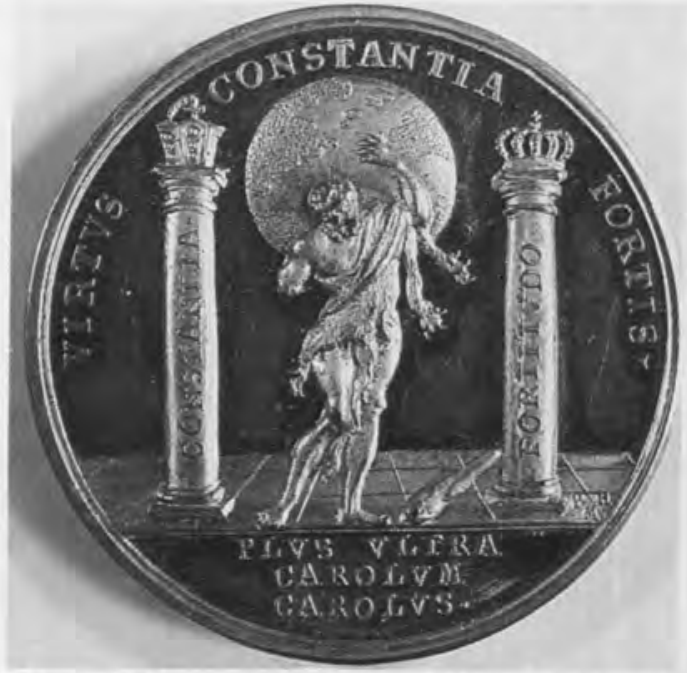

25. G. W. Vestner, Ph. H. Müller, Medaille auf die Kaiserkrönung Karls VI., Nürnberg 1712

26. Fassade der Karlskirche, Zeichnung im Codex Albrecht, um 1730, Wien, Osterreichische Nationalbibliothek

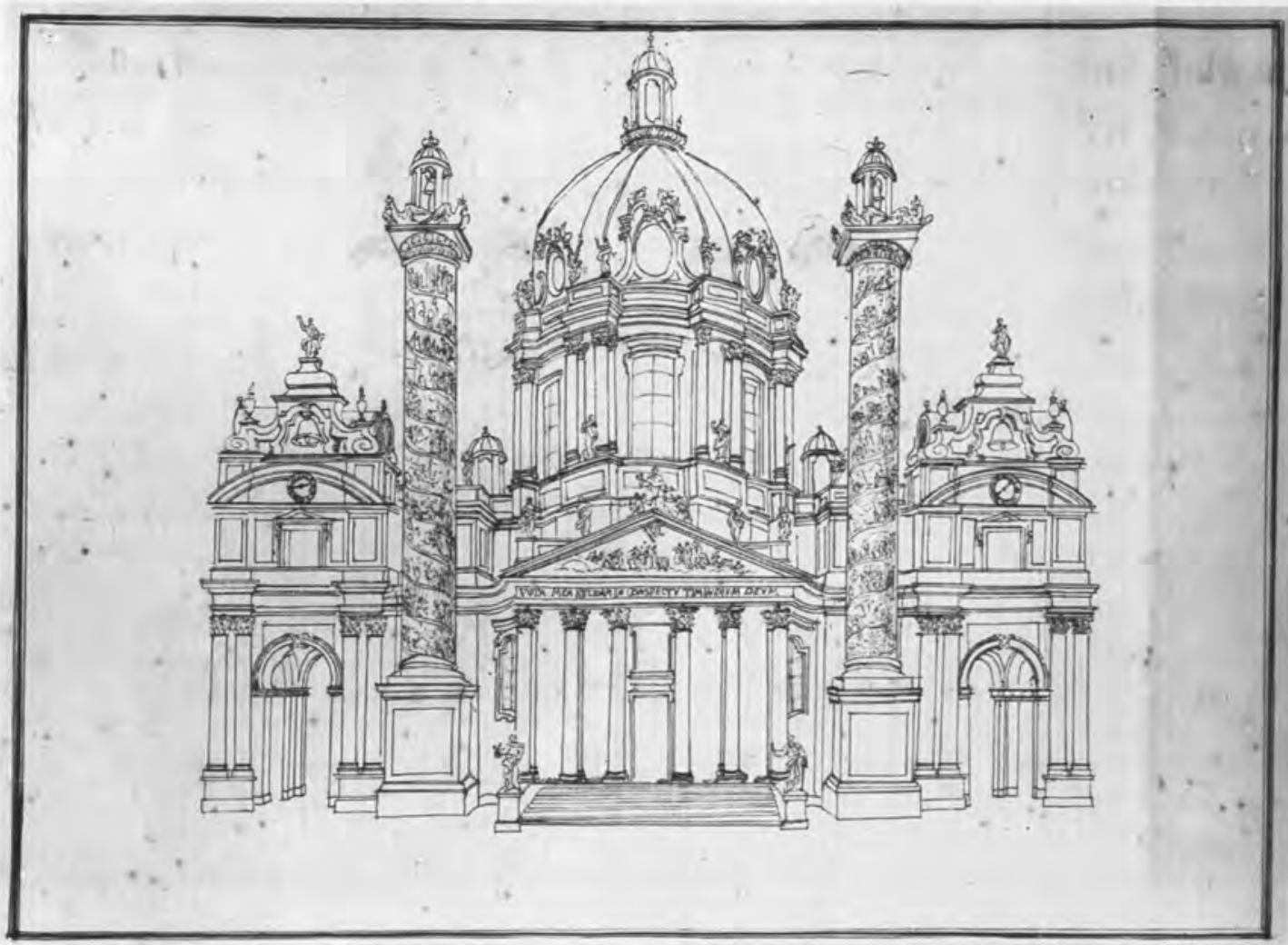

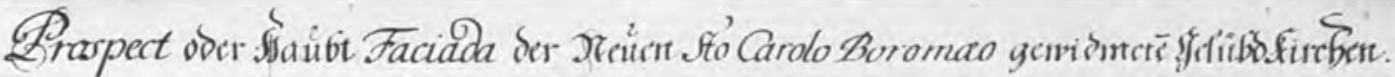




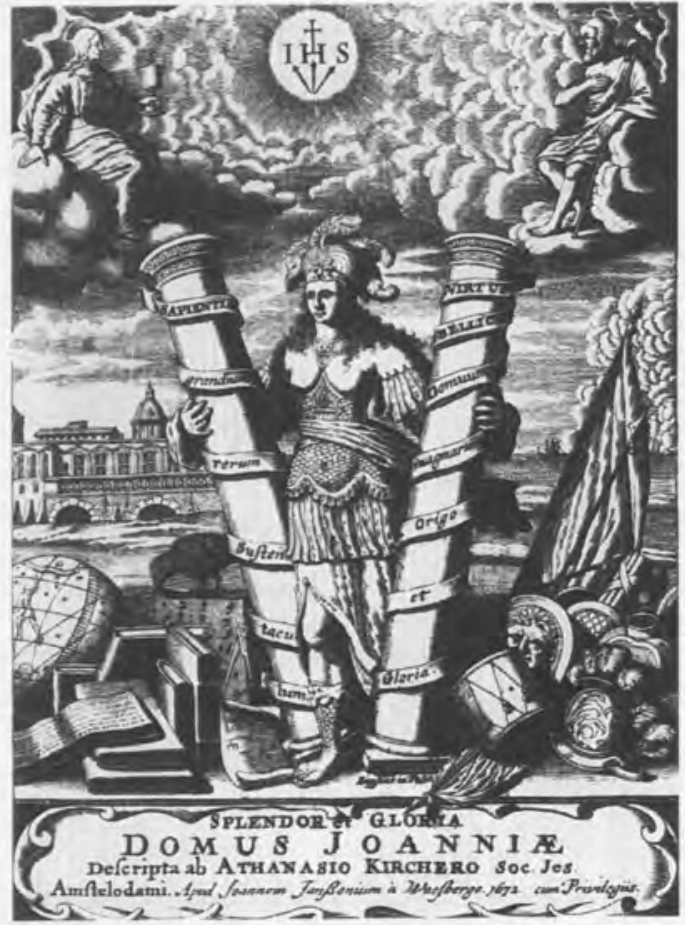

27. Allegorie d. fürstl. Kriegs- und Friedenswissenschaft, A. Kircher, Princeps Christiani Archetypon, 1672

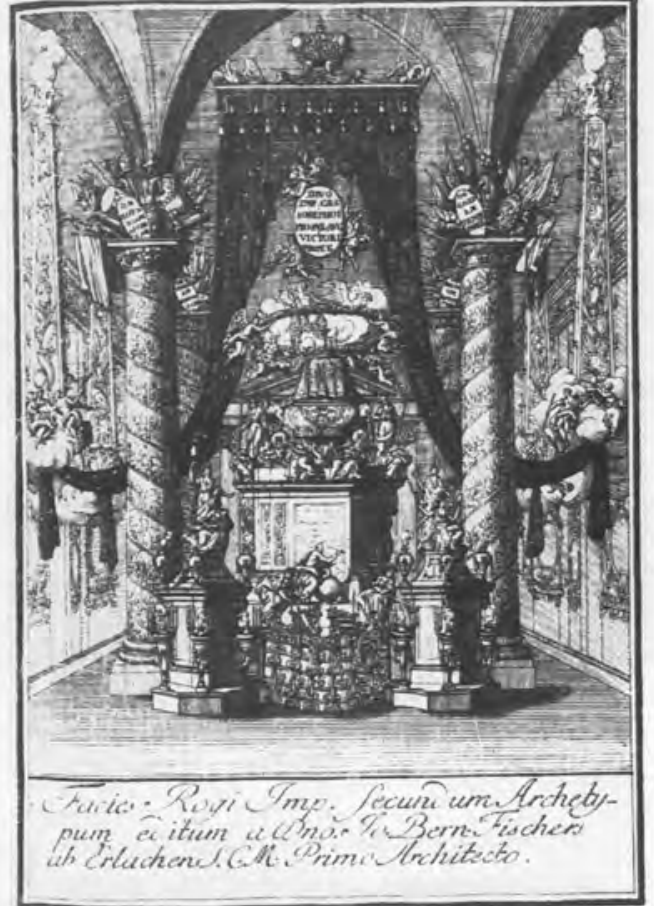

28. J. B. Fischer v. Erlach, Trauergerüst f. Joseph I., 1711, Radierung in: C. G. Heraeus, Inscriptiones, 1721

29. Wien, Fassade der Hofbibliothek, Kupferstich, 1729

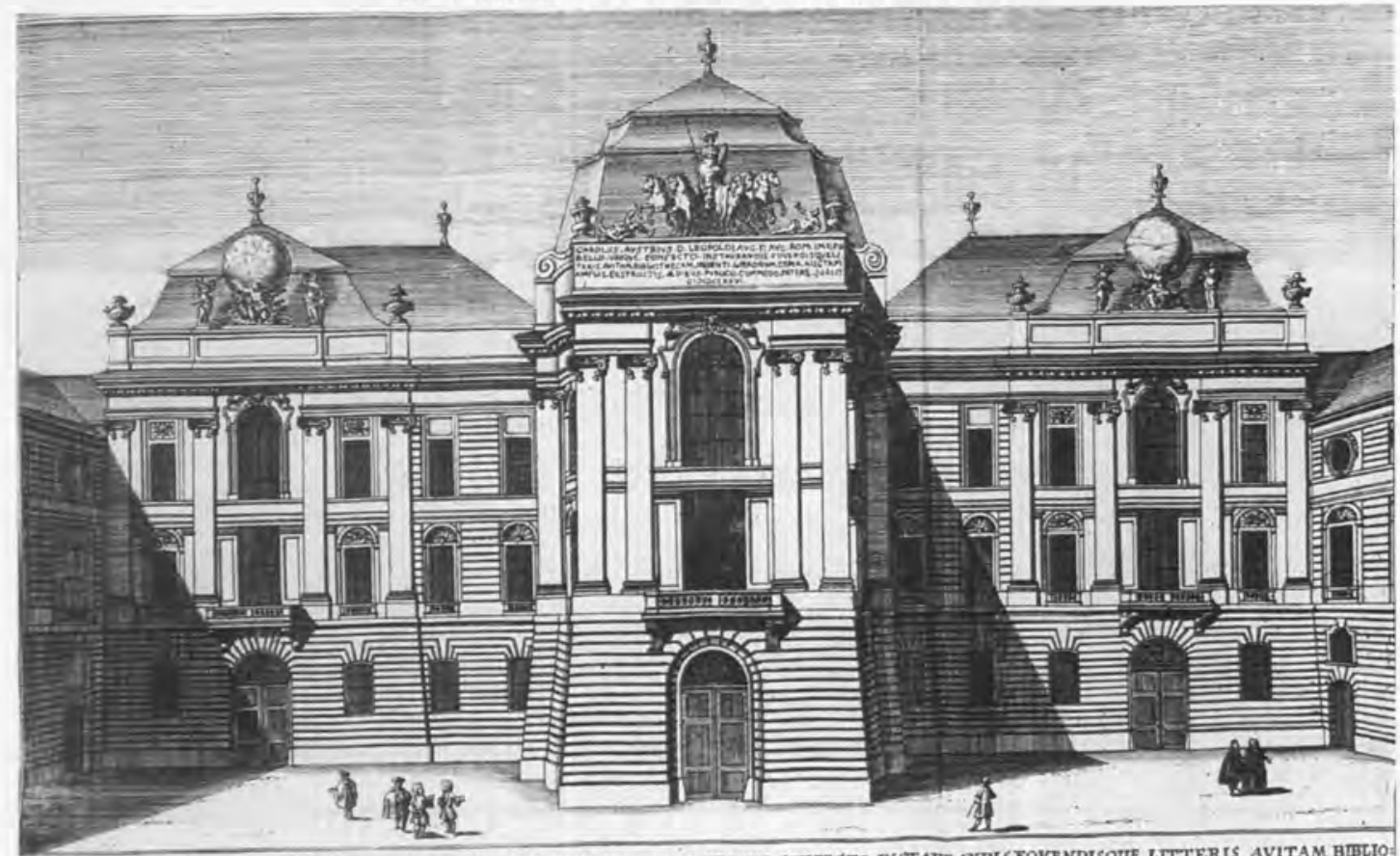




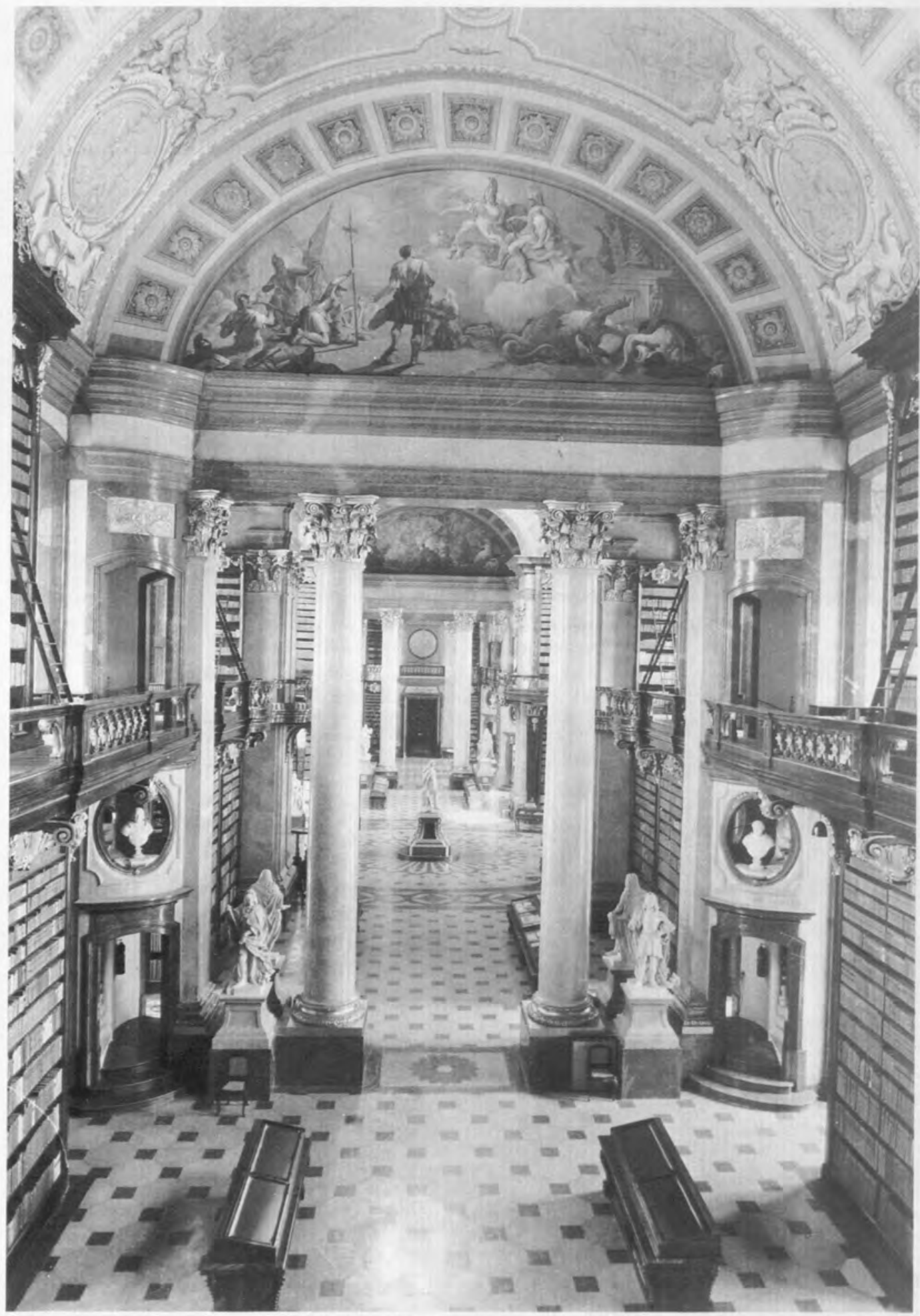

30. Wien, Prunksaal der Hofbibliothek 


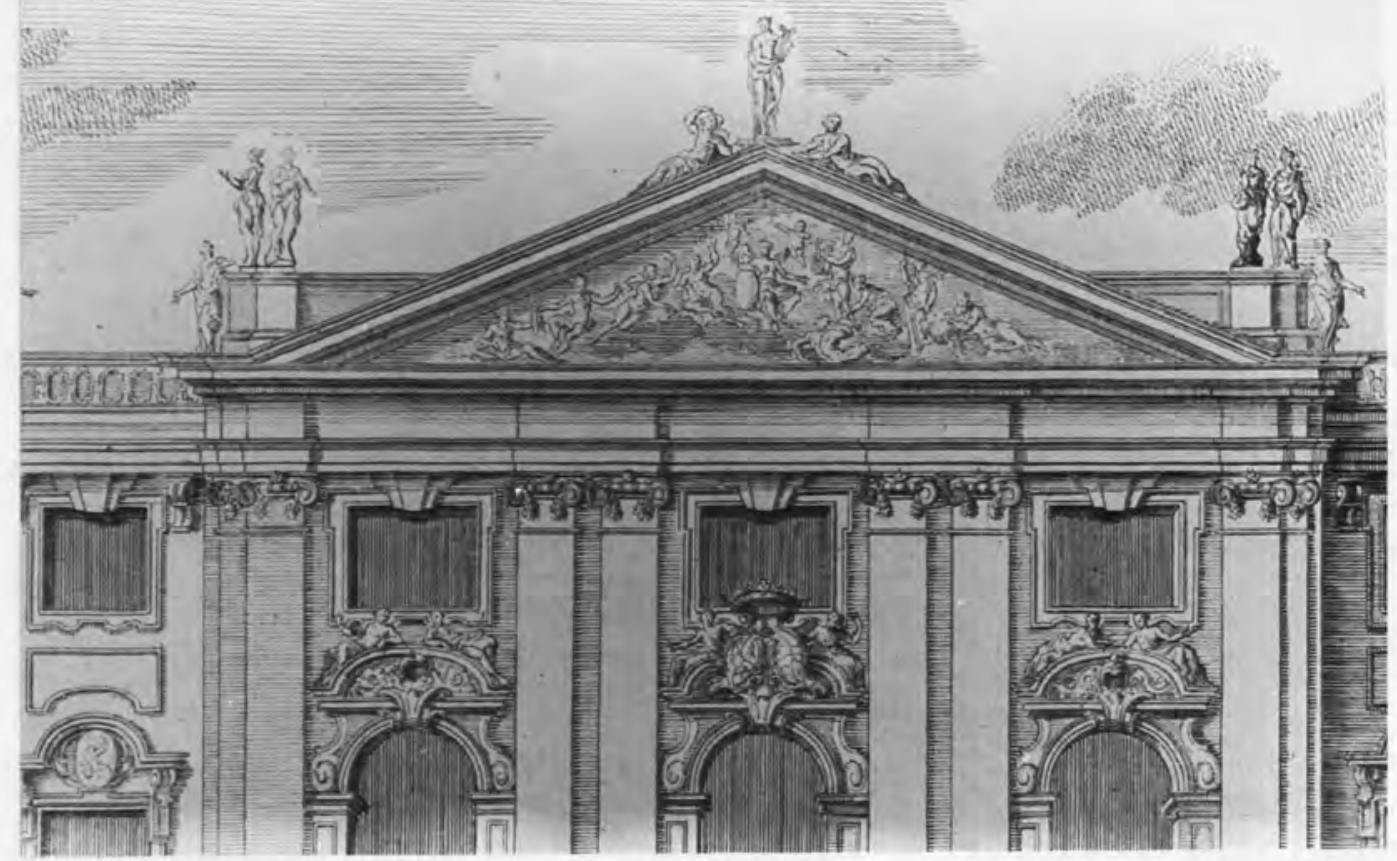

31. Wien, Palais Trautson, erster Entwurf, Radierung von J. E. Fischer v. Erlach, Chr. Engelbrecht u. J. A. Pfeffel, 1710, Ausschnitt

32. Wien, Palais Trautson, Radierung von S. Kleiner u. I. A. Corvinus, 1725, Ausschnitt

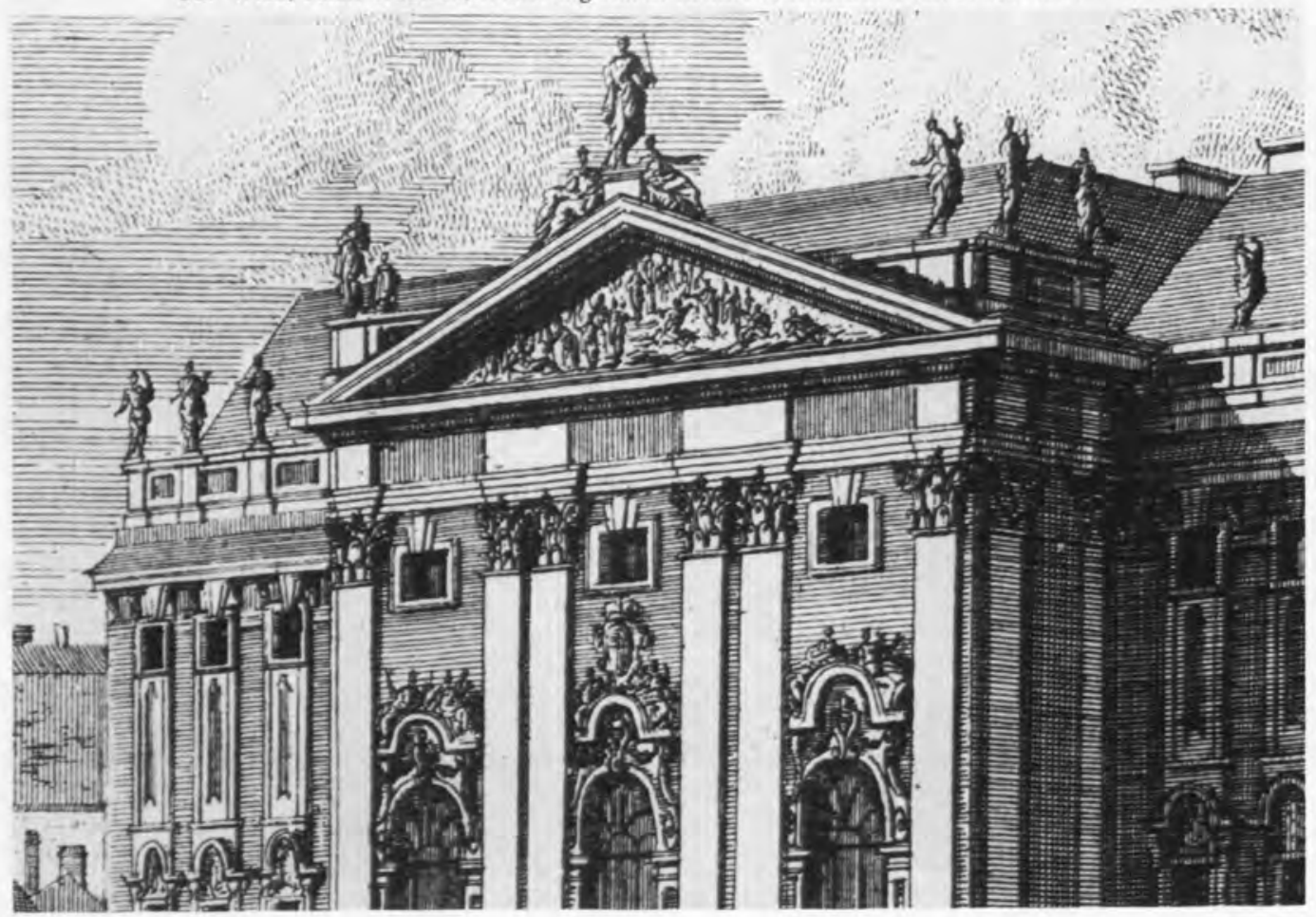




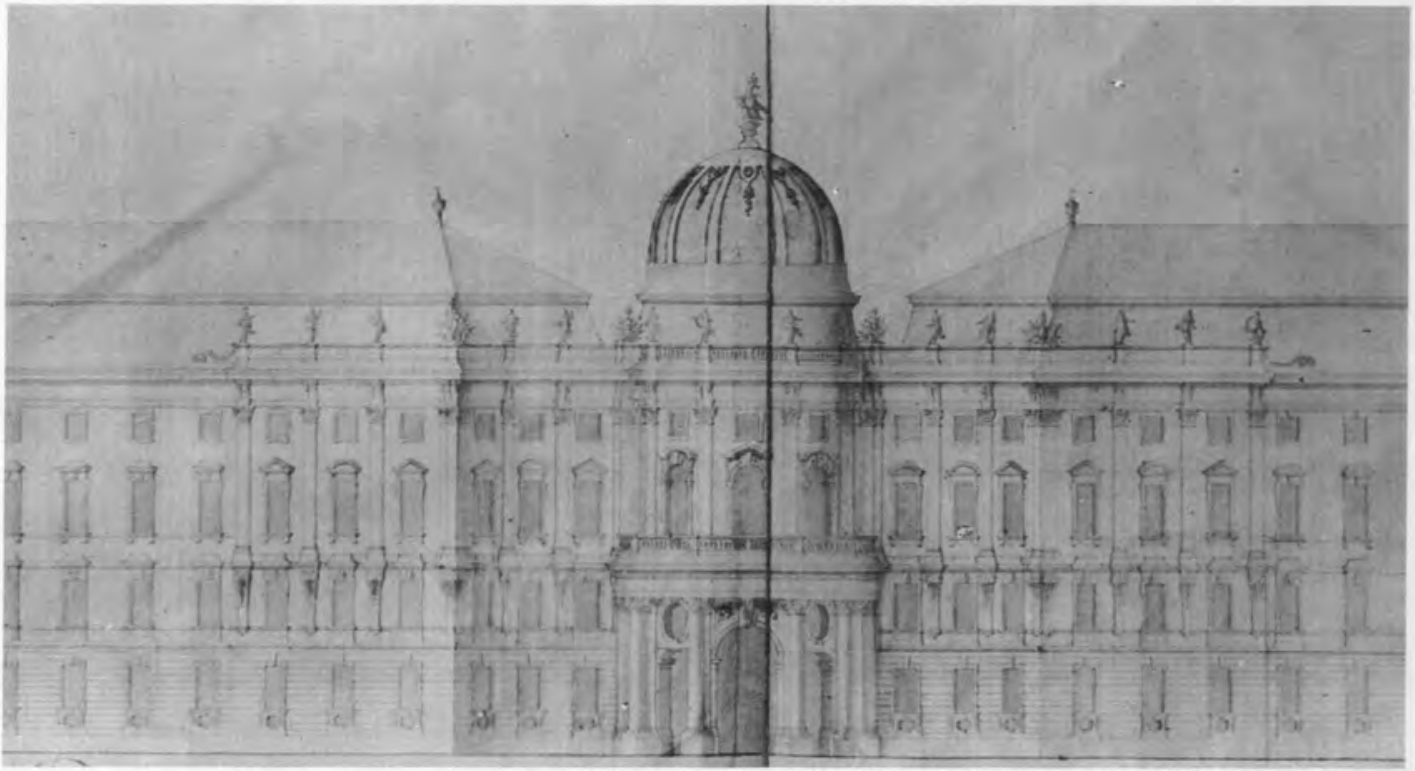

33. Johann Lucas von Hildebrandt, Entwurf für die Michaelerfassade der Hofburg, 1725, Wien, Graphische Sammlung Albertina, Ausschnitt

34. Joseph Emanuel Fischer von Erlach, erster Entwurf für die Michaelerfassade d. Hofburg, 1726, Wien, Graphische Sammlung Albertina, Ausschnitt

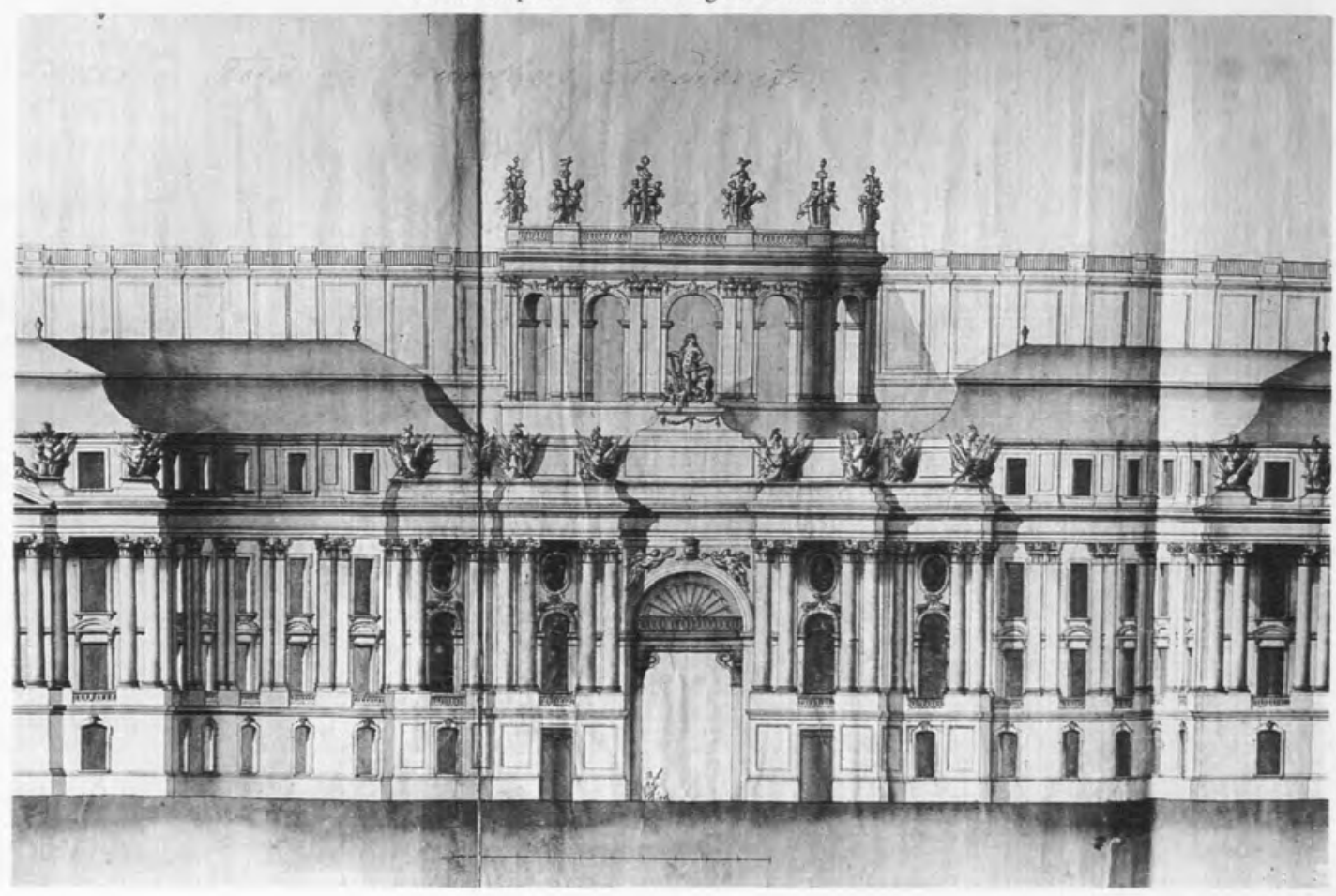




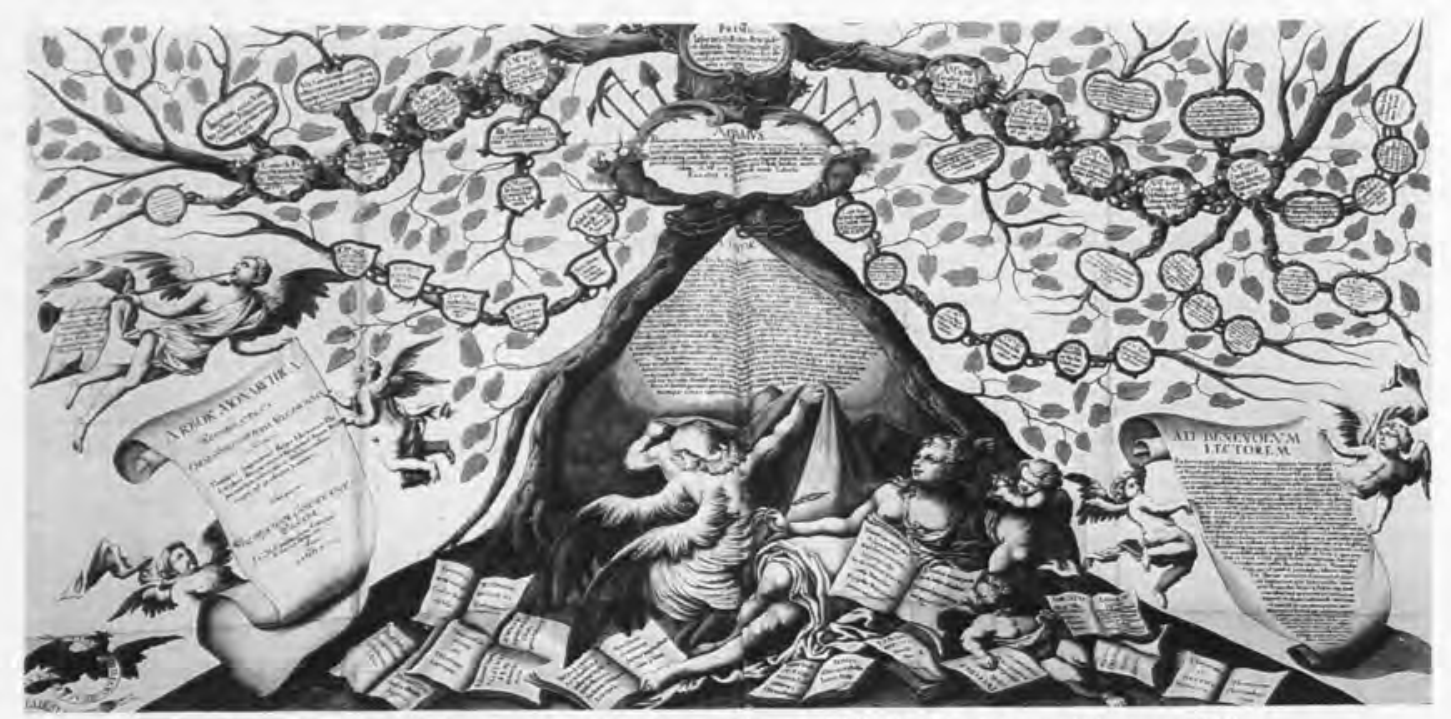

35. Wolfgang Wilhelm Prämer, Arbor Monarchica, 1. Teil, Kupferstich von Schmuzer, 1698

36. Die Weltwunder als Sinnbilder der vier Weltmonarchien, Kupferstich in: H. A. Chatelin, Atlas historique, Amsterdam 1703-1720

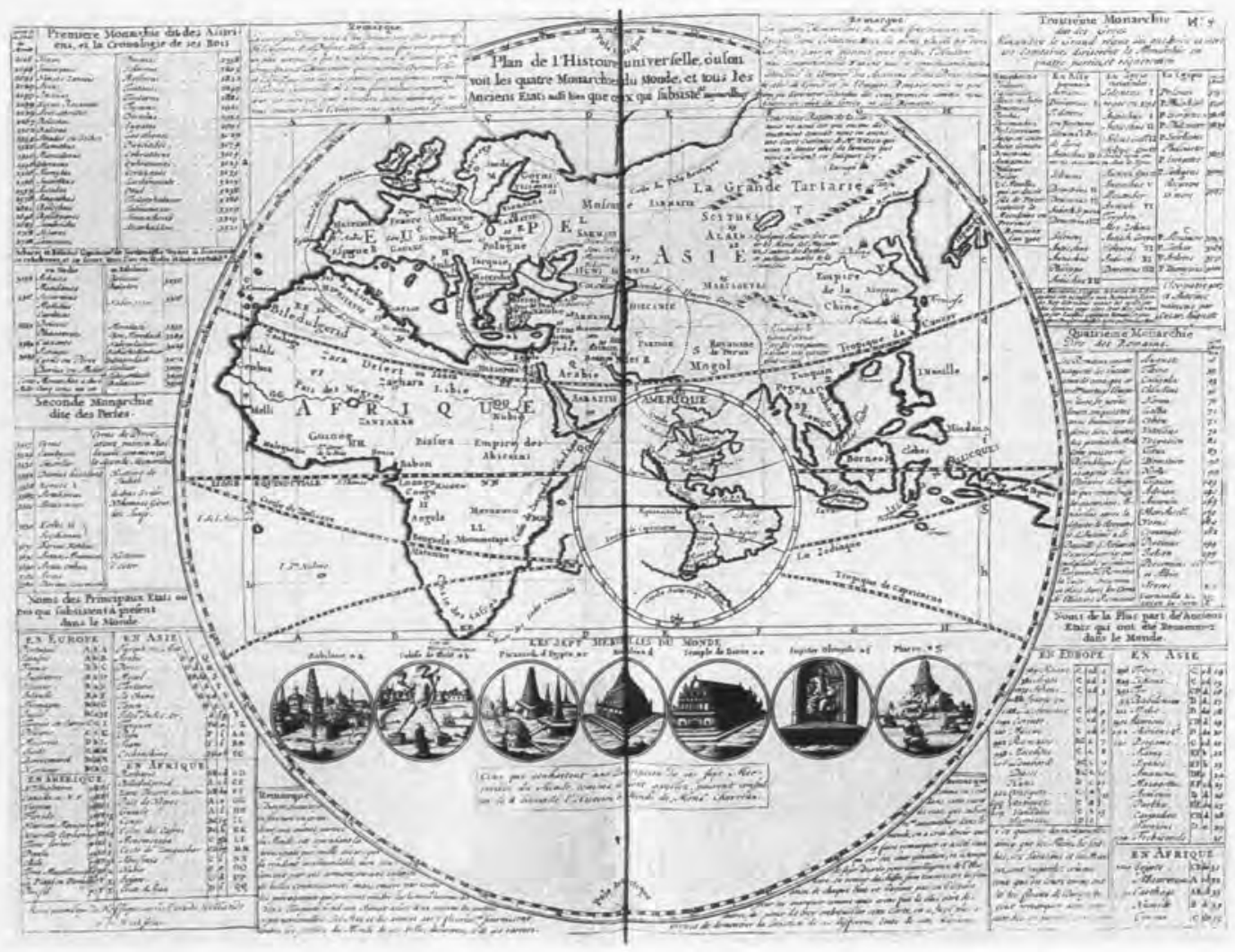


37. Karl VI. als neuer Augustus, Kupferstich in: Matthias Fuhrmann, Altund Neues Österreich, Wien 1734

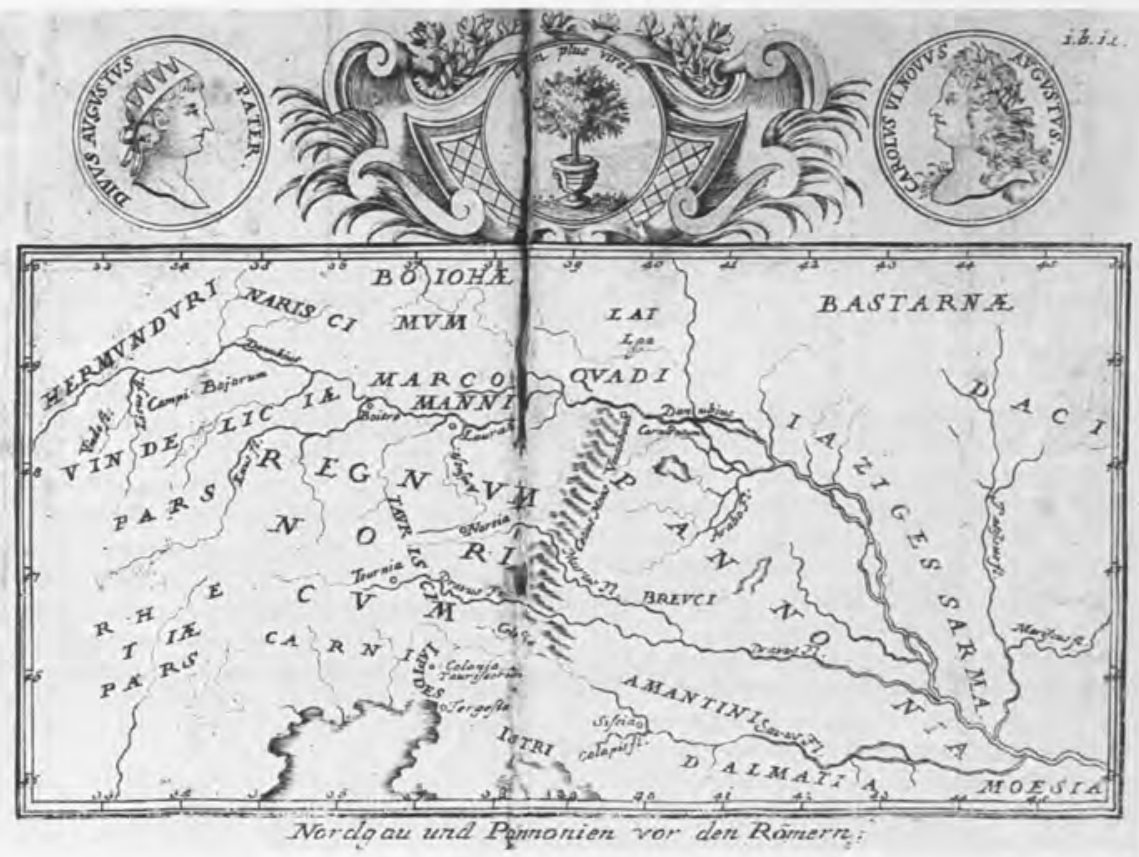

38. Titelblatt einer Dissertation über die Hofbibliothek und ihre antiken Wurzeln, Wien 1729

\section{BIBLIOTHECÆ Veterum Deperditæ AUGUSTA VINDOBONENSI C $Æ$ S A R E A Inftauratie \\ $\mathrm{H} O \mathrm{~N} O \mathrm{R} I$}

Perillaftrium, Reverendorum, Pranobilium Nobilium, ac Eruditorum,

DOMINORUM, DOMINORUM BACCALAUREOKUM,

In AntiquiJjima, ac Celeberrima UNIVERSITATE VIENNENSI, PROMOTORE

R.P.IGNATIO KAMPMILLER è Soc. Jesu,

AA. LL.\&Philor. Doctore, ejusdémque in Phyficis Profeffore Ordinario,

Frimâ AA. LL. đo Pbilofophic Laureâ infignirentwr,

A B

ILLUSTRISSIMA POËSI VIENNENSI inferiptxe

Annt $M D C C X X I X$. Menje Majo, die VIENNE AUSTRIA,

Typis Wolffgangi Schwendimann, Univ. Typ.
39. Antike Autoren im Prunksaal der Hofbibliothek, Zeichnung im Cod. Albrecht, um 1730, Wien, Österr. Nationalbibliothek

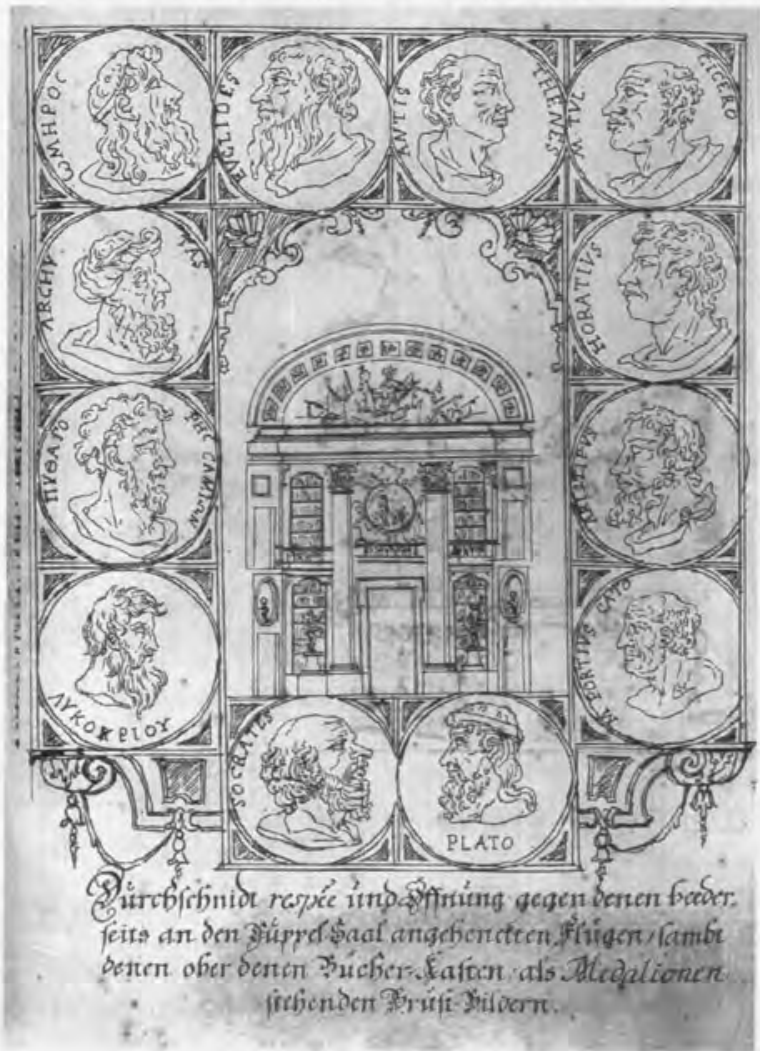




\section{6

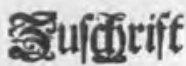

Des Settr Fif Fert. Dbere = Dau 3nfpectors / vor ber von 3bme erfunbenen unb gejeidineten fo genarmten Jit to" rifien $\mathfrak{B}$ au s Sunft.

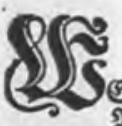

\author{
Tit. Plen.
} Iauditigften Ramen gegenvodrtiges geringíd)disiges अBert thm einen (Slam ju entlebnen fid) unterfänget; To wirb falbiges mur gurtidgebaltea bon feimer lamboll tommenheit, nidit von ber tiefeften Ebrfurd)t fur bit

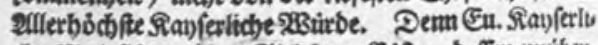

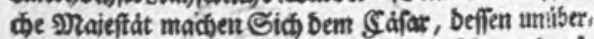

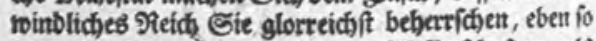
gleid burd bie Jodibjitung Der-2Btfenfithaften, als

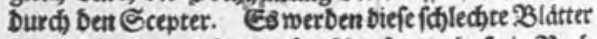
aud) unidit abgetwiefen von ber $2 B$ eb (orge, Dafi ein 2 ut) gu bermefen zu ben Rorbeet : Reifern eines SelDenge, leget werbe. Eure Rayferl. Maieftát futs ebenfals Dem SÉfiar tidi)t mu in Denen am Enbe Guropens be fiegten Jerculifí)en Sáulen, fonbern audi barin gleid), Daß̧ Eie bafutit baiten, Dte 23üdjer fenen einem Jelben midht unanftánbiger, als bie 23 affen : uno bas wabre

\section{SACRAE CAES, MAI.}

Confiliarii , \& Rei Antiqua , nec non feriundis Numifmatibus Prafedi

\section{Caroli Gustavi Heraei} INSCRIPTIONES ET SYMBOLA
VARII ARGVMENTI.

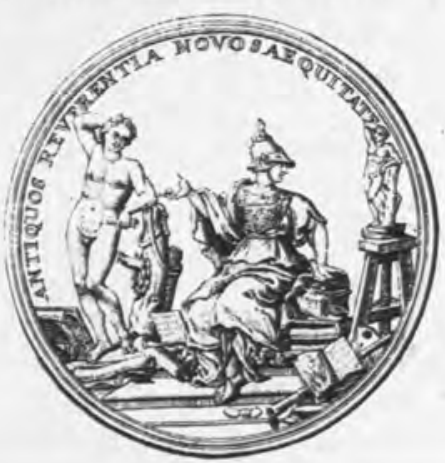

Noriberge,

Apud. Perr. Cons, Moaath A. MDCCXX1.
J07

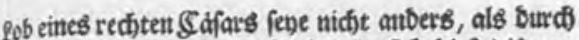
benbes su erlangen. Enblid Iaffet fid biefes Itnters nebmen, als umbeitig, nidi)t abfífrecteit von benen graufamen Sirteges . Eduften, tweld)e bifí anbero Die gantise R3elt beum

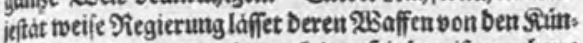
fen, und Diefen son jenen feine Sinbernis macjen; Dero gebeiligte Yjerion felbft tan aud) fo wemig von (jef(d)dften ermibet, als von Sd)twierigteiten ixr ge" madit wer Den: fo Daf uns alle 2utfalten bet) Der Streity barteit (D) avidos und Şäfars, auch) mitten im Striege bie Beiten Salomons und 2luguftus feben laffer. In Dies

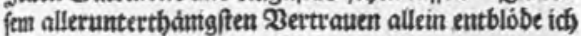
mid mit einem, roie ben Nebenfumben unternomme, nen, alfo aud unbollfommenten झBert vor Guer Says

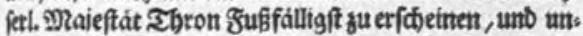
ter beffen Sdjatten einen Sduts wiber Lbel s wollenbe juerlangen ; Der id) nảd)ft Siujufügung meintes (Se) bets ju Der $\mathfrak{B}$ orbitte Der (S briftenbeit, fitr (Eurer Ray), (erlicben פrajeftdt langes Qeben, unb bon gefegnete Regierung, in allertiefiter Intermerfiuts berbarre $2 c$.
40. Carl

Gustav

Heraeus,

Text der Wid-

mung der

"Historischen

Architekrur"

an Karl VI.,

1721
41. Die antike Kunst als „Magistra artis“, Emblem von Carl Gustav Heraeus, 1721
42. Benedikt Richter, Revers der Porträtmedaille von J. B. Fischer v. Erlach, 1719, Wien, Kunsthistorisches Museum

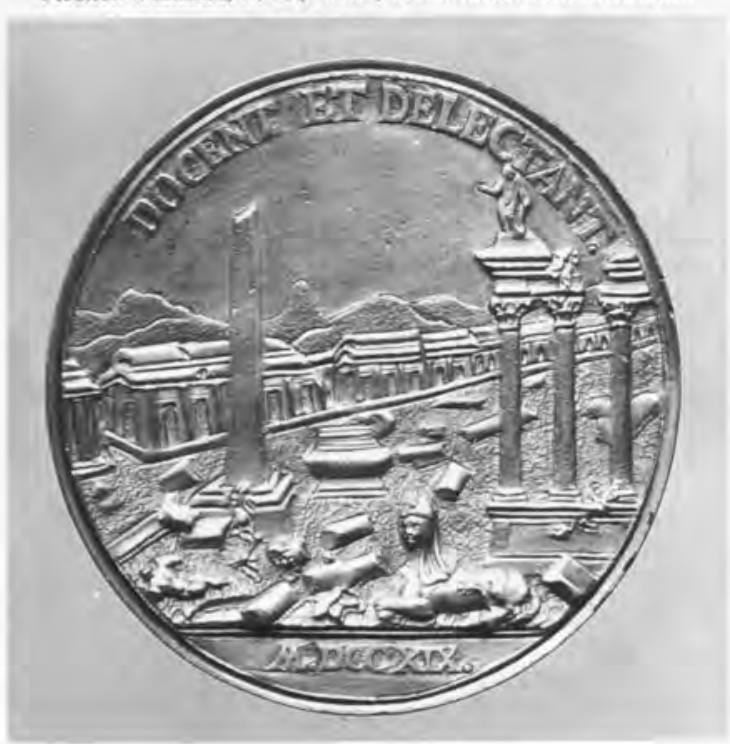

